\title{
HIDRÁLICA DA FERTIRRIGAÇÃO POR GOTEJA UTILIZANDO TANQUE DE DERIVAÇÃO DE FLUXO E BOMBA INJETORA
}

\author{
JOSE RENATO ZANINI \\ Engenhelro Agrónomo
}

Orientador: Prof. Dr. ANTONIO FERNANDO LORDELO OLITTA

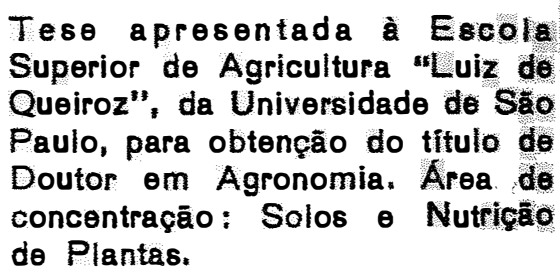

scola
uiz de Superior de Agricultura auiz do Queiroz", da Universidade de Sao Paulo, para obtenção do título de Doutor em Agronomia. Area de concentraçāo: Solos $\theta$ Nutriçăo de Plantas.

\footnotetext{
PIRACICABA

Estado de São Paulo - Brasil

Fevereiro - 1987
} 


\title{
HIDRÁULICA DA FERTIRRIGACÃO POR GOTEJAMENTO UTILIZANDO TANQUE DE DERIVAÇÃO DE FLUXO E BOMBA INJETORA
}

\author{
JOSÉ RENATO ZANINI
}

APROVADA EM: 10/04/87

COMISSÃO JULGADORA

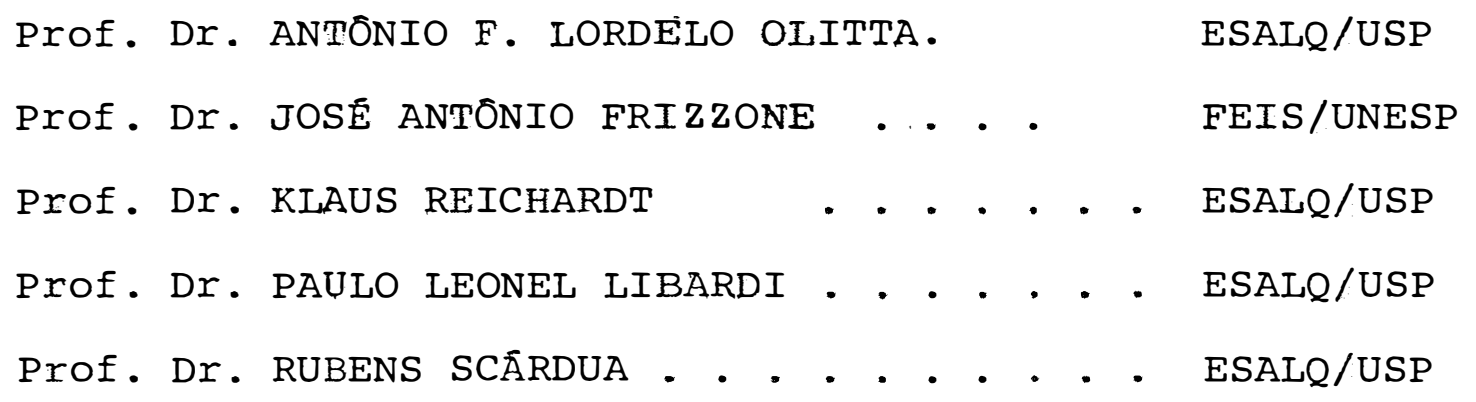

Prof. Dr. ANTÓNIO FERNANDO I . OLITTA 
iii.

Com esperanca que em alguma época - Brasil importemenos alimentos e use pouco sua agricultura para pagamento de uma inter minäver divida externa. 


\section{A G R A D E C I M N T O S}

Ao Prof. Dr. Antōnio Fernando Loderlo Olitta, pela orientação e apoio recebidos para realização desta pes quisa.

$\overline{\mathrm{A}}$ Universidade Estadual Paulista (UNESP) e Universidade de São Paulo (USP) que me permitiram realizar o curso de doutorado.

Ao Programa Institucional de Capacitação Do cente (PICD) da Coordenação de Aperfeiçoamento de Pessoal de NÍvel Superior (CAPES), pela bolsa de estudo concedida.

À indústria Aspersão no Brasil (ASBRASIL) pe Io fornecimento de tubulações, gotejadores e bomba injetora de fertilizantes utilizados nesta pesquisa.

Ao Centro de Energia Nuclear na Agricultura (CENA), que me possibilitou realizar análises químicas, no Laboratório de Análises de Água e Plantas.

Aos Profs. Gener Tadeu Pereira e Humberto de Campos pela colaboração nas análises estatísticas.

A todas as pessoas que de diversas formas con tribuiram para a realização deste trabalho. 
RESUMO $\ldots \ldots \ldots \ldots \ldots \ldots \ldots \ldots \ldots \ldots \ldots \ldots \ldots \ldots \ldots \ldots \ldots \ldots$

SUMMARY $\ldots \ldots \ldots \ldots \ldots \ldots \ldots \ldots \ldots \ldots \ldots \ldots \ldots \ldots \ldots \ldots \ldots \ldots$

1. INTRODUÇÃO $\ldots \ldots \ldots \ldots \ldots \ldots \ldots \ldots \ldots \ldots \ldots \ldots \ldots \ldots$

2. REVISÃO BIBLIOGRÁFICA ................... 3

2.1. Vantagens e Limitações da Fertirrigação ..... 3

2.2. Sistemas de Injeção de Fertilizantes à Rede

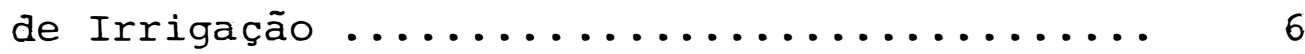

2.3. Operação do Sistema de Fertirrigação ....... 11

2.4. Concentrações Aplicadas Durante a Fertirriga-

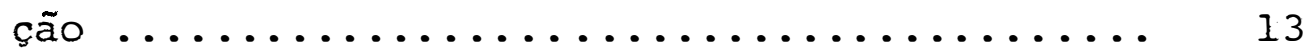

2.5. Uniformidade de Distribuição ........... 17

3. MATERIAL e mÉtodos ........................ 21

3.1. Método de Irrigação Utilizado .............. 2 I

3.1.1. Sistemas de Injeção de Fertilizante .. 22

3.1.1.1. Injeção por Derivação de Flu-

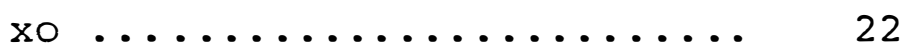

3.1.1.2. Bomba Injetora .......... 22

3.1.2. Cabeçal de Controle com Tanque de Fer-

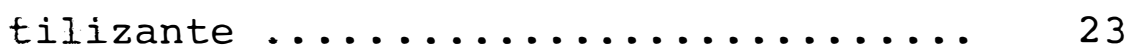

3.1.3. Cabeçal de Controle com Bomba Injetora 27

3.1.4. Linha de Gotejadores ............ 29 
3.2. Injeção de Fertilizante por Derivação de Flu xo $\ldots \ldots \ldots \ldots \ldots \ldots \ldots \ldots \ldots \ldots \ldots \ldots \ldots$

3.2.1. Equação de Regressão entre Diferença de Pressão e Vazão Derivada ........

3.2.2. Tempos de Fertirrigações e Instantes de Coleta de Amostras ............

3.2.3. Pressão e Vazão ao Longo da Linha de

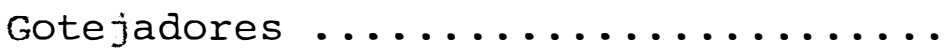

3.2.4. Fertilizante e Manejo do Sistema para

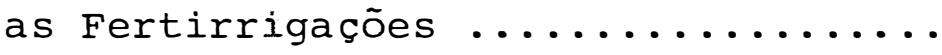

3.2.4.1. Fertilizante ........... 39

3.2.4.2. Manejo do Sistema ........ 40

3.2.5. Previsão das Concentrações a serem ob tidas e Quantidades Aplicadas de Fer tilizante $\ldots \ldots \ldots \ldots \ldots \ldots \ldots$

3.3. Injeção do Fertilizante com Bomba ........ 45

3.3.1. Controle da Taxa de Injeção ........

3.3.2. Tempo de Fertirrigação e Instantes de Coleta de Amostras ............. 45

3.3.3. Manejo do Sistema para Fertirrigação.

3.3.4. Previsão das Concentrações a serem ob tidas $\ldots \ldots \ldots \ldots \ldots \ldots \ldots \ldots \ldots \ldots \ldots \ldots \ldots \ldots \ldots \ldots \ldots \ldots$

3.3.5. Solução Fertilizante ........... 48

3.4. Coleta e Análise de Amostras ............ 48 
vii.

Página

3.5. Uniformidade de Distribuição do Fertilizante.

3.6. Análises Estatisticas ................. 51

4. RESUltados E discussão ..................... 53

4.1. Pressão na Linha de Gotejadores .......... 53

4.2. Vazão na Linha de Gotejadores ........... 55

4.3. Injeção por Derivação de Fluxo .......... 55

4.3.1. Diferença de Pressão e Vazão Derivada. 55

4.3 .2 . Teores de cloreto .............. 58

4.3.2.1. Teores no Tanque de Fertili-

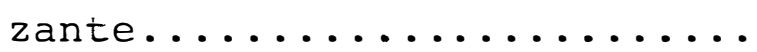

4.3.2.2. Teores na linha de Gotejadores......................

4.3.3. Quantidade Aplicada de Cloreto .......

4.3.3.1. Vazão de Derivação de $3721 / \mathrm{h}$

e Tempo de Fertirrigação de

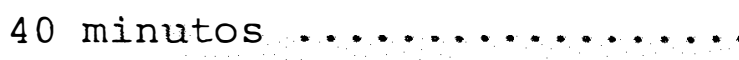

4.3.3.2. Vazão de Derivação de $186 \mathrm{l} / \mathrm{h}$ e Tempo de Fertirrigação de 80 minutos $\ldots \ldots \ldots \ldots \ldots \ldots$

4.3.3.3. Vazão de Derivação de $931 / \mathrm{h}$ e Tempo de Fertirrigação de 160 minutos ........... 80

4.4. Injeção com Bomba .................. 84

4.4.1. Taxa de Injeção da Bomba .......... 84 
viii.

Página

4.4.2. Teores de Cloreto ................ 86

4.4.3. Quantidade Aplicada de Cloreto ....... 88

4.5. Comparação entre Aplicação com Derivação de Fluxo e com Bomba Injetora ............. 92

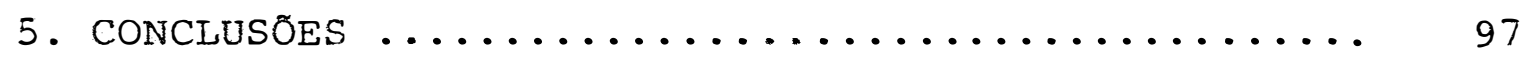

6. REFERENCIAS BIBLIOGRÁficAS ............... 100 
.ix.

\title{
HIDRÁULICA DA FERTIRRIGAÇÃO POR GOTEJAMENTO UTILIZANDO TANQUE DE DERIVACÃO DE FLUXO E BOMBA INJETORA
}

\author{
Autor: JOSE RENATO ZANINI
}

Orientador: Dr. ANTONIO FERNANDO L. OLITTA

\section{RESUMO}

Com o objetivo de estudar a hidráulica da fertirrigação por gotejamento com tanque de derivação de fluxo e bomba injetora de fertilizantes, utilizando-se o ion cloreto como traçador, foi conduzido um experimento no Laboratório de Hidráulica do Departamento de Engenharia Rural da Escola Superior de Agricultura "Luiz de Queiroz", $\underline{\text { i }}$ racicaba, SP. Para isso foi instalado um sistema de irrigação por gotejamento, com cabeçal de controle e uma linha de $52,25 \mathrm{~m}$, contendo 210 gotejadores espaçados de $0,25 \mathrm{~m}$.

Com derivação de fluxo injetaram-se 93, 186 e $372 \ell / h$ de solução de KCl à linha de gotejadores e com bomba injetora $372 \mathrm{l} / \mathrm{h}$. Amostras de solução distribuídas pe Ios gotejadores foram coletadas na saida do tanque de ferti lizante e em 20 pontos da Iinha de gotejadores, em dez instantes. Essas amostras foram analisadas determinando-se 0 teor de cloreto nas mesmas. 

cluiu-se que:

a) A vazão derivada através do tanque de fertilizante é diretamente proporcional à diferença de pressão entre os pontos de entrada e saída do tanque, seguindo o Teorema de Torricelli.

b) A concentração do ín cloreto no tanque em relação à sua concentração inicial diminui com o aumento do volume derivado atravēs do mesmo, segundo um modelo exponencial.

c) A quantidade de cloreto distribuida pela linha de goteja dores, diminuiu linearmente do início para o final da li nha, tanto com a utilização de tanque de derivação de fluxo como para bomba injetora. Ainda, esses dois siste mas não diferiram entre si com relação às quantidades aplicadas e a redução dessas quantidades.

d) Aumentando-se o tempo de aplicação de cloreto obtiveram-se menores diferenças entre quantidades do mesmo distrí buidasem diversos pontos na linha de gotejadores.

e) A uniformidacle de distribuição de cloreto avaliada pelo Coeficiente de Uniformidade de Christiansen foi elevada, sendo maior ou igual a 97,3\%, para os dois sistemas de injeção de fertilizantes. 


\section{HYDRAULIC OF THE FERTIGATION BY DRIP USING TANK OF FLOH DERIVATION AID INSECTOR PUMP}

Author: JOSE RENATO ZANINI

Adviser: Dr. ANTÓNIO FERNADO L. OLITTA

\section{SUMMARY}

In this work the objective was to study the hydraulic of the fertigation by drip with tank of flow derivation and injector pump of fertilizer, using the chloride ion as a tracer.

At the Hydraulic Laboratory of Escola Superior de Agricultura "Luiz de Queiroz", Piracicaba, SP, Brazil, a drip irrigation system was installed with control head and one line of $52.25 \mathrm{~m}$, with 210 emitters spaced $0.25 \mathrm{~m}$.

Ninety three, 186 and $372 \mathrm{l} / \mathrm{h}$ of $\mathrm{KCl}$ solution were injected in the emitters line by flow derivation and $372 \mathrm{l} / \mathrm{h}$ with an injector pump. Samples of KCl solution were collected on the outlet of the fertilizer tank and also in 20 points of the emitters line, in ten different instants. These samples were analised and then the chloride content 
was determined.

The analysis of the results led to the following conclusions:

a) The flow through the fertilizer tank is directly proportional to the pressure difference between the enter and outlet points of the tank, according to Torricelli's Theorem;

b) The chloride ion concentration in the tank in relation to its initial concentration decreases with the increase in the volume derivated through it, according to an exponential model;

c) The quantity of chloride distributed by the emitters line, decreased linearly from the beginning to the end of the line using either the tank of flow derivation or the injector pump. Still, these two systems didn't differ from each other in relation to the quantities applied and the reduction of these quantities;

d) With the increase in the application time of chloride smaller differences were obtained among quantities of it, distributed in different points in the emitters line; 
xiii.

e) The chloride distribution uniformity evaluated by Christiansen's Uniformity Coefficient was high, being larger or equal to $97.3 \%$, for the two injection fertilizers systems. 


\section{INTRODUÇÃO}

o fornecimento de água e nutrientes é essencial para se obter boa produção das culturas, porém, a irri gação e fertilização estão se tornando cada vez mais caras e dificeis devido à pouca disponibilidade e elevado custo de mão-de-obra, fertilizantes, sistemas de irrigação e ener gia.

Fertirrigação consiste na aplicação simultānea de agua e fertilizantes, através de um sistema de irrigaçao. É uma técnica relativamente antiga, que os agriculto res de muitos países têm utilizado, por meio de diversos mé todos de irrigação. Em países como os Estados Unidos, Israel, Itália e outros, tornou-se de uso generalizado, principalmente com o desenvolvimento da irrigação por gotejamen to.

No Brasiz sao ainda poucas as áreas que rece bem fertirrigação, porém, com as vantagens que oferece e a necessidade de se aumentar o uso da irrigação, abrem-se grandes perspectivas à utilização de tal prática. Contudo, necessita-se de pesquisas sobre este assunto, tais como siste mas de injeção de fertilizantes, uniformidade de distribuiçao de fertilizantes na rede de irrigação e no solo.

No presente trabalho teve-se como objetivo 
estudar a hidráulica da fertirrigação por gotejamento com tanque de derivação de fluxo e bomba injetora, utilizando-se o ín cloreto como traçador, proveniente de solução de $\mathrm{KCl}$, para se verificar a sua distribuição espacial e temporal pelo sis tema de irrigação. 


\section{REVISÃO BIBLIOGRÁFICA}

Conforme WOODWARD (1959), a introdução de vạ rios materiais fertilizantes, orgânicos e inorgānicos, em água de irrigação é praticada há séculos. Uma das primeiras apli cações por aspersão foi com adubos Iíquidos em pastagens.

De acordo com BOAZ \& HALEVY (1974), a fertili芒 zação combinada com a água de irrigação é perfeitamente adap tável a diferentes sistemas de irrigação, sejam eles fixos, semi-fixos ou móveis. ' GOLDBERG \& SHMUELI (1970) e BRESIER (1977) afirmam que a fertirrigação é mais indicada por gotejamento, seguida pela aspersão, principalmente em sistemas fi xos.

\subsection{VANTAGENS E LiMITAÇÕES DA FERTIRRIGACÃO}

os aspectos favoráveis da fertirrigação são relatados por diversos autores.

WIERSMA (1969) menciona as seguintes vanta gens: o trabalho necessário para realizar fertirrigação é poụ co maior do que para irrigação; com os mesmos equipamentos de fertirrigação podem-se aplicar herbicidas e outros produtos químicos, utilizando-os também para desobstrução de goteja 
dores pela da aplicação de ácidos; necessita-se menor quantidade de fertilizante quando comparado com outros méto dos de fertilização.

POMPA (1974) comenta que por meio da fertirrigação é possivel: fracionar e dosificar a aplicação de fertị lizante tanto quanto se deseja; economizar mão-de-obra; redu zir a lixiviação e distribuir melhor os nutrientes no perfil do solo.

Segundo RAPOSO (1979), com fertirrigação é possível realizar adubação foliar e também: evitar compacta ção do solo pela nāo necessidade de máquinas; facilitar a adu bação de cobertura em culturas densas e dosar com rigor as quantidades de nutrientes de acordo com a marcha de absorção; maior uniformidade de distribuição e melhor localização dos nutrientes no volume de solo ocupado pelo sistema radicular.

FREY (198I) cita como aspectos favoráveis: pos sibilidade de utilizar mais intensamente o sistema de irriga ção, evitando uso de tratores, aviões, custando em geral um terço dos métodos convencionais de aplicação; permite aplica ção independente da cultura e cobertura do solo; não provoca compactação do solo; devido à menor quantidade de produtos aplicados e possibilidade de melhor controle, podem-se redu zir os casos de contaminações de águas superficiais e subter rāneas sendo também menor o risco de intoxicações de trabalhạ dores, quando comparado com métodos convencionais de aplica ção de produtos químicos destinados à agricultura. 
Comentando sobre a fertirrigação utilizada em Israel, SHANI (1981) expõe as vantagens: é uma maneira rápi da e bastante cômoda, podendo ser realizada por um equipamen to central para toda a área ou para uma parcela; a coinci dência do momento de aplicação da água e do fertilizante au menta a eficiência de ambos; a época de fertilização pode ser planejada pelo estágio da planta e não por fatores físicos ou técnicos; o sistema pode servir para aplicar outros produtos químicos ou água quente contra geadas, apesar de existir pou ca experiência neste aspecto.

Embora sejam diversos os aspectos favoráveis da fertirrigação, existem também algumas limitações.

Conforme WIERSMA (1969), um sistema indevida mente projetado fará distribuição desuniforme. Se chover quando a fertirrigação está programada, o sistema terá que ser acionado da mesma forma ou então transferir-se a época de realização. Muitos fertilizantes baratos não podem ser utilizados. Dependendo do sistema de irrigação a aplicação localizada não pode ser realizada. Adubos fosfatados concen tram-se na superfície do solo. Operação inadequada pode da nificar equipamentos. Alguns fertilizantes favorecem a obs trução de gotejadores.

FRIZZONE et alii (1985) comentam sobre as se guintes Iimitações:

a) Contaminações e envenenamento: as águas de irrigação que contêm fertilizantes ou outras substâncias po 
dem contaminar fontes ou envenenar trabalhadores. Deve-se orientá-los e instalar válvulas de retenção e anti-vácuo, im pedindo inversão do fluxo na rede de irrigação.

b) Tipos de fertilizantes: o método nãoé apro priado para produtos pouco solúveis ou insolúveis. Alguns fertilizantes, principalmente fosfatados, podem provocar rea çōes químicas originando precipitados, limitando o uso de go tejadores. Outros produtos são corrosivos podendo danificar alguns sistemas de irrigação.

2.2. Sistemas de InJecão de Fertilizantes À Rede de IRRI GACฺ̃O

Segundo WOODWARD (1959), POMPA (1974) e GOLD BERG et alii (1976), os sistemas mais comuns de aplicação de fertí lizantes com equipanentosde irrigação podem ser divididos em:

a) Tanque de fertilizante Este sistema opera com um tanque conectado em paralelo à tubulação de irrigação. Provocando-se uma di ferença de pressão entre os pontos de entrada e saída do tan que, parte do fluxo da água de irrigação flui através do mes mo e dilui a solução de nutrientes, a qual vai sendo injetada à rede de irrigação.

b) Bombas Injetoras

A solução contida num reservatório aberto é introduzida ao sistema de irrigação por meio de uma bomba. 
Em principio existem dois tipos de bombas: aquelas operadas por uma fonte de energia independente da bom ba de irrigação e bombas acionadas por meio da própria pres são da água no sistema.

c) Aplicadores tipo Venturi

Succionam a solução fertilizante de um tạ que aberto ou fechado utilizando-se do princípio de Venturi.

d) Tubo ligado à sucção da bomba de irrigação Com um tubo conectado à tubulação de sucção de ãgua, a solução fertilizante é aspirada, passando pela bom ba de irrigação. Por este motivo, produtos corrosivos ou abrasivos são contra-indicados. Tambēm segundo GOIDBERG et alii (1976), a escolha do sistema vai depender de cada si tuação, levando-se em. consideração diversos aspectos: volume do tanque, exatidão de diluição, possibilidade de ser portátil, custo da unidade em relação à área que pode atender e demanda de operador.

HOLMAN (1978), referindo-se a bombas injeto ras, comenta que devem desenvolver pressão maior do que a da linha de irrigação. Muitas são acionadas eletricamente e com dispositivo que permite controlar a quantidade de solução in. jetada. As bomb̄as com pistão ou diafragma, operadas hidraulicamente ou eletricamente, são usadas mais frequentemente e permitem amplo ajuste do fluxo para regulagem da taxa de in jeção. 
Tal como apresentado em boletim da FAO (1980), existem muitas maneiras de injetar fertilizantes em uma rede de irrigação. Contudo, os dois sistemas básicos são:

a) Sistema de pressāo diferencial.

E também chamado de derivação de fluxo ou simplesmente tanque de fertilização.

Com este sistema, a concentração da solução in jetada diminui continuamente com o tempo, consequentemente a desuniformidade de distribuição pode tornar-se um problema. Quan do o fertilizante contido no tanque deve ser totalmente apli cado após determinado período, em uma única ārea, não há pro blema de desuniformidade. O mesmo não ocorre quando pretendese atingir ciclicamente diversas unidades, necessitando-se aplicar quantidades distintas para cada área.

b) Bombas injetoras

Para casos onde não existe energia para acioná-las, além da fonte de energia para o sistema de irrigação, tem-se desenvolvido bombas que são acionadas utilizan do-se da pressão do sistema.

Estas bombas operam proporcionalmente, ou se ja, a quantidade de solução injetada no sistema de irrigação é diretamente proporcional ao fluxo do mesmo.l

SHANI (198I), discorre sobre dois sistemas de injeçāo de fertilizantes:

a) Tanque com derivação de fluxo E um dos meios mais difundidos para fertir 
rigação; é padrão em gotejamento e representa uma unidade inseparável do cabeçal de controle. Porém, com aumento do tamanho das parcelas irrigadas supōe-se que outros métodos se rão preferidos.

\section{b) Injetor de fertilizante}

Este sistèna está bastante difundido no mun do, com muitas variações. A solução contida num tanque aberto é injetada à rede, por uma bomba: Fssa geralmente é de diafragma e protegida contra corrosão. Tem os seguintes as pectos favoráveis: é possível controlar a taxa de injeção; permite uso de tanque grande e aberto, com pouca necessidade de recarga.

Em contraposição tem as seguintes desvantagens: o equipamento é caro e relativamente complexo; muitos tipos requerem fonte externa de energia; a injeção prossegui rá em casos de interrupção do fluxo de água, exceto para bon bas acionadas hidraulicamente.

Também, segundo SHANI (1981), o equipamento pa ra fertirrigação pode localizar-se em trēs posições: no pon to central de uma grande área, nas parcelas ou no início de uma Iinha distribuidora.

Sobre este mesmo aspecto, FINKEL (1982) diz que o aplicador (tanque) de fertilizante é um integrante do cabeçal de controle devendo ser instalado à montante do fil tro de tela. 
Discorrendo sobre fertirrigação por gotejamer to, GROBBELLAR \& LOURENS (1974) comentam que as bombas injetoras podem ser do tipo taxa proporcional. Com estas, a taxa de injeção se altera com o fluxo do sistema de irrigação. Ou tros tipos são de taxa constante, independendo do fluxo do sistema, porém, podem ser reguláveis para obterem-se diferen tes concentraçōes na rede de irrigação. Esses autores citam também que normalmente são injetados $80 \mathrm{l} / \mathrm{h}$ de solução em sistemas de gotejamento.

De acordo com KENNEDY (1984), diversos siste mas de injeção são frequentemente usados na Austrália. Tal vez o mais comum seja introdução da solução utilizando-se um tubo ligado à tubulação de sucção da bomba de irrigação. Es te sistema, apesar de ser fácil e de baixo custo, pode apre sentar problema quando o produto é corrosivo ou abrasivo, da nificando os componentes da bomba; quando mal manejado faci lita a ocorrência de cavitação e perda do escorvamento da bom $\mathrm{ba}$.

Também segundo este autor, o sistema de derivą ção de fluxo através de pressão diferencial tem como primei ra objeção a excessiva perda de carga pela necessiade de se criar pressão diferencial. Porém, esta colocação do autor pode ser contra-argumentada, pois pode-se ter menores perdas quando a vazão de derivação é pequena. 
Outras abjeções levantadas por rENNEDY (1984) sao: dificuldade de controle da vazão derivada e da concentração aplicada. Embora isto seja válido a nível de agricultor, po de também ser refutado, pois, com manōmetro e medidor de va zão, é possível calibrar o sistema e calcular a concentração a ser aplicada.

Ainda segundo KENNEDY (1984), o sistema Ventu ri é um dos melhores meios de aplicação, embora provoque per da de carga e o controle da taxa de aplicação seja problemático. A aplicação mais eficiente seria com bomba in jetora, com um sistema próprio de acionamento, necessitandose, porém, uma fonte de energia próxima ao ponto de injeção. Este autor comenta também gue é desejável que o sistema te nha como características: fácil controle da quantidade total a ser injetada; independência de fonte externa de energia; possibilidade de automação ; construção com material leve e não corrosível.

\subsection{Operaç̃̃o do Sistema de FertirRigação}

Segundo WOODWARD (1959), o tempo de aplicação irá variar em função de diversos fatores: tamanho e tipo de equipamento de injeção, fertilizante e taxa de aplicação. A maioria dos materiais são injetados entre 30 a 40 minutos; deve se evitar interrupção e reinício da aplicação, o que poderia. levar a distribuição desuniforme ou excessiva fixação da subs tância aplicada sobre a planta. Após o tempo de injeção de- 
ve-se continuar a operação do sistema por mais 30 minutos para lavagem do injetor, tubulações e cultura.

* SHANI (1981) e O SOIL CONSERVATION SERVICE - USDA (1968) indicam que a aplicação de fertilizantes via sistemas de irrigação envolve trés etapas. Em um período inicial o sistema é operado com água para molhar a folhagem e o solo ou somente o solo. o período de aplicação de fertilizante ra ramente deverá ser menor que 30 minutos, sendo aconselhável uma a duas horas. O terceiro período deverá ser suficientemente longo para lavagem do sistema de irrigação e das plantas.

KELLER \& KARMELII (1975) indicam que a razão entre o tempo de aplicação de fertilizante e o tempo de irri gação é geralmente tomado como $0,8 \cdot \lambda$

XA vazão derivada através do tanque é diretamente proporcional à pressão diferencial. Nesse sentido, tam bém SHANI (1981) cita que o valor dessa pressão deve ser de 1 a 2 metros de coluna de áqua $(9,806$ a $19,612 \mathrm{kPa})$. $x$

Com relação a esse mesmo aspecto, FINKEI (1982) comenta que o cálculo da pressão diferencial é complexo. Cada tanque, junto com as conexões, deve ser calibrado na posi ção de trabalho; a pressão diferencial deve ser da ordem de 1 a 2 m.c.a. $(9,806$ a $19,612 \mathrm{kPa})$, enquanto HAGIN \& TUCKER (1982) indicam 2 m.c.a. $(19,612 \mathrm{kPa})$.

Entretanto, para nenhuma dessas pressões mencionadas os autores indicam as relações entre vazões derivadas e as vazões totais dos sistemas. 


\subsection{Concentrações Aplicadas durante a FertirRigaç̃o}

Tal como apresentado pela FAO (1980), para os sistemas de derivação de fluxo, a concentração da solução in jetada varia com o tempo; diminui rapidamente no inicio, po rém, cada vez menos com o decorrer da aplicação. A diferença básica entre derivação de fluxo e bombas injetoras, é que essas apresentam taxa constante de injeção.

Como a variação da concentração da solução injẹ tada diminui com o transcorrer da aplicação, os tempos decor ridos entre as amostragens podem ser cada vez maiores.

GOLDBERG et alii (1976), comentam que a calibração do tanque não é difícil de ser efetuada, porém, è complexa. Indicam que uma pequená quantidade de sal deve ser dissolvida no tanque e o sistema colocado em operação normal. A seguir, amostras de solução são coletadas dos emissores, inicialmente cinco vezes por minuto e poste riormente a cada cinco minutos. Periodicamente, amostras são coletadas também da solução do tanque-e testadas quanto à condutividade elétrica, informando o tempo requerido para - fertilizante pássar do tanque para o sistema de irrigação. Essa informação não satisfaz plenamente, pois não segue nenhum critério.

Melhores considerações sobre concentrações in jetadas utilizando sistema de derivação de fluxo são encontradas em FAO (1980). 
Segundo essa publicaçāo, considerando-se a concentraçāo inicial no tanque igual a $100 \%$, o tempo de apli caçāo requerido para uma taxa de injeção preestabelecida po de ser determinado usando-se a Figura 1 .

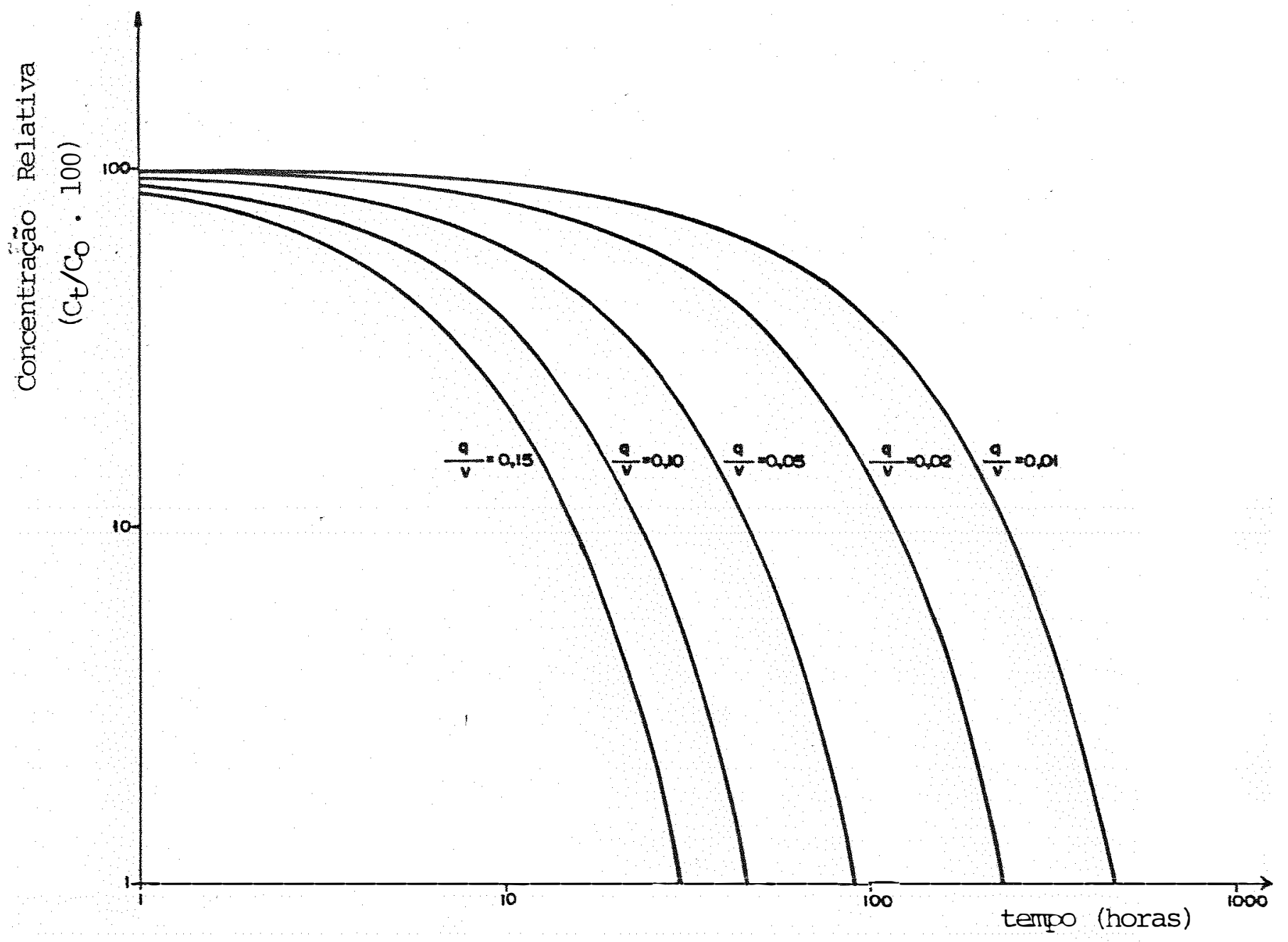

FIGURA 1. Curvas de concentração relativa $l_{0}=$ concentração inicial $=100 \% ; C_{t}=$ concentração em um tempo $t$ ) versus tempo de aplicação, para diversas relações entre vazão derivada (q) e volume do tanque (v). FAO (1980). 
As curvas apresentadas na Figura 1 foram obti das a partir da equação

$$
x=2,303 \log \frac{1}{c_{t} / c_{0}}
$$

onde:

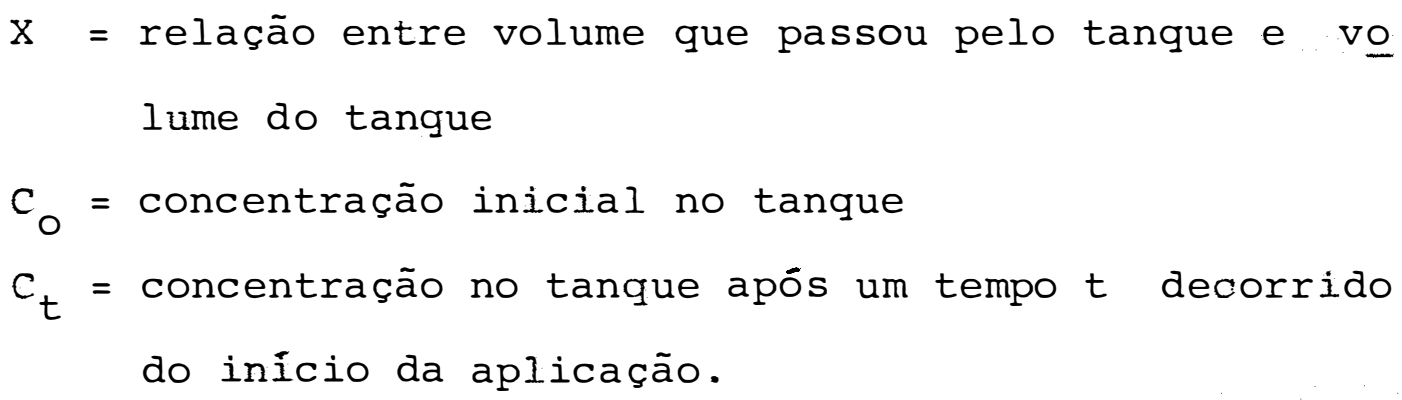

Embora não apresentado na referēncia citada, a eq. (1) pode ser deduzida partindo-se da equação geral empregada para um reservatório (tanque) com diluição contínua, que é:

$$
c_{t}=c_{0} \cdot e^{-x}
$$

onde:

$$
\begin{aligned}
c_{t}= & \text { concentração no reservatório em um tempo } t \\
c_{0}= & \text { concentração inicial no reservatório } \\
e= & \text { base do logarítimo neperiano } \\
\mathrm{x}= & \text { relação entre volume que passou pelo reservatório }(\mathrm{V}) \\
& \text { até o tempo } t \text { e o volume do reservatório (v) }
\end{aligned}
$$


$\mathrm{Da}$ eq. (z) temos:

$$
\begin{aligned}
& \frac{c_{t}}{c_{0}}=e^{-x} \Rightarrow \text { ln } \frac{c_{t}}{c_{0}}=-x \Rightarrow \text { ln } \frac{1}{c_{t} / C_{0}}=x, \\
& \text { portanto, } \quad x=2,303 \log \frac{1}{c_{t} / C_{0}} \text { que corresponde à eq }(I) .
\end{aligned}
$$

Embora teoricamente corretas, as curvas apre sentadas na Figura 1 estão relacionadas com baixos valores de $\mathrm{q} / \mathrm{v}$, que só se enquadram para pequenas taxas de injeção (q), necessitando-se Iongos tempos de aplicação, o que dificilmente ocorre na prática.

Como também discutido pela FAO (1980), a mistura do material no tanque irá depender das características do mesmo. Na maioria dos casos considera-se que ocorre mistura imediata e uniforme, podendo-se aplicar a eq. (1). Por ou tro lado, para objetivos práticos, valores apresentados gra ficamente semelhantes à Figura 1 , podem ser considerados de boa precisão.

Também com objetivos práticos, SHANI (1981) apresentou a eq. (2) graficamente. Nessa forma é possivel verificar a concentração relativa no tanque após determinado volume de aplicação, conforme apresentado na Figura 2. 


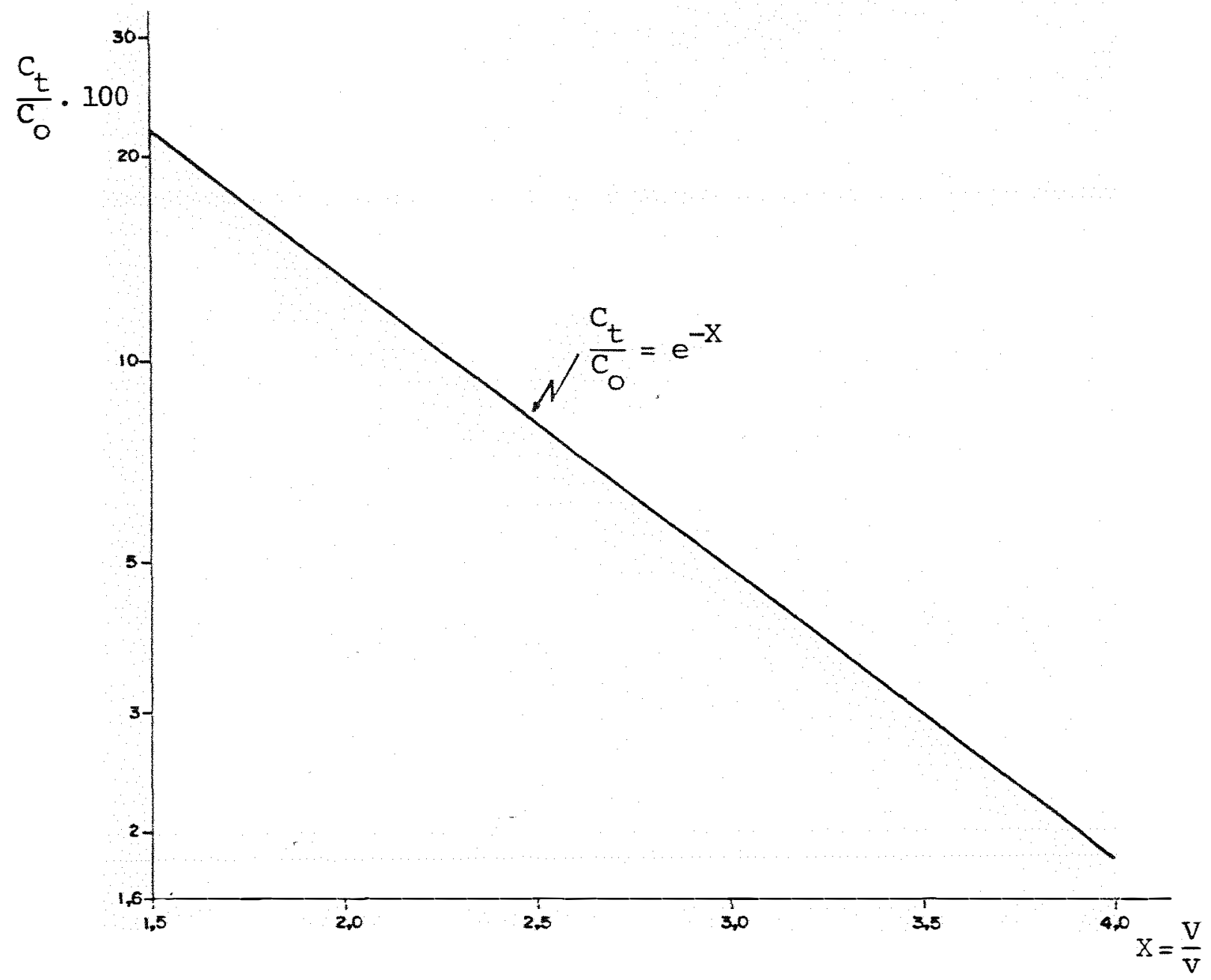

FIGURA 2. Concentração relativa $\left(C_{t} / C_{0}\right)$ versus relação entre volume aplicado (V) e volume do tanque (v). SHANI (198I).

\subsection{UNIFORMIDADE DE DISTRIBUIÇÃO}

São poucas as citações encontradas sobre uni formidade de distribuição de fertilizantes por meio de siste mas de irrigação. A maioria das considerações são incomple tas e de natureza apenas descritiva.

WIERSMA (1969), referindo-se à aspersão, co menta que a solução de fertilizante deve ser injetada a uma taxa constante para se obter aplicação uniforme. 
Descrevendo sobre fertirrigação por gotejamento, GROBBELAAR \& LOURENS (1974) indicam que para materiais pouco solúveis ou para melhor uniformidade de distribuição, o tempo de fertirrigação deve ser longo, de 3 a 5 horas.

GOLDBERG et a Ii (1976) comentam que testes realizados, utilizando derivação de fluxo com tanques pequenos, têm mostrado distribuição uniforme, por exemplo em sis tema fixo de aspersão, especialmente quando o diāmetro da tú bulação é pequeno e a pressão é alta. Se a pressão não ne cessita ser alta e o diāmetro for grande, para a distribui ção manter-se uniforme deve-se injetar o fertilizante em menor taxa. Diāmetro e comprimento dos tubos de entrada e saída do tanque têm considerável influência na taxa de in jeção.

Com relação a fertilizantes e produtos quimicos, HOLMAN (1978) sugere que em quase todos os casos é pre ferível injetá-los vagarosamente ao sistema de irrigação, pa ra ocorrer cobertura uniforme. A injeção muito rápida pode distribuir o material somente a uma parte do campo.

XROLSTON et alii (1981), mencionando sobre sis temas de gotejamento, citam que a uniformidade de distribui ção de fertilizantes depende da eficiência da agitação da so lução no tanque da uniformidade de aplicação de água edas ca racteristicas do fluxo da água e solutos na tubulação de ir rigação. Muitos sistemas projetados adequadamente distribuem com boa uniformidade. BESTER et alii* (1974), citados

* BESTER, D.H.; IOITER, D.C.; VELDMAN, G.H. Drip irrigation on citrus. Second International Drip Irrigation Congress Proceedins. San Diego, 1974, pp. 58-64. 
por esses autores, verificaram que iniciando-se a injeção após completo enchimento das tubulaçōes com āgua, a distri buição foi bastante uniforme.

Comparando métodos e sistemas de irrigação, HAGIN \& TUCKER (1982) afirmam que com irrigação por superfície o uso da fertirrigação deve resultar em distribuição ina dequada." Pivó central, aspersão convencional e gotejamento dão melhores resultados.

Embora se tenha encontrado poucos trabalhos so bre fertirrigação, estudos de uniformidade de distribuição em sistemas de irrigação são diversos, porém, referem-se ape nas à distribuição de água.

CHRISTIANSEN (1942) sugeriu um critério, que se tornou bastante utilizado, conhecido como coeficiente de Uniformidade de Christiansen (CUC). Este coeficiente é uma medida de dispersão, sendo definido como:

$$
\operatorname{CUC}\left(\frac{\circ}{\sigma}\right)=100\left(1-\frac{\sum_{i=1}^{n}\left(x_{i}-\bar{x}\right)}{n \bar{x}}\right)
$$

onde,

$$
\begin{aligned}
& \mathrm{x}_{i}=\text { valor observado no ponto } i \\
& \overline{\mathrm{x}}=\text { média dos valores observados } \\
& \mathrm{n}=\text { número de observações. }
\end{aligned}
$$

Christiansen indica como aceitáveis valores de CuC iguais ou maiores que $80 \%$. 
O SOIL CONSERVATION SERVICE (1968) adotou

$\circ$

CUC como base para irrigação por aspersão, indicando valores iguais ou maiores a $85 \%$; abaixo desse limite ocorre dis tribuição desuniforme de água na área molhada. 


\section{MATERIAL E MÉTODOS}

O experimento foi instalado no Laboratório de Hidráulica do Departamento de Engenharia Rural da Escola Superior de Agricultura "Luiz de Queiroz", Piracicaba, da Universidade de são Paulo.

Foi montado um sistema de irrigação por gotejamento, composto basicamente de um cabeçal de controle e uma linha de gotejadores, visando-se estudar a distribuição do ion cloreto ao sistema de irrigação, aplicado por dois sis temas de injeção de fertilizantes: tanque com derivação de fluxo e bomba injetora.

\subsection{MÉTOdO DE IRRIGACÃo UTILIZADO}

A água para as irrigações foi tomada de um re servatório do Laboratório de Hidráulica e bombeada até o cabeçal de controle.

Para o sistema de injeção de fertilizante com derivação de fluxo, utilizou-se uma bomba centrifuga com va zão e altura manométrica nominais de $25 \mathrm{~m}^{3} / \mathrm{h}$ e $25 \mathrm{~m} \cdot \mathrm{c} \cdot \mathrm{a} \cdot 1245$ $\mathrm{k}(\mathrm{Pa})$, respectivamente, acionada por motor elétrico de $5 \mathrm{cv}$ $(3,7 \mathrm{~kW})$.

Para injeção de fertilizante com bomba injetô ra, foram utilizados uma bomba centrifuga de $40 \mathrm{~m}^{3} / \mathrm{h}$ 
$100 \mathrm{m.c.a.}(980 \mathrm{kPa})$, respectivamente, e motor elētrico de $30 \mathrm{cv}(22 \mathrm{~kW})$.

\subsubsection{SistemAS DE INJECÃO DE FERTILIZANTE}

3.1.1.1. INJEÇÃO POR DERIVAÇÃO DE FLUXO

Consistiu da aplicação de fertilizante conti do em um tanque conectado à linha principal de irrigação. Com esse sistema, ocorre derivação de parte do fluxo da linha principal, entrando continuamente pelo tan que e voltando à mesma. Isso provoca a injeção do fertilizante à rede de irrigação, levando-o em solução até os gotejadores.

A montagem e melhor descrição desse sistema se rão apresentadas nas figuras 3 e 4 , no item 3.1 .2 .

\subsubsection{BOMBA INJETORA}

Foi utilizada uma bomba injetora fabricada pe la indústria ASBPASIl (Aspersão no Brasil S/A), de acionamento hidráulico.

Este equipamento utiliza a própria āgua do sis tema de irrigação para impulsionar hidraulicamente um pistão. Utilizando-se do principio de Ariete, a água utilizada para acionamento é ejetada e não se mistura com a solução fertilizante. Portanto, a solução contida em um re cipiente aberto não sofre diluição durante a.aplicação, sendo succionada e injetada à linha de irrigação, a uma taxa cons tante. 
A montagem dessa bomba junto ao cabeçal de con trole e melhor descrição do mesmo serão apresentadas nas $\mathrm{F}$ i guras 5 e 6 , no item 3.1.3.

3.1.2. CABECAL DE CONTROLE COM TANQUE DE FERTILIZANTE

O cabeçal de cóntrole e seus componentes es tão apresentados nas Figuras 3 e 4 , a seguir.

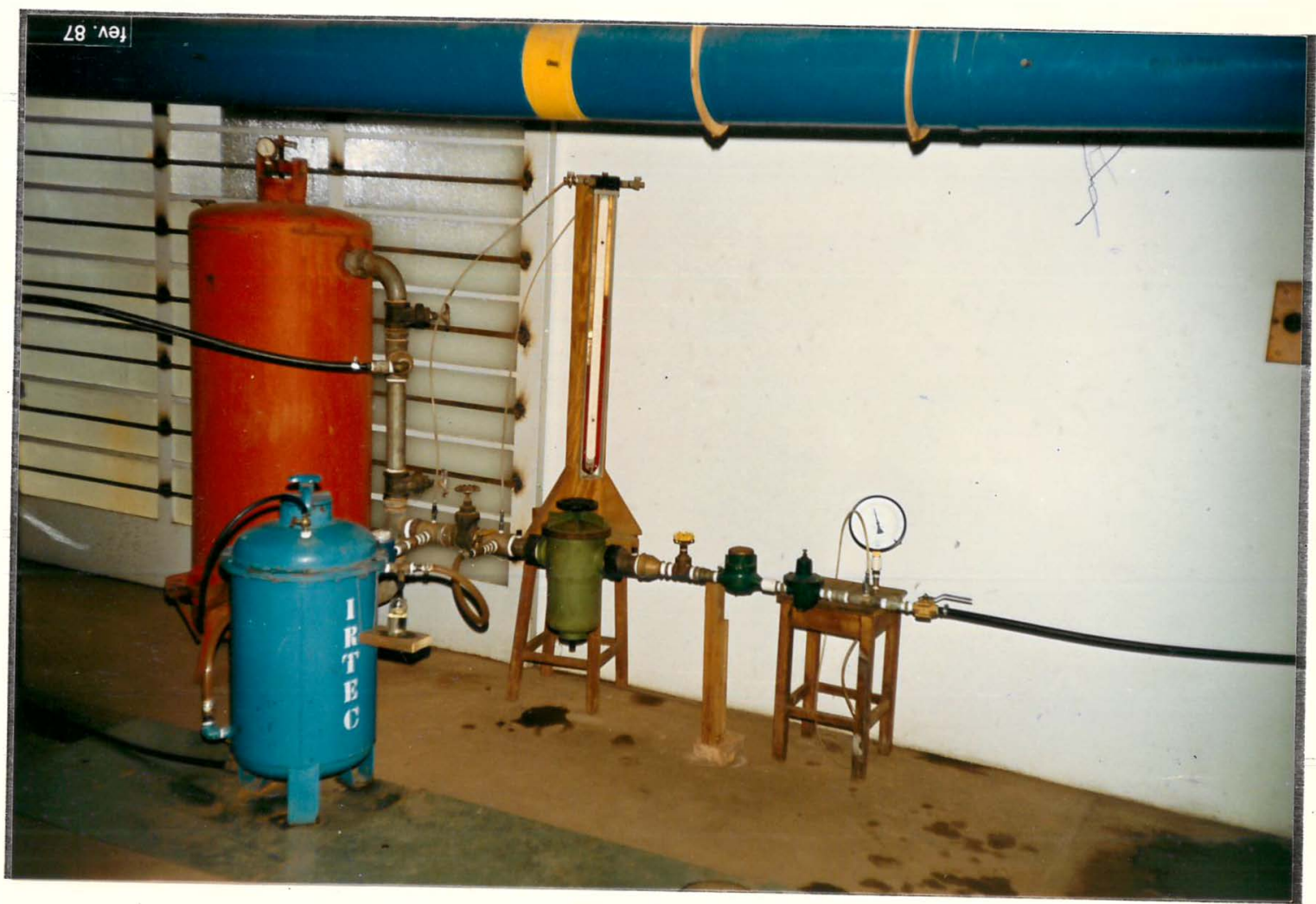

FIGURA 3. Cabeçaí de controle utilizado com derivação de flụ xo. 
24.

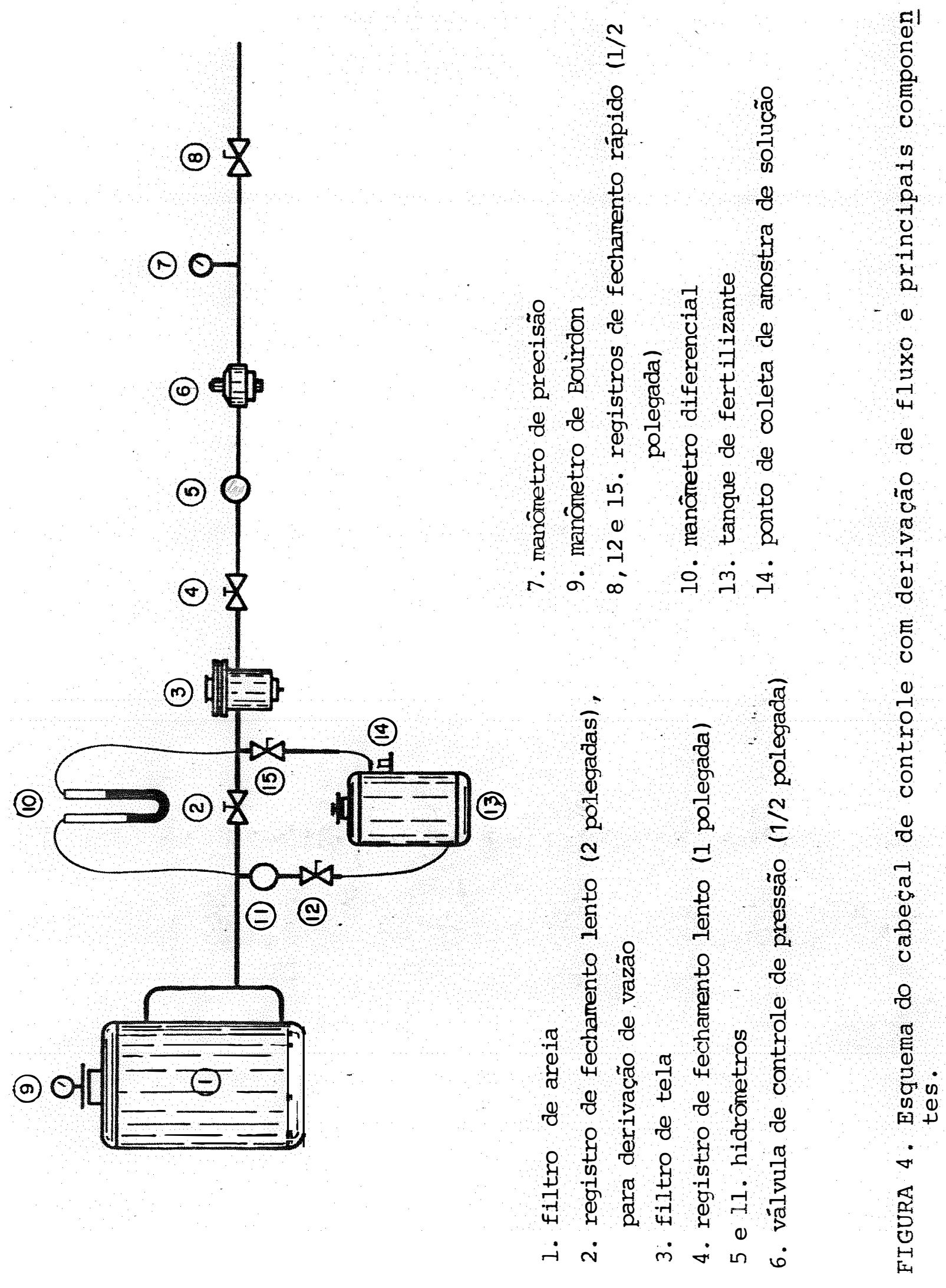


Conforme mostram as Figuras 3 e 4, foram uti lizados os componentes discriminados e operados como a seguir: Filtro de areia (no 1, Figura 4): este reser vatório foi utilizado sem areia, servindo apenas como suporte de outros componentes do cabeçal de controle; a água pro veniente da moto-bomba preencheu totalmente este reservató rio, atingindo uma pressão de $25 \mathrm{~m} . \mathrm{c} . \mathrm{a} .(245 \mathrm{kPa})$, medida no manōmetro instalado na parte superior do filtro (no 9, Figu ra 4 ).

Registro de fechamento lento (no 2, Figura 4): a água que passava pelo filtro de areia atingia em seguida es te registro. Pelofechamento parcial do mesmo provocou-se perda de carga, resultando uma derivação do fluxo da linha principal em direção ao tanque de fertilizante. A perda de carga originada do fechamento deste registro foi acusada pelo manô metro diferencial.

Filtro de tela (no 3 , Figura 4): foi utilizado um filtro de 150 "mesh", com a finalidade de reter impure zas minerais provenientes principalmente do fertilizante.

Hidrōmetros (nos 5 e II, Figura 4): o hidrōmetro indicado com número 5, instalado na linha principal, foi utilizado para calcular a vazão total do sistema; com o ou tro, instalado em direção à entrada do tanque, calculou-se a vazão derivada. Foram usados hidrômetros domiciliares, com vazāo nominal de $3 \mathrm{~m}^{3} / \mathrm{h}$ e com graduação que permite leitura minima de um litro. 
Válvula de controle de pressão lno 6, Figura 4): esta vālvula, de operação manual, foi utilizada com a fi nalidade de ajustar a pressão após a mesma, acusada no manō metro de precisão(n! 7, Figura 4). Com a instalação dessa válvula, a pressão na saída da central de controle foi mantí da em 11,2 m.c.a. $(109,83 \mathrm{kPa})$, resultando em uma pressão de serviço na linha de gotejadores de $10 \mathrm{~m} . \mathrm{c} . \mathrm{a} .(98,06 \mathrm{kPa})$.

Registros de fechamento rápido (nos 8, 12 e 15, Figura 4): os registros instalados na tubulação de entra da e saída do tanque foram utilizados para possibilitaro iso lamento do mesmo em relação à linha principal. o registro instalado na saída do cabeçal de controle foi utilizado com a finalidade de permitir interrupção brusca do fluxo. Isso possibilitou a leitura dos hidrômetros em determinado ins tante, permitindo obter-se uma relação entre perda de carga, acusada no manômetro diferencial e vazão derivada ao tanque de fertilizante.

Manômetro diferencial (no 10, Figura 4): foi utilizado um manōmetro em "U", com líquido manométrico à. densidade igual a 1,75 .

As tomadas de pressao foram conectadas a li nha principal, antes e após o registro de controle de deriva çao de fluxo,por meio de engates rápidos.

Com a perda de carga acusada no manômetro cau sada pelo fechamento parcial do registro localizado entre as tomadas de pressão, e volume lido no hidrômetro, obteve-se 
uma relação entre perda de carga e vazão derivada. Esta re lação foi utilizada para controlar a vazão de solução fertilizante injetada à linha principal.

Tanque de fertilizante (no 13, Figura 4):

utilizou-se tanque da incústrib. IRTEC, com capacidade de 62 l. No início da tubulação de saída do tanque (no 14, Figura 4), foi inserido um gotejador, permitindo coleta de amostras de solução durante as fertirrigaçōes.

\subsubsection{CABECAL DE CONTROLE COM BOMBA INJETORA}

O. cabeçal de controle contendo a bomba. injeto ra e demais componentes estão apresentados nas Figuras 5 e 6 .

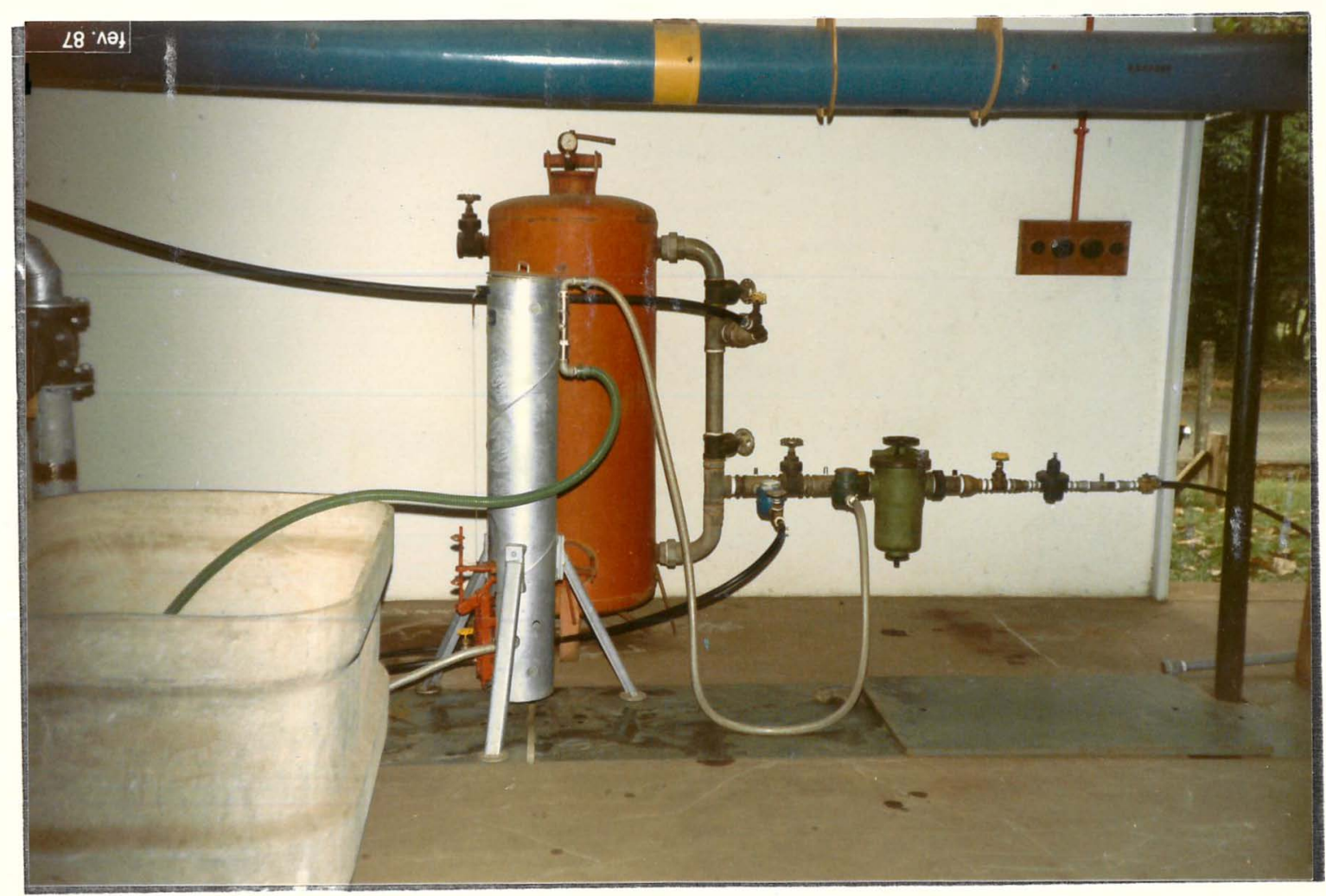

FIGURA 5. Cabeçal de controle com bomba injetora 

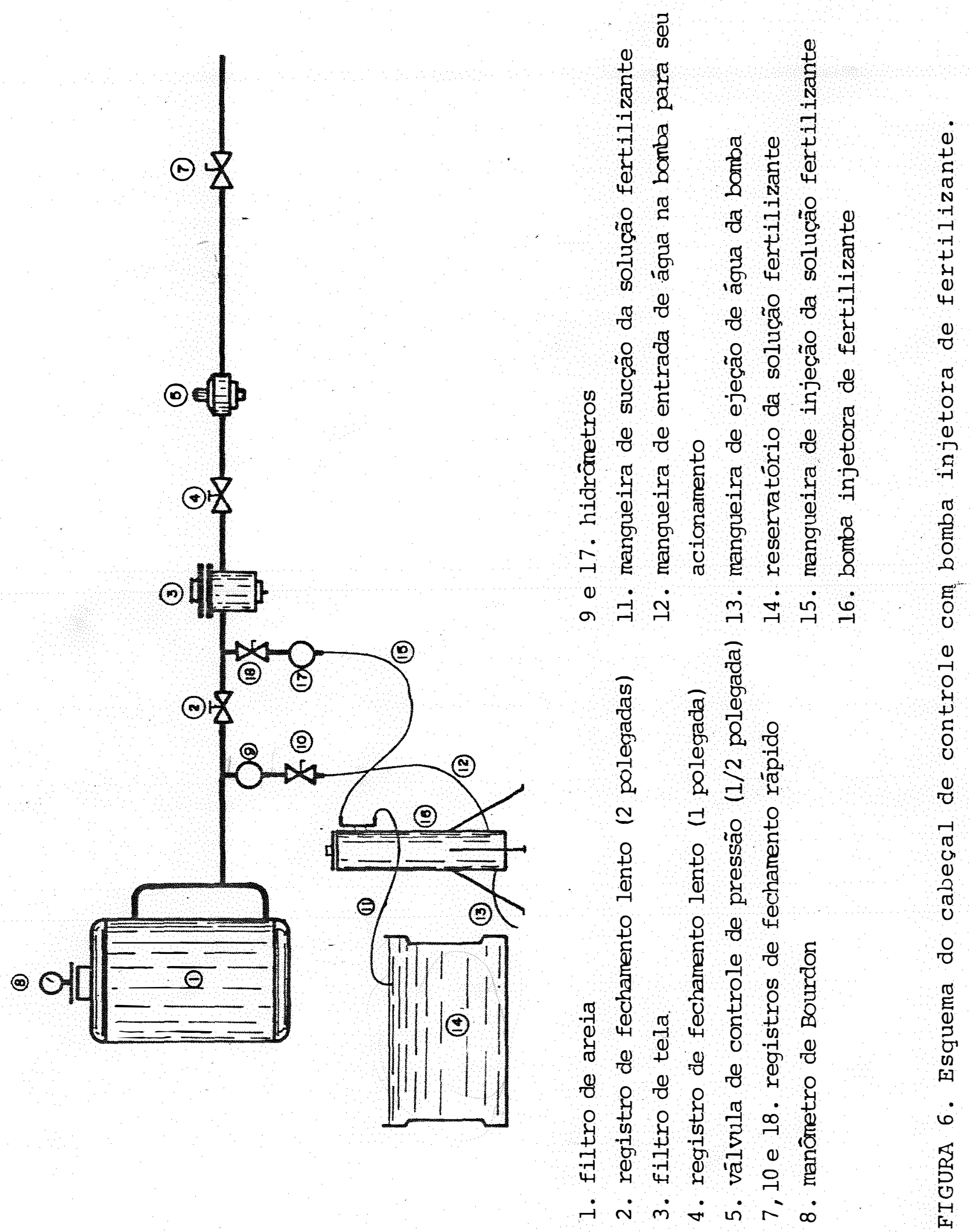
Tal como descrito para o tanque de fertilizan te, foj utilizado o mesmo cabeçal de controle para instala ção da bomba injetora.

Para operação do sistema com a bomba injetora, os seguintes aspectos diferiram em relação ao tanque de fertilizante:

Registro de fechamento (no 2, Figura 6): man tido totalmente aberto.

Manômetro de Bourdon (no 8, Figura 6) : devido à necessidade de maior pressão para acionamento da bomba, a pressão controlada por meio deste manōmetro foi de $4 \mathrm{kgf.cm}^{-2}$ $(392,2 \mathrm{kPa})$.

Reservatório de solução fertilizante (no 14, Figura 6): foi utilizada uma caixa de cimento amianto aberta, com capacidade de 500 \&.

Hidrômetro (no 17, Figura 6) : este hidrōmetro instalado na mangueira de injeção de solução fertilizante, permitiu verificar o volume de solução injetada, e relacioná lo ao volume ejetado pela bomba.

\subsubsection{LINHA DE GOTEJADORES}

A I inha de gotejadores foi conectada ao final do cabeçal ãe controle e estendida em uma área externa ao la boratório de Hidráulica. Nas Fiquras 7 e 8 estão apresenta dos os detalhes da linha de gotejadores. 
30.

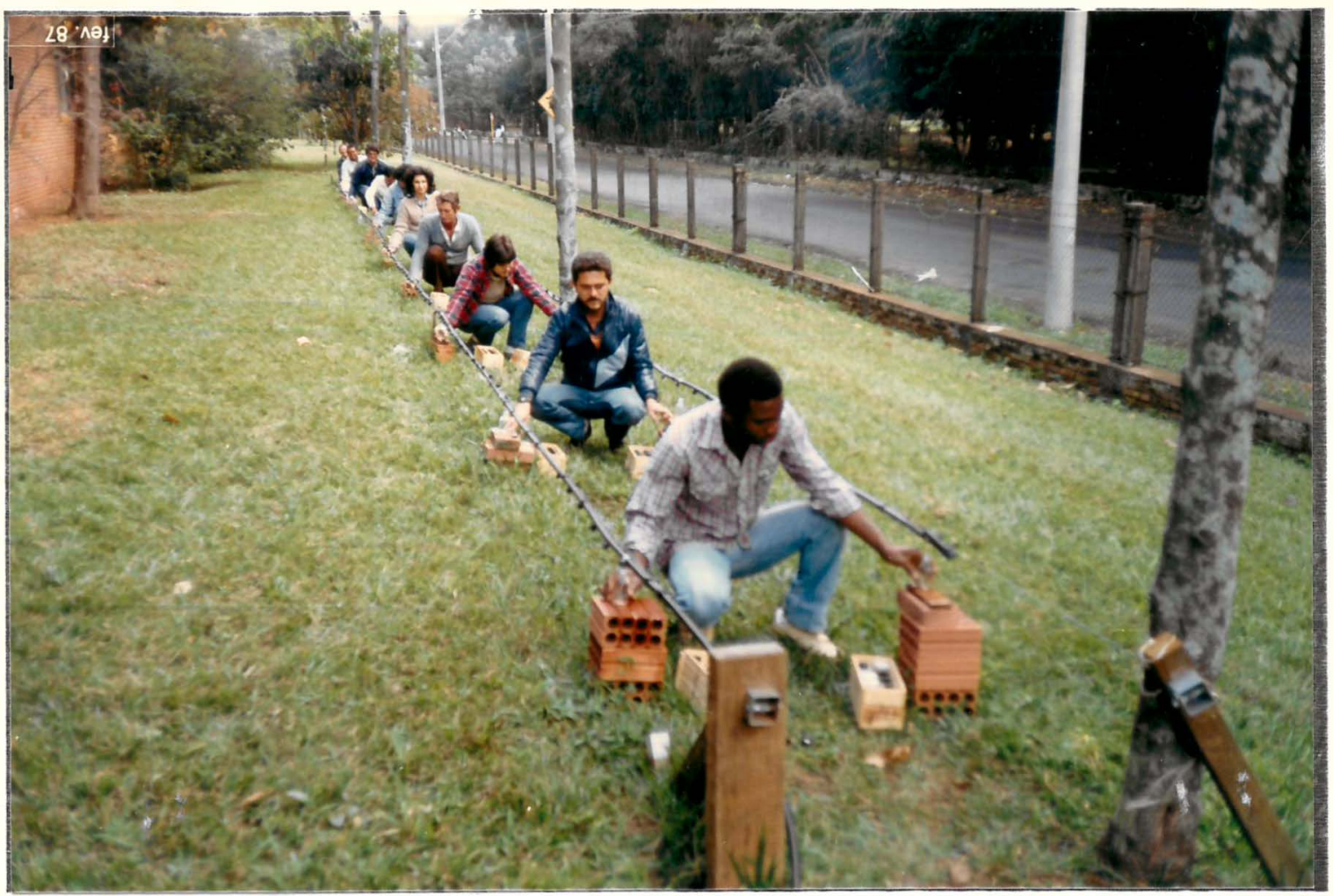

FIGURA 7. Aspecto da linha de gotejadores em um momento de coleta.

Para constituição da linha de gotejadores foi utilizado tubo de polietileno com $17 \mathrm{~mm}$ de diāmetro interno e $2 \mathrm{~mm}$ de espessura e gotejador de inserção sobre a linha ("on line"), internamente de longo percurso (labirinto) e des montável, possibilitando limpeza. O tubo e gotejador procederam da indústrià ASBRASIL (Aspersão no Brasil S/A) .

O tubo foi perfurado com vazador manual a ca da $0,25 \mathrm{~m}$, tendo-se utilizado 210 gotejadores.

No sistema de irrigação utilizado no presente trabalho, a vazão média dos 210 gotejadores, à pressão de ser viço de 10 m.c.a., calculada pelo volume marcado no hidrômetro da saida da central de controle foi de 3,238 1/h. 

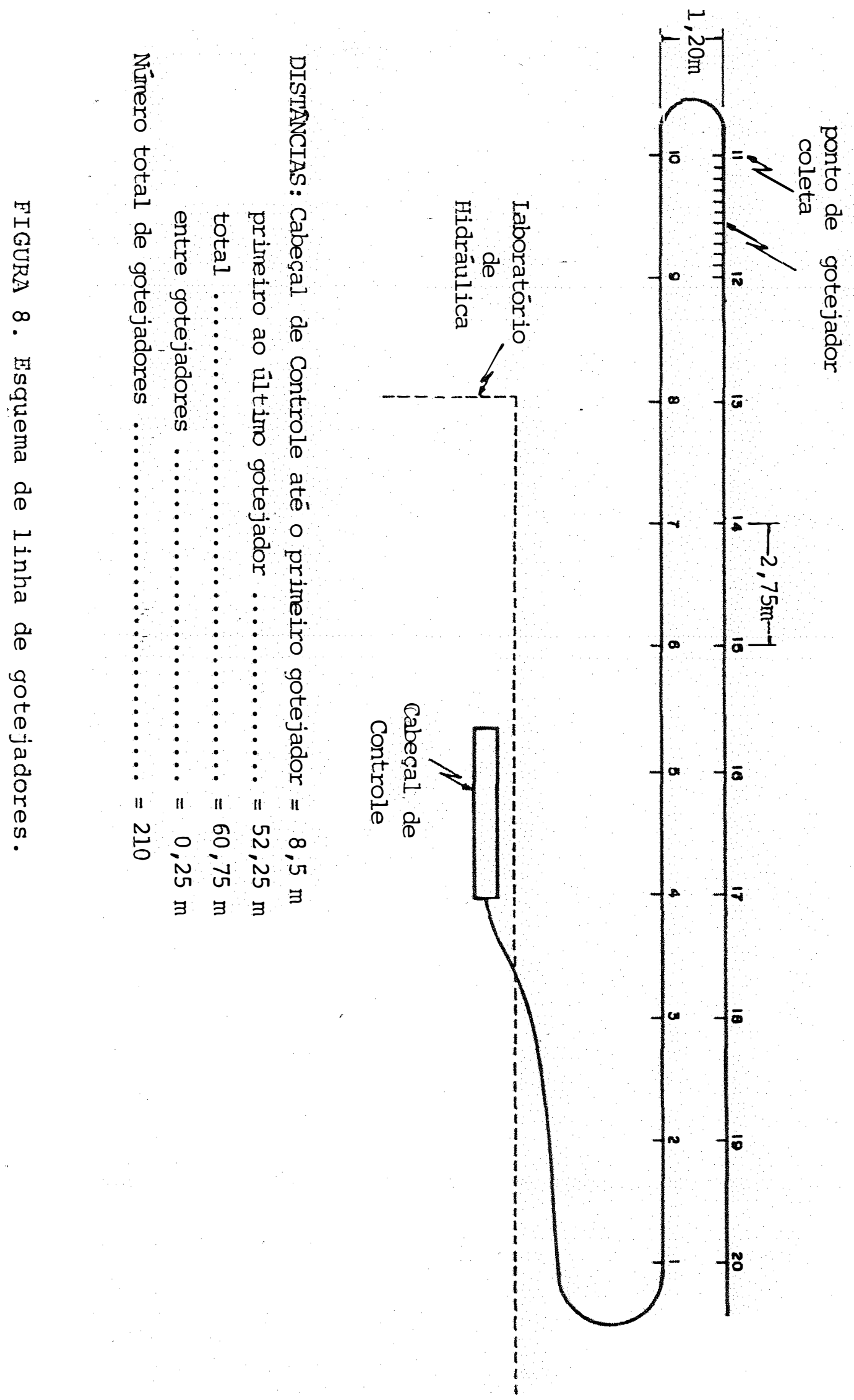
Para estabelecimento do comprimento da linha de gotejadores, adotou-se o critério de KELLER \& KARMELI (1975), o qual indica que o comprimento máximo da mesma deve ser tal que a perda de carga ocorrida entre os gotejadores extremos seja de $12 \%$ da pressão de serviço.

Esses mesmos autores determinaram que $3 / 4$ da perda de carga ocorre do iníció da linha até a posição da pressão de serviço e que o restante da perda ocorre dessa po sição até o final da linha.

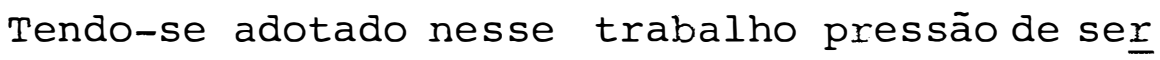
viço igual a 10 m.c.a. $(98,06 \mathrm{kPa})$, a perda de carga permitida foi igual a $1,2 \mathrm{~m} . \mathrm{c} \cdot \mathrm{a} \cdot(11,77 \mathrm{kPa})$ e os valores de pressão no primeiro e último gotejadores foram 10,9 e 9,7 m.c.a. (106,9 e $95,12 \mathrm{kPa})$, respectivamente. Para ocorrência desses valores, por meio de tentativas, foi-se aumentando o nümero de gotejadores na linha e medindo-se a pressão nos pontos de inserção do primeiro e do último gotejador, com o manônetro de precisão (no 7, Figura 4). Esse manômetro é padrão para aferição de outros manônetros, tem divisões de escala de $0,1 \mathrm{~m} . \mathrm{c} \cdot \mathrm{a} \cdot(0,98 \mathrm{kPa})$ e imprecisão de lei tura de $\pm 0,5 \%$. Encontrou-se a condição desejada para o comprimento de $52,25 \mathrm{~m}$, com 210 gotejadores.

o controle da pressão na linha foi feito com a válvula de regulagem de pressão, localizada na saída do cabeçal de controle.

Também segundo KELLER \& KARMELI (1975), a pres são de serviço ao longo de uma linha de gotejadores ocorre na posição de $39 \%$ do comprimento da mesma, a partir do pri meiro gotejador instalado. 
Baseando-se nessa informação, instalou-se uma tomada de pressão nessa posição, a fim de regular a pressão de serviço durante as fertirrigações utilizando-se do manôme tro de precisão e da válvula de controle de pressão localizada no final do cabeçal de controle.

Conforme pode-se observar nas Figuras 7 e 8 , para instalação da linha de gotejadores, utilizou-se como suporte dois fios de arame esticados em nivel, distanciados la teralmente de $1,20 \mathrm{~m}$.

Do primeiro ao décimo ponto de coleta, a li nha foi fixada a um dos fios e do décimo primeiro até a ex tremidade final ao outro fio; esta disposição, formando um U entre o décimo e décimo primeiro ponto, permitiu que cada pessoa coletasse amostras em dois pontos ao mesmo tempo.

\subsection{InJeção de Fertilizante por DeRivaç̃o de Fluxo}

\subsubsection{EQUAÇÃO DE REGRESSÃO ENTRE DIFERENÇA DE PRES SÃO E VAZÃO DERIVADA}

Para controle da vazão derivada ao tanque de fertilizante, em função da diferença de pressão existente en tre os pontos de tomada de pressão, localizados antes e de pois do registro de controle de vazão, foram correlacionados valores de pressão diferencial e vazão derivada, procedendose como descrito a seguir. 
Fechando-se gradativamente o registro indicado com número 2 na Figura 4, consequentemente aumentando-se a diferença de pressão acusada no manōmetro diferencial, obtiveram-se aumentos da vazão derivada para o tanque.

As vazões derivadas foram calculadas pelas leituras do hidrōmetro localizado na tubulação da entrada do tanque, permitindo-se e interrompendo-se momentaneamente o flu $\underline{u}$ xo através do registro de fechamento rápido localizado na tu bulação de saỉda do tanque.

Foram relacionados 18 valores de diferença de pressäo, de 0,02 até $1,40 \mathrm{~m} . c . a \cdot(0,196$ até $13,73 \mathrm{kPa})$ e cor respondentes vazões derivadas, com quatro repetições.

Com esses dados obteve-se uma equação de regressão entre as variáveis citadas, a partîr da qual, esti maram-se as vazões desejadas.

\subsubsection{TEMPOS DE FERTIRRIGAC̆ÕES E INSTANTES DE COLETA DE AMOSTRAS}

Para estabelecimento dos instantes de coleta de amostras de solução fertilizante, partiu-se da equação ge ral de diluição em que se enquadra a situação empregada nes te trabalho, ou seja: tendo-se uma vazão constante passando por um reservatório de volume e concentração inicial conheci dos, considerando-se que ocorra mistura perfeita, a concen tração neste reservatório em determinado tempo será dada pe la eq. (2). 
Deste modo, pode ser calculado o volume que passou pelo tanque até um determinadoinstante e a concentra ção teoricamente existente nesse instante.

Para o presente trabalho, estabeleceu-se que seriam coletadas amostras na saida do tanque e nos diversos pontos da linha de gotejadores, para três vazões derivadas ao tanque, sempre que teoricamente a concentração no tanque baixasse $10 \%$ em relação à concentração inicial (considerada 100\%), definindo-se assim dez instantes de coleta.

SHANI (1981) recomenda que a reiação entre o volume que deve passar pelo tanque (V) e o volume do tanque (v), seja no minimo igual a quatro, para que se garanta boa solubilização do fertilizante e aplicação uniforme.

Adotando-se esse critério, a concentração fi nal no tanque em relação à concentração inicial será de 1,83\%. Para valores iquais ou. inferiores a esse poder-se-á admitir fina lizada a aplicação. No presente trabalho, adotou-se esse va lor de concentração para definição do último (décimo) instan te de coleta.

Conforme SHANI (198I) e SOIL CONSERVATION SER vice (1968), o periodo de aplicação do fertilizante raramen te deverá ser menor que 30 minutos, sendo aconselhável usar um período entre uma e duas horas.

Baseando-se messa indicação, para este trabaIho, adotaram-se três tempos de fertirrigação: 40,80 e 160 minutos. 
Uma vez que para os três témpos de fertirriga

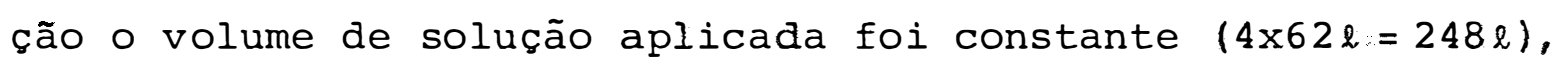
obtiveram-se três vazões de derivação, indicadas na Tabela 1 . Nessa mesma tabela também estão apresentados os tempos de aplicação do fertilizante e respectivos instantes de coleta.

A redução da concentração relativa de fertili zante no tanque para os três valores de vazão e tempos de co leta de amostras marcados apenas para a vazão de $3721 / \mathrm{h}$, es tão apresentados graficamente na Figura 9 . 
TABELA 1 - Instantes de coleta de amostras, para os tempos de fertirrigação e vazões de derivação.

\begin{tabular}{|c|c|c|c|}
\hline $\begin{array}{l}\text { Concentração } \\
\text { relativa no } \\
\text { tanque } \\
\left.\left(\frac{C_{t}}{C_{0}}\right) \cdot 100\right)\end{array}$ & $\begin{array}{l}\mathrm{T}=40 \mathrm{~min} \\
\mathrm{q}=372 \mathrm{l} / \mathrm{h} \\
\mathrm{q} / \mathrm{Q}=0,5470\end{array}$ & $\begin{array}{l}T=80 \mathrm{~min} \\
q=186 \mathrm{l} / \mathrm{h} \\
q / Q=0,2735\end{array}$ & $\begin{array}{l}\mathrm{T}=160 \mathrm{~min} \\
\mathrm{q}=931 / \mathrm{h} \\
\mathrm{q} / \mathrm{Q}=0,1367\end{array}$ \\
\hline $100^{*}$ & $0^{\prime}$ & $0^{\prime}$ & $0^{\prime}$ \\
\hline 90 & I'03" & $2 \cdot 06 "$ & $4 ' 13 "$ \\
\hline 80 & $2 \cdot 14 "$ & 4 ' 28 " & $8^{\prime} 55^{\prime \prime}$ \\
\hline 70 & 3 ' 34 " & 7 " & $14 ' 16 "$ \\
\hline 60 & $5 \cdot 06^{\prime \prime}$ & $10 ' 13$ " & $20^{\prime} 26^{\prime \prime}$ \\
\hline 50 & $6^{\prime} 56^{\prime \prime}$ & $13 \cdot 52 "$ & $27^{\prime} 44^{\prime \prime}$ \\
\hline 40 & " & $18 \cdot 20 "$ & $36^{\prime} 39 \prime$ \\
\hline 30 & $12^{\prime} 02 "$ & $24 \cdot 05^{\prime \prime}$ & $48 ' 10 "$ \\
\hline 20 & $16^{\prime} 06^{\prime \prime}$ & $32 ' 11 "$ & $64 ' 22$ " \\
\hline 10 & $23^{\prime} 02 "$ & $46^{\prime} 03^{\prime \prime}$ & 92 " \\
\hline 1,83 & $40^{\prime} 00^{\prime \prime}$ & $80^{\prime} 00^{\prime \prime}$ & $160^{\prime} 00^{\prime}$ \\
\hline
\end{tabular}

* amostras coletadas somente no tanque

$T$ = tempo de fertirrigação

$\mathrm{q}=$ vazão de derivação $=\mathrm{V} / \mathrm{T}$

$\mathrm{Q}=$ vazão do sistema $=680 \mathrm{l} / \mathrm{h}$

$\mathrm{V}=$ volume que passa pelo tanque no tempo $\mathrm{T}=248 \mathrm{\ell}$

$\mathrm{C}_{t}=$ concentração no tanque, em determinado momento

$c_{0}^{t}=$ concentração inicial no tanque (100\%) . 
38.

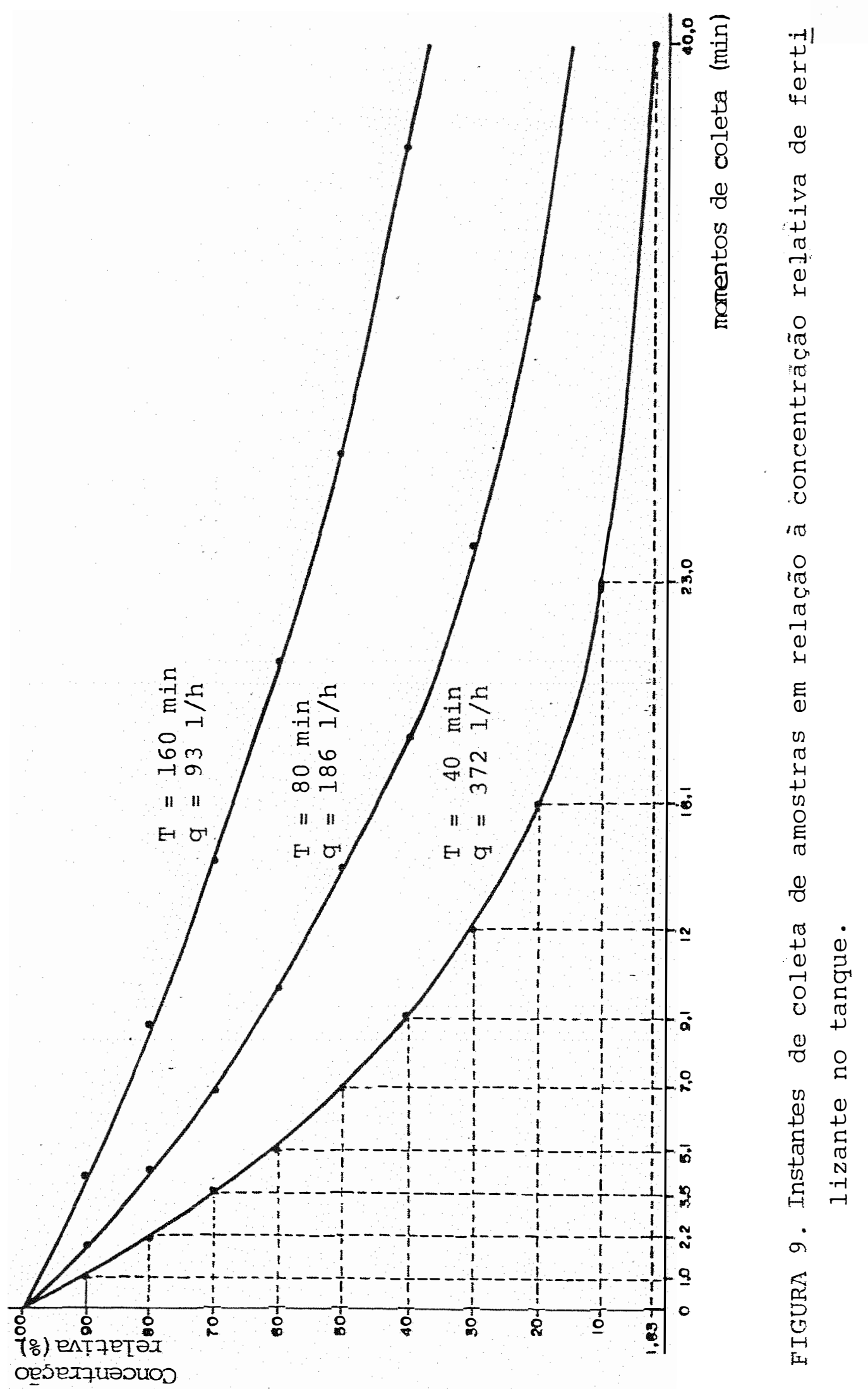




\subsubsection{PRESSÃO E VAZÃO AO LONGO DA LINHA DE GOTEJADO RES}

Após estabelecido o comprimento da linha de gotejadores, conforme descrito em 3.1.3., utilizando-se manômetro de precisão (nழ 7, Figura 4), determinou-se a dis tribuição da pressão ao longo da linha de gotejadores, medi da no ponto de inserção dos 20 gotejadores destinados à coleta de amostras de solução fertilizante.

Nesses pontos determinaram-se também os valores de vazão, coletando-se o volume aplicado por cada goteja dor durante dez minutos, com quatro repetições.

\subsubsection{FERTILIZANTE E MANEJO DO SISTEMA PARA AS FER TIRRIGACÕES}

\subsubsection{FERTILIZANTE}

Para estudo da distribuição de fertilizante com os sistemas de injeção, foi utilizado cloreto de po tássio (KCl). Esse fertilizante apresenta alta solubilidade, pequenahigroscopicicidade, facilidade de análise e pouco problema de conservação de amostras em solução quando é necessá rio armazenamento.

Foi empregado $\mathrm{KCl}$ destinado ao uso agricola, procedente da indústria FOSFANIL S/A, de natureza física fá relada. 
A análise desse fertilizante, realizada

no

Departamento de Química da Escola Superior de Agricultura "Luiz de Queiroz" em Piracicaba, a partir de amostra mantida em estufa a $105^{\circ} \mathrm{C}$ durante duas horas revelou teores de $61,3 \%$ de $\mathrm{K}_{2} \mathrm{O}$ e $46,3 \%$ de $\mathrm{Cl}$.

\subsubsection{MANEJO DO SISTEMA}

Para todas as fertirrigações, operou-se o sis tema inicialmente apenas com ägua, regulando-se o registro de derivação de fluxo para se obter a vazão desejada em direção ao tanque, a qual fora previamente estabelecida. Em seguida, mantendo-se a posição encontrada para esse registro, inter rompeư-se a operação, desligando-se a bomba.

Para colocação de fertilizante no tanque, ini cialmente foram fechados os registros das tubulações de entra da e saída do mesmo e, então, transferida a quantidade prédeterminada de $\mathrm{KCl}$; em seguida, fiez-sé a complementação do volume do tanque com àgua e agitação da mistura. Após isso, uma ámostra de solução foi retirada para análise da concentração inicial no tanque, fechando-se em seguida o mesmo.

$$
\text { Mantendo-se o tanque isolado da linha princi- }
$$
pal, por meio dos registros fechados, a bomba foi novamente acionada e aplicou-se apenas ãgua até que toda a linha de, gotejadores estivesse operando à pressão de serviço.

Estando posicionadas as pessoas para coleta de amostras na saída do tanque e ao longo da Iinha de goteja 
dores, os registros de ligação do tanque ao sistema foramaber tos e então iniciada a fertirrigação.

Decorrido o tempo total da fertirrigação,

tanque foi esgotado e lavado; para lavagem também de todo o sistema de irrigação, fioi mantida a aplicação apenas de água durante mais 30 minutos.

3.2.5. PREVISÃo das CONCENTRAÇ̃̃es a SEREM obtidas E QUANTIDADES APLICADAS DE FERTILIZANTE

Anteriormente à realização das fertirrigações, analisou-se o teor de cloreto da água utilizada, o qual foi de $15 \mathrm{ppm}$. Esse mesmo resultado foi obtido para outras aná Iises realizadas durante o transcorrer do experimento.

Baseando-se nesse valor e-considerando-se que a aplicação seria realizada de tal modo que no final das fer tirrigações a concentração média da solução na linha de gote jadores seria teoricamente de $30 \mathrm{ppm}$, calcularam-se as quantidades de $\mathrm{KCl}$ a serem colocadas no tanque, da seguinte ma neira: 
a) Para $\mathrm{T}=40$ minutos e $\mathrm{q}=372 \mathrm{l} / \mathrm{h}$

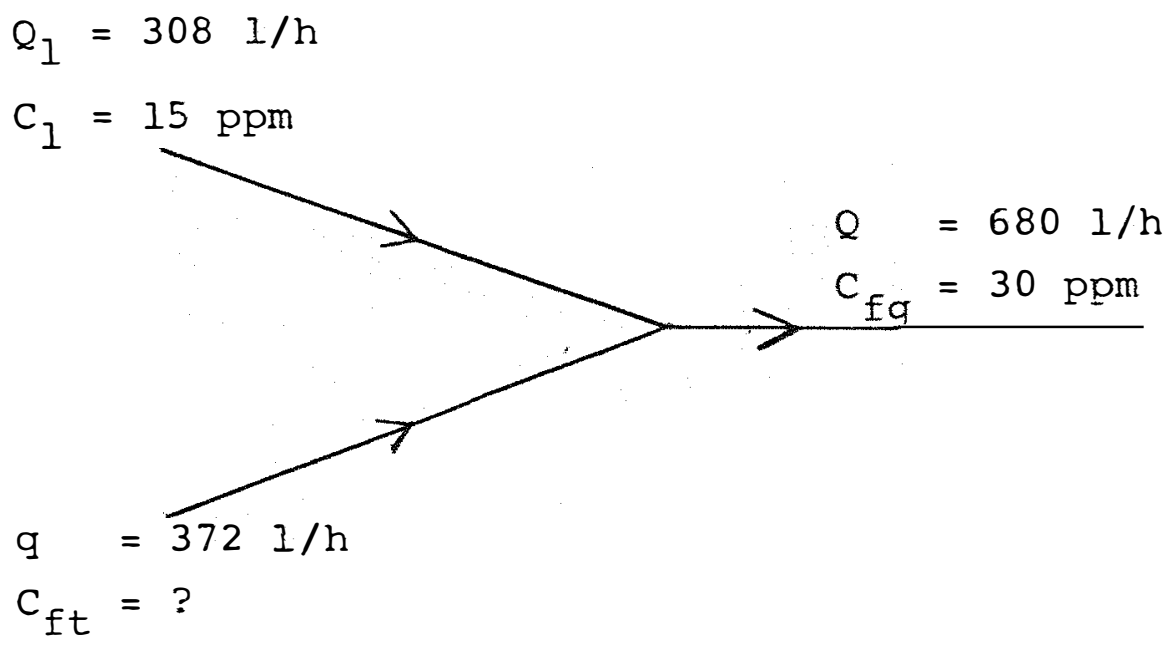

onde,

$$
\begin{aligned}
Q_{1}= & \text { vazão que passa pelo registro de derivação na li } \\
& \text { nha principal } \\
Q= & \text { vazão total do sistema de irrigação } \\
q= & \text { vazão derivada ao tanque de fertilizante } \\
C_{1}= & \text { concentração natural de cloreto na água } \\
C_{f g}= & \text { concentraçãa final desejada na linha de gotejado } \\
& \text { res } \\
C_{f t}= & \text { concentração necessária no tanque, no final da } \\
& \text { aplicação. }
\end{aligned}
$$

- Cálculo da concentração $\left(C_{f t}\right)$ necessária no tanque no final da aplicação:

$$
Q_{I} \cdot C_{I}+q \cdot C_{f t}=Q \cdot C_{f g} \Rightarrow C_{f t}=\frac{Q \cdot C_{f g}-Q_{I} \cdot C_{I}}{q} \Rightarrow C_{f t}=42,4 \mathrm{ppm}
$$


- Sendo $\mathrm{C}_{\text {ft }}$ igual a 1,838 da concentração ini cial no tanque $\left(C_{i t}\right)$, esta deverá ser:

$$
C_{\text {it }}=\frac{100 \cdot 42,4}{1,83}=2.317 \mathrm{ppm}
$$

- Concentração inicial na linha de gotejado-

$\operatorname{res}\left(\mathrm{C}_{i g}\right)$

$$
\begin{aligned}
Q_{I} \cdot C_{I}+q \cdot C_{i t}=Q \cdot C_{i g} \Rightarrow C_{i g}=\frac{Q}{C_{I} \cdot C_{I}+q \cdot C_{i t}} & Q \\
\Rightarrow & C_{i g}=\frac{308 \times 15+372 \times 2317}{680} \Rightarrow C_{i g}=1.274 \mathrm{ppm}
\end{aligned}
$$

- Quantidade de Cl a ser colocado no tanque, com volume $(\mathrm{v}):=62 \ell$

$$
\mathrm{Cl}=\mathrm{v} \cdot \mathrm{C}_{\mathrm{it}}=62 \ell .2317 \mathrm{ppm}=\frac{62000 \mathrm{ml} .2317 \mathrm{a}}{1.000 .000 \mathrm{ml},}=143,6 \mathrm{~g}
$$

Como o conteúdo de $\mathrm{Cl}$ contido na água para en chimento do tánque é de $0,9 \mathrm{~g}$, a quantidade de $\mathrm{Cl}$ será $=142,7 \mathrm{~g}$.

- Quantidade (peso seco) de $\operatorname{KCl}(46,3 \%$ de $\mathrm{Cl})$ a ser colocado no tanque

$$
\mathrm{KCl}=\frac{\mathrm{Cl} .100}{46,3}=\frac{142,7.100}{46,3}=308,2 \mathrm{~g}
$$


Por analogia ao item a, obteve-se:

b) Para $T=80$ minutos e $q=186 \mathrm{l} / \mathrm{h}$

- Concentração $\left(C_{f t}\right)$ necessária no tanque, no final da aplicação $=69,8$ ppm.

- Concentração inicial no tanque $\left(C_{i t}\right)=3.814,2$ ppm.

- Concentração inicial na linha de gotejadores $\left(C_{1 g}\right)=1.054,2 \mathrm{ppm}$.

- Quantidade de $\mathrm{KCl}$ a ser colocado no tanque= $508,8 \mathrm{~g}$

c) Para $T=160$ minutos e $q=931 / \mathrm{h}$

- Concentração $\left(C_{f t}\right)$ necessária no tanque, no final da aplicação $=124,7 \mathrm{ppm}$.

- Concentraçāo inicial no tangue $\left(C_{i t}\right)=6.812,9$ ppm .

- Concentração inicial na linha de gotejadores $\left(C_{i g}\right)=944,7$ pom. 
- Quantidade de $\mathrm{KCl}$ a ser colocado no tanque =

$910,3 \mathrm{~g}$

\subsection{INJECÃO DO FERTILIZANTE COM BOMBA}

\subsubsection{CONTROLE DA TAXA DE INJECÃO}

A taxa de injeção é proporcional à frequência de golpes e curso do pistão da bomba. A frequência pode ser regulada com um registro localizado na mangueira de entrada de água na bomba, controlando-se a vazão.

No presente trabalho determinou-se a relação ejeção/injeção da bomba, fazendo-se medições dos volumes de ejeção e injeção resultantes de dez golpes do pistão, repe tindo-se quatro vezes.

Para tal, o volume ejetado foi coletado em um recipiente de 20 \& e medido com proveta graduada; 0 volume de injeção correspondente foi medido com o hidrô metro localizado na tubulação de injeção.

Uma vez determinada a relação ejeção/injeção, por tentativas, controlando-se a vazão de entrada de água na bomba, regulou-se para 11,15 golpes/minuto a frequên cia de golpes, correspondendo à taxa de injeção de 372 l/h.

\subsubsection{TEMPO DE FERTIRRIGACÃO E INSTANTES DE COLETA DE AMOSTRAS}

O tempo de fertirrigação utilizado empregando se a bomba injetora foi de 40 minutos com taxa de aplicação 
de 372 l/h, injetando-se 248 litros de solução.

Durante a fertirrigação as amostras de solução fertilizante foram coletadas nos seguintes instantes: I, $2,4,8,16,24,32,40,42$ e 44 minutos.

\subsubsection{MANEJO DO SISTEMA PARA FERTIRRIGACÃO}

Para todas as fertirrigaçōes operou-se inicialmente o sistema com a bomba injetora succionando apenas água, controlándo-se a pressão estabelecida de $4 \mathrm{kgf} / \mathrm{cm}^{2}$ (392,2 $\mathrm{kPa})$.

Usando-se o registro na entrada da bomba, um marcador de golpes instalado na mesma e um cronómetro, regu l.ou-se a frequēncia de golpes.

Em seguida, sem interromper a irrigação, fechou-se o registro de acionamento rápido instalado na saída da bomba e transferiu-se a mangueira de sucção para o reservatório de solução fertilizante.

Abrindo-se o registro da saída da bomba, ini ciou-se a fertirrigação, coletando-se as amostras nos instan tes programados.

Decorridos 40 minutos de injeção de solução à rede de irrigação, voltou-se novamente a mangueira de sucção para um reservatório contendo apenas água.

Para coletar amostras nos dois últimos instan tes e lavagem do sistema, a irrigação foi mantida até 60 mi nutos. 


\subsubsection{PREVISÃO DAS CONCENTRACÕES A SEREM OBTIDAS}

No preparo da solução fertilizante, utilizouse a mesma quantidade de $\mathrm{KCl}$ empregada para a injeção realizada com derivação de fluxo.

Para a aplicação correspondente realizada com derivação de fluxo, com vazão de 372 l/hora e tempo de $40 \mathrm{mi}$. nutos, a quantidade de cloreto contido no tanque foi de $143,6 \mathrm{~g}$ e no final da aplicação restou $1,83 \%$ desta quantidade.

Assim, a quantidade de cloreto injetada foi $0,9817 \times 143,6=140,97 \mathrm{~g}$.

Como o volume de solução injetada é de 248 l, a concentração da solução foi de 568,4 ppm.

Tendo-se essa concentração no reservatório de fertilizante, a previsão da concentraçã̃o na linha de gotejadores foi calculada da seguinte maneira:

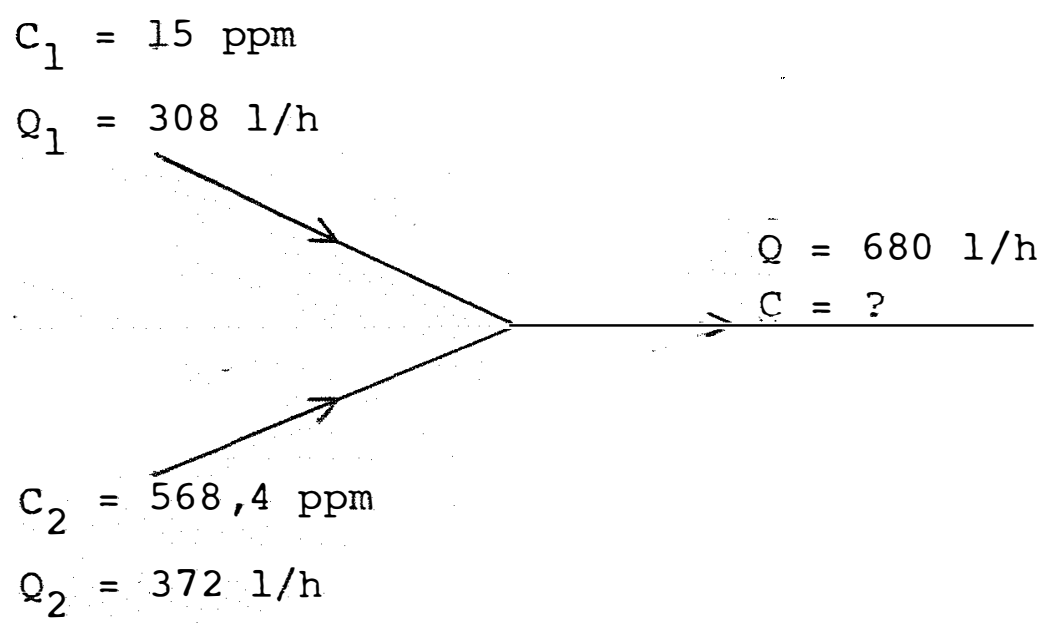

$15 \times 308+568,4 \times 372=680 \mathrm{C}$

$C=317,8 \mathrm{ppm}$ 
onde,

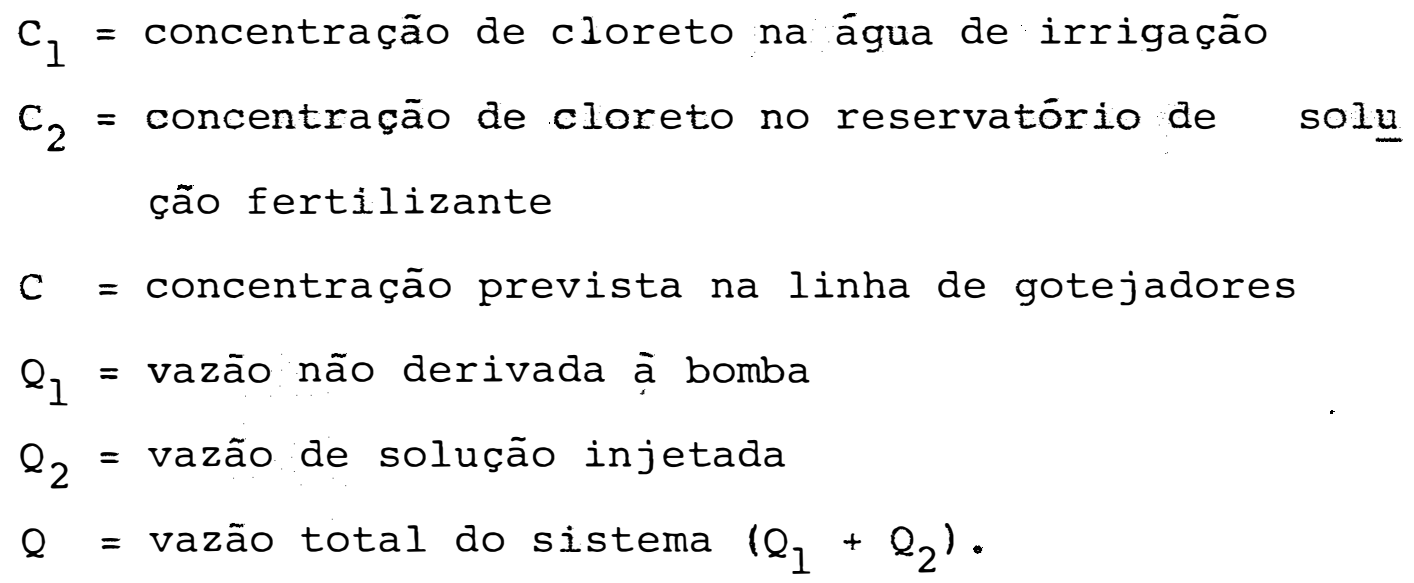

\subsubsection{SOLUCÃO FERTILIZANTE}

Embora se tenha injetado 248 \& de solução, 0 volume de solução preparado para cada injeção foi de 300 \&, possibilitando a sucção da mesma até o final da fertirrigação. O volume não aplicado foi descartado.

\subsection{Coleta e AnÁlise de Amostras}

As amostras de solução de $\mathrm{KCl}$ foram tomadas du rante 20 segundos para cada instante de amostragem, totalizan do aproximadamente $20 \mathrm{ml}$, sendo coletadas em recipientes de vidro com capacidade de $50 \mathrm{ml}$.

Em cada fertirrigação com derivação de fluxo as amostras foram tomadas na saida do tanque e nos 20 pontos ao longo da linha de gotejadores, por 11 pessoas, in dicando-se os dez instantes de amostragem com um cronōmetro. Para as fertirrigações com bomba injetora as amostras foram 
tomadas apenas nos 20 pontos de coleta,

Dor dez pes soas.

As amostras de solução de $\mathrm{KCl}$ foram analisa das no Laboratório de Análises de Águas e Plantas, no Centro de Energia Nuclear na Agricultura (CENA) em Piracicaba.

Uma vez que tanto o potássio como o cloreto são bons elementos indicadores, da fase dispersa da solução e como o resultado obtido para o presente estudo deve ser seme Ihante para ambos, analisou-se apenas o cloreto. Para tal, utilizou-se sistema de injeção em fluxo, seguindo-se recomen daçōes de ZAGATTO et alii (1981).

Esse método baseia-se na reação entre cloreto e tiocianato de mercúrio, com liberação de ions tiocianatos,os quais, em presença de ions férricos, formam o complexo colorido tiocianato férrico, a ser medido.

o preparo da solução reagente consistiu de: $30 \mathrm{~g}$ de nitrato férrico $\left[\mathrm{Fe}\left(\mathrm{NO}_{3}\right)_{3} 9 \mathrm{H}_{2} \mathrm{O}\right], 0,626 \mathrm{~g}$ de tiociana to de mercúrio $\left[\mathrm{Hg}(\mathrm{SCN})_{2}\right]$ e $6 \mathrm{ml}$ de ácido nitrico $\left(\mathrm{HNO}_{3}\right)$ con centrado $(6 \mathrm{~N})$, completando-se o volume a um litro com água destilada.

A montagem do sistema de análises foi realizá da conforme esquema a seguir.

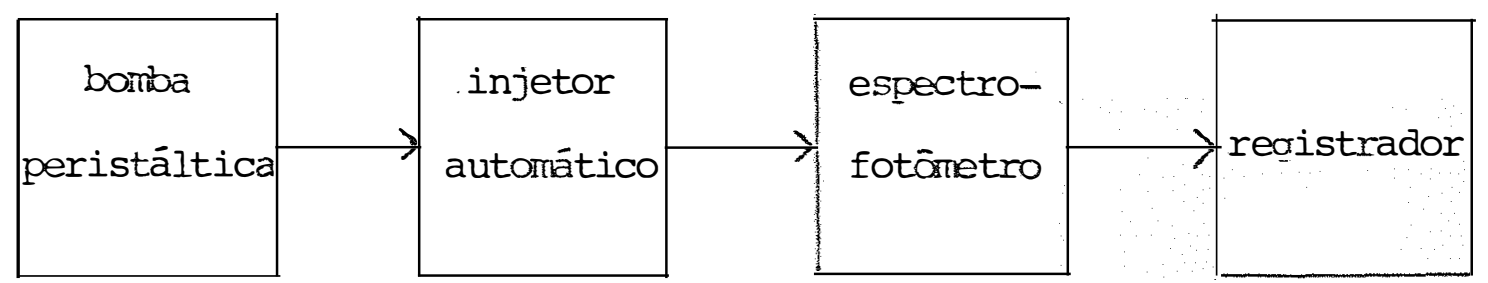


A determinação dos teores de cloreto foi ba seada em padrões de concentração conhecida, preparados com NaCl, com registro de picos em triplicata, conforme ilustrado a seguir, na Figura 10.

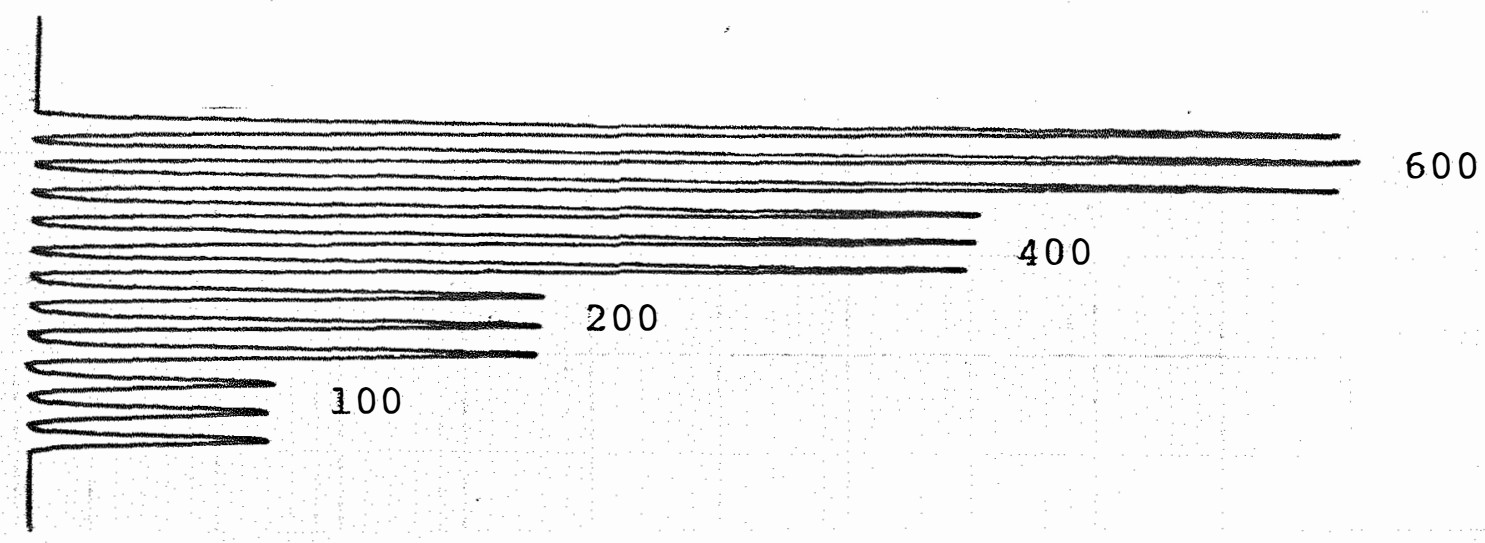

FIGURA 10. Valores registrados para determinação de cloreto em soluções padrões de concentrações de 100, 200, 400 e 600 ppm.

Os picos de análises de amostras foram obtidos em duplicata e a estimativa dos teores médios de cloreto feita por meio de equação de regressão. Para soluções padrão, utilizando computador, obtiveram-se as equações de regressão, como exemplificado a seguir com os dados da Figura 10. 


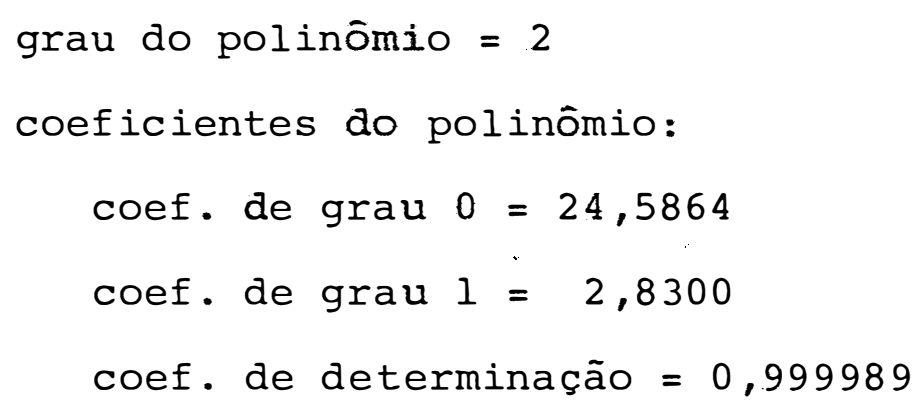

\begin{tabular}{|c|c|c|c|}
\hline \multirow{2}{*}{$\begin{array}{l}\text { Comprimento médio } \\
\text { de picos (mm) }\end{array}$} & \multicolumn{2}{|c|}{ Concentração (ppm) } & \multirow{2}{*}{$\begin{array}{l}\text { Desvio } \\
\text { (ppm) }\end{array}$} \\
\hline & esperada & estimada & \\
\hline 24 & 100 & 99,6 & $-0,4$ \\
\hline 51 & 200 & 200,9 & 0,9 \\
\hline 94 & 400 & 399,2 & $-0,8$ \\
\hline 130 & 600 & 600,3 & 0,3 \\
\hline
\end{tabular}

\subsection{UNIFORMIDADE DE DISTRIBUIÇ̃̃O DO FERTILIZANTE}

Para análise da uniformidade de distribuição do fertilizante aos diversos pontos da linha de gotejadores, as quantidades totais calculadas para os mesmos foram avalia das usando-se o Coeficiente de Uniformidade de Christiansen (C.U.C.), conforme eq. (3) , apresentada no item 2.5.

\subsection{ANÁlises ESTATISTICAS}

Para facilidade de aplicação do fertilizante e coleta de amostras, o sistema de irrigação foi utilizado 
com apenas uma linha de gotejadores.

Deste modo, para efeito de repetições, todas fertirrigações estudadas foram efetuadas três vezes, reali zando-as em dias diferentes.

Uma vez que para cada aplicação as condições foram as mesmas para os diferentes pontos a serem compa rados, o experimento foi analisado em blocos ao acaso e fez-se. comparação de médias pelos testes $F, t$ e Tukev, com o seguinte esquema de análise de variância:

\begin{tabular}{cc} 
causas de variação & graus de liberdade \\
\hline $\begin{array}{c}\text { blocos } \\
\text { tratamentos } \\
\quad(\text { regressões) } \\
\text { residuo }\end{array}$ & 2 \\
total & 38 \\
\hline
\end{tabular}

Foram considerados como tratamentos as distân cias dos pontos de coleta ao início da linha de gotejadores e os blocos corresponderam às repetições.

Como a montagem deste experimento não satis fez inteiramente às condições de casualização e independência de tratamentos, as análises mais apropriadas para o mes mo foram realizadas por meio de regressões. A comparação en tre equações de regressão foi realizada segundo DIXON \& MASSEY JR. (1969) . 


\section{RESULTADOS E DISCUSSÃO}

Para facilitar a exposição, a apresentação ea discussão dos resultados obtidos foram feitas em itens distin tos.

\subsection{PRESSÃO NA LinHA DE GOTEJADORES}

Na Figura 11 estão apresentados os valores de pressão medidos na linha de gotejadores.

Com estes valores traçou-se a curva de perda de carga (H), ocorrida ao longo da linha.

Observando-se esta figura, verifica-se que, do início da linha até a posição de pressão de serviço, a per da de carga ocorrida foi de $0,75 . \mathrm{H}$ e deste ponto até o final da linha foi de $0,25 . H$.

Esses valores são semelhantes aos ci tados por KELLER - \& KARMELI (1975) que indicam $0,77 . \mathrm{He} 0,23 . \mathrm{H}$ para os respectivos trechos.

Pode-se observar também que tal como indicado por estes autores, estabeleceu-se perda de carga total igual a $11,76 \mathrm{kPa}$, correspondendo a $12 \%$ da pressão de serviço $(98,06$ $\mathrm{kPa}$. Por outro lado, a pressão de serviço preestabelecida 
54.

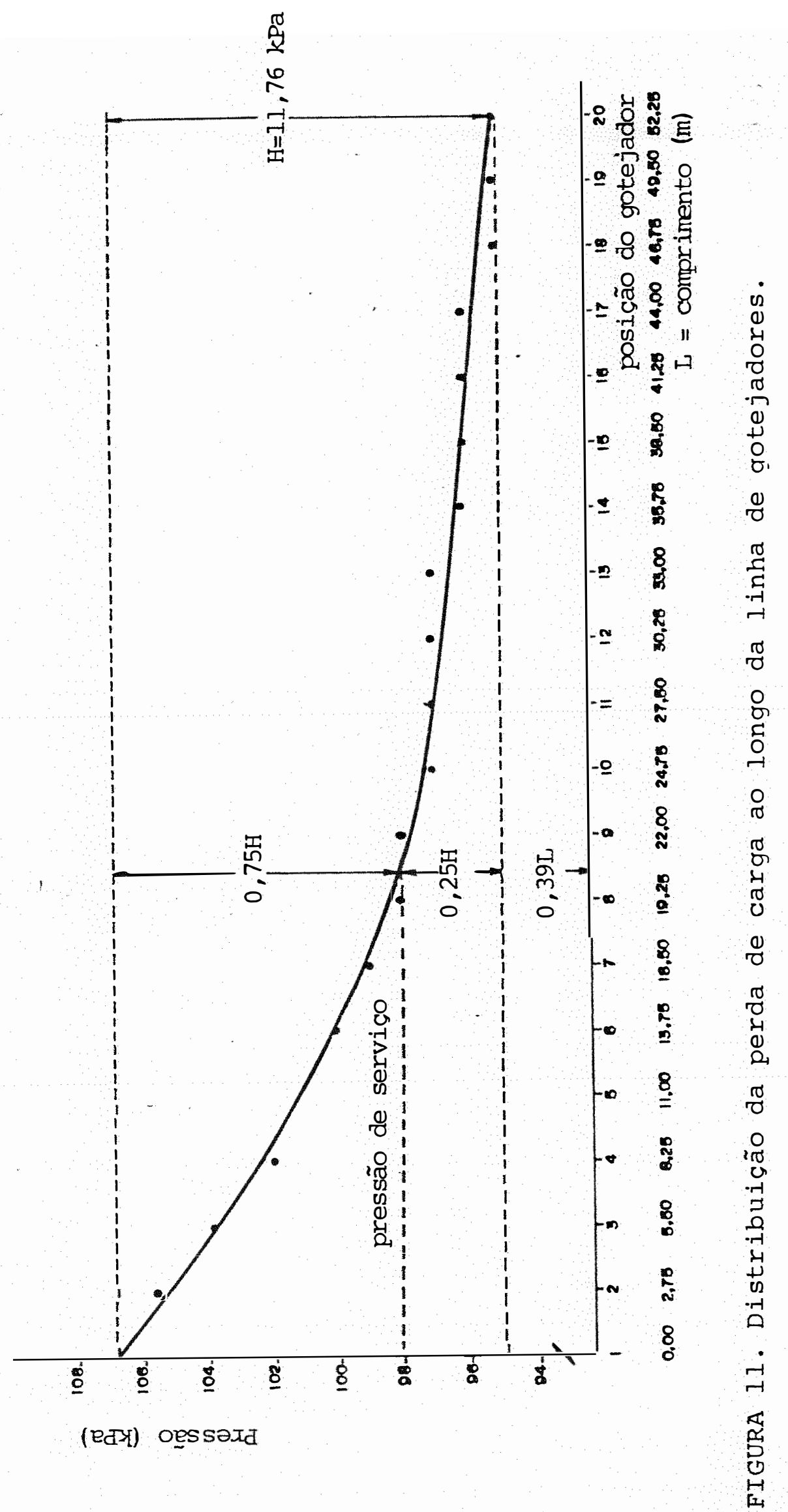


ocorreu em posição correspondente a 398 do comprimento total da linha, concordando plenamente com KELLER \& KARMELI (1975) que citam essa mesma posição.

\subsection{VAZÃO NA LINHA DE GOTEJADORES}

Os valores de vazão medidos nos pontos de amos tragem da linha de gotejadores, bem como curva e equação de regressão obtidas, estão apresentados na Figura 12 .

Verificando-se esta figura, observa-se que a equação de regressão tem modelo exponencial. Esta equação foi adotada por ter apresentado o maior coeficiente de deter minação $\left(r^{2}\right)$, quando comparado com coeficientes de outros mo delos testados. Porém, este modelo se aproximou bastante do linear.

Com a equação obtida, estimaram-se as vazões para os diversos pontos de amostragem, utilizando-as posteriormente para determinação de volumes de solução aplicados. durante as fertirrigações.

4.3. INJEÇ̃̃o POR DERIVACÃo DE FluXo

4.3.1. DifERENÇA DE PRESSÃO E VAZÃO DERIVADA

Conforme descrito em 3.2.1., na Figura 13 es tão apresentados os valores de diferença de pressão e vazões derivadas, bem como curva e equação de regressão obtidas a partir destes valores. 


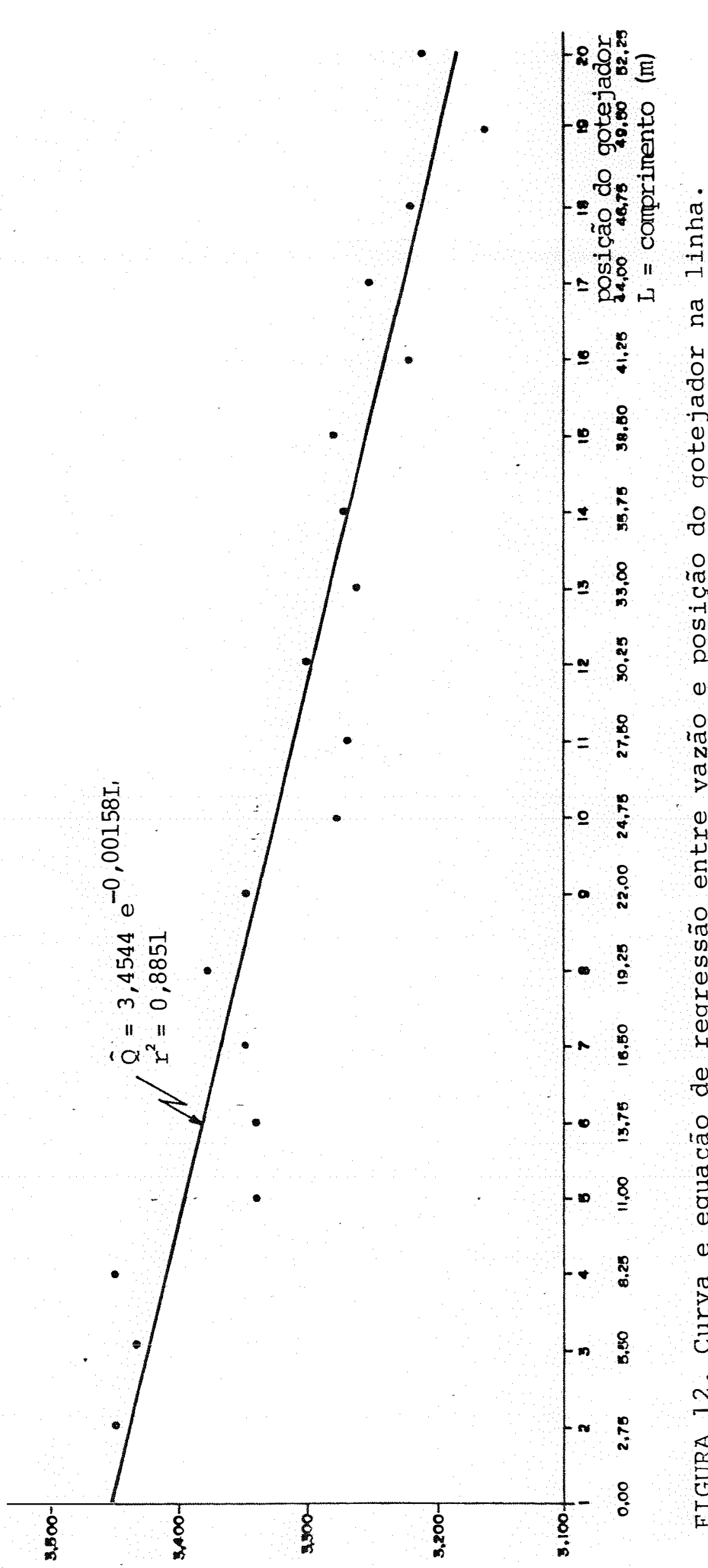

56.

(U/T) ogzen $=0$ 
57.

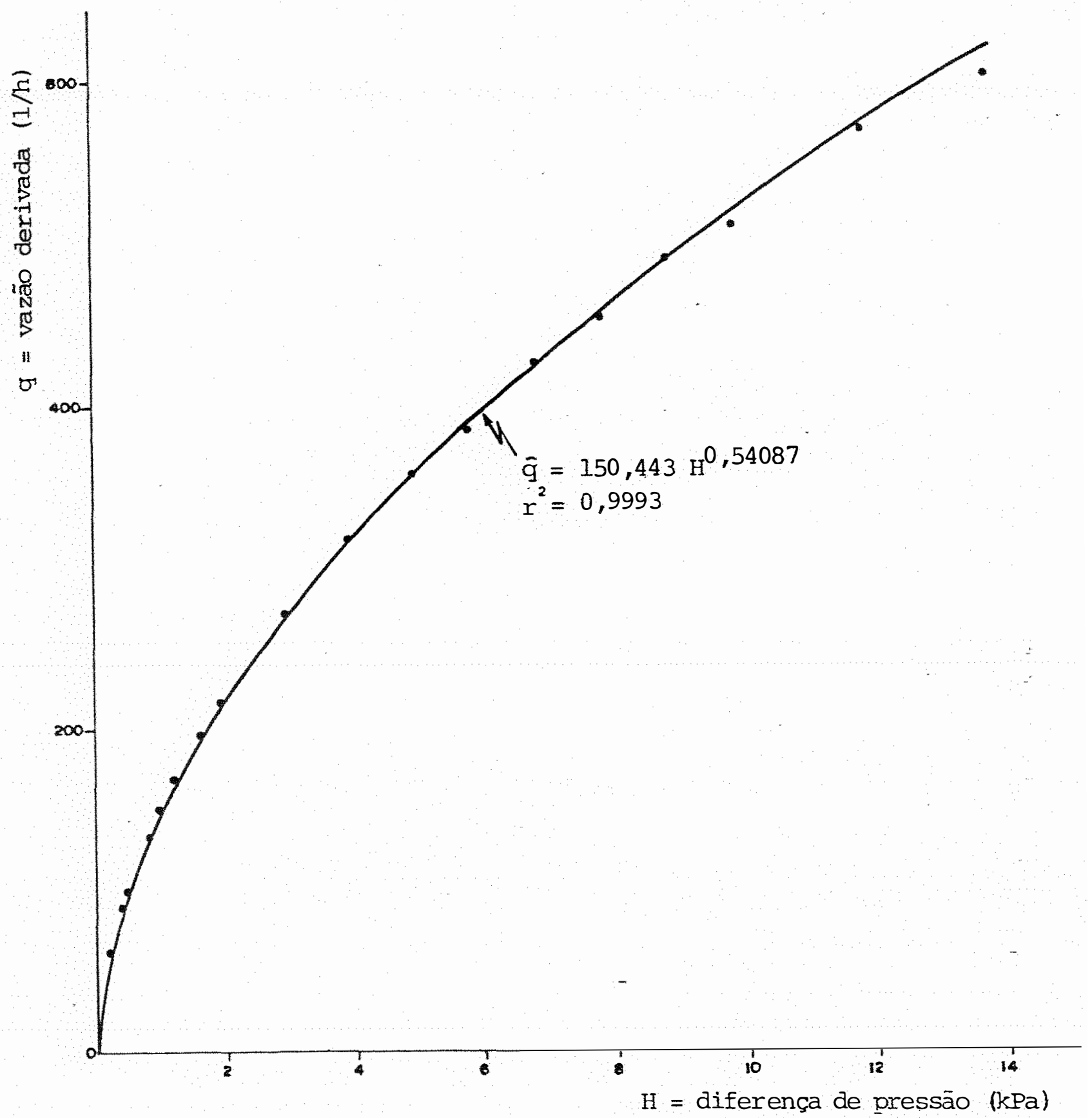

FIGURA 13. Curva e equação de regressão entre diferença de pressão e vazão derivada. 
58.

Analisando-se a equação ajustada, verifica-se que o coeficiente de determinação é 0,9993, indicando que os valores estimados representam bem os valores reais.

Por outro lado, a equação obtida assemelha-se ao modelo $\mathrm{q}=\mathrm{K} \cdot \mathrm{H}^{0,5}$, sendo que $\mathrm{K}$ deve assumir valores diferentes para cada instalação do sistema de fertirrigação. Esse modelo representa a equação de vazão em orifícios obtida a partir do Teorema de Torricelli, indicando que a vazão é proporcional à raiz quadrada da pressão.

A equação de regressão $\left(\bar{q}=150,443 \mathrm{H}^{0,54087}\right)$ foi comparada ao modelo $\mathrm{q}=\mathrm{KH}^{0}, 5$, confrontando-se seus ex poentes pelo teste $t$. Esse teste indicou que os expoentes não diferem estatisticamente entre si,.. ao nível de 5\% de pro babilidade.

\subsubsection{TEORES DE CLORETO}

Os teores de cloreto obtidos nas amostras co letadas na saída do tanque e nos 20 pontos da linha de gote jadores, para os instantes estabelecidos, estão apresentados nas Tabelas 2 a 4 . 
TABELA 2 - Teor médio de cloreto (ppm), obtido com vazão de derivação de $372 \mathrm{I} / \mathrm{h}$ e tempo de fertirrigação de 40 minutos.

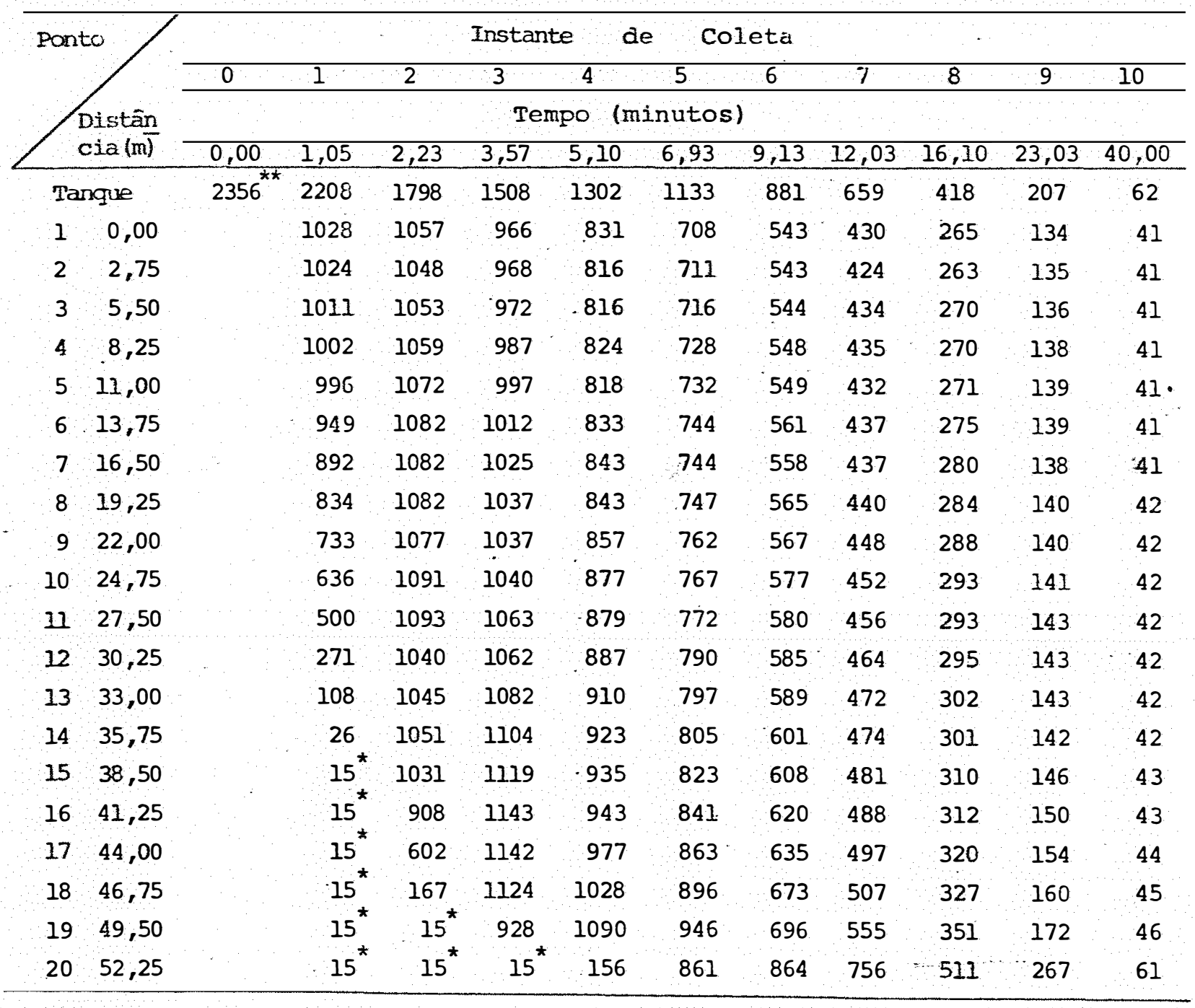

* teor natural da água

** teor inicial no tanque 
60.

TABELA 3 - Teor médio de cloreto (ppm), obtido com vazão de derivação de $186 \mathrm{l} / \mathrm{h}$ e tempo de fertirrigaçāo de 80 minutos.

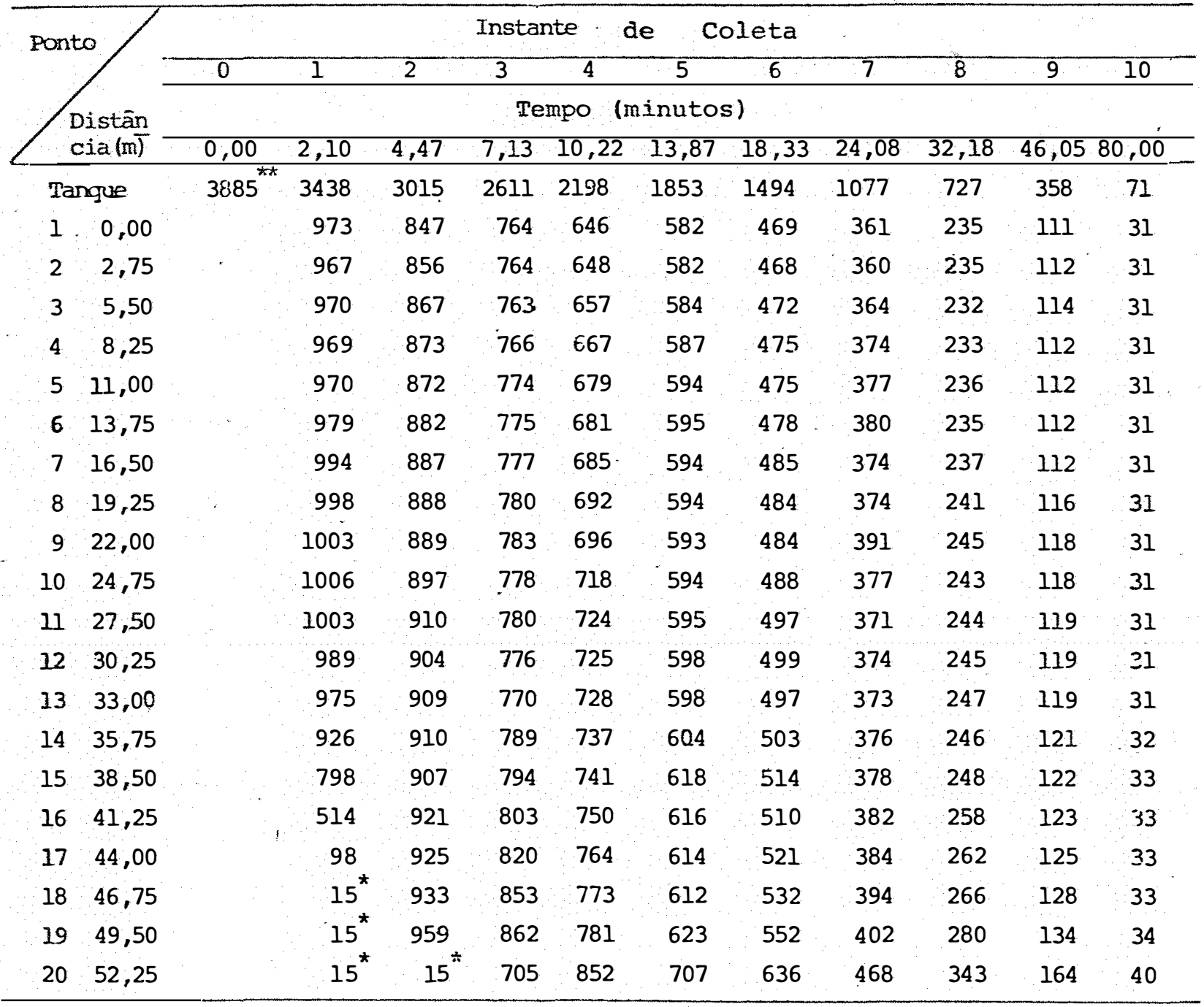

* teor natural da água

** teor inicial no tanque 
61.

TABELA 4 - Teor médio de cloreto (ppm), obtido com vazão de derivação de $93 \mathrm{l} / \mathrm{h}$ e tempo de fertirrigação de 160 minutos.

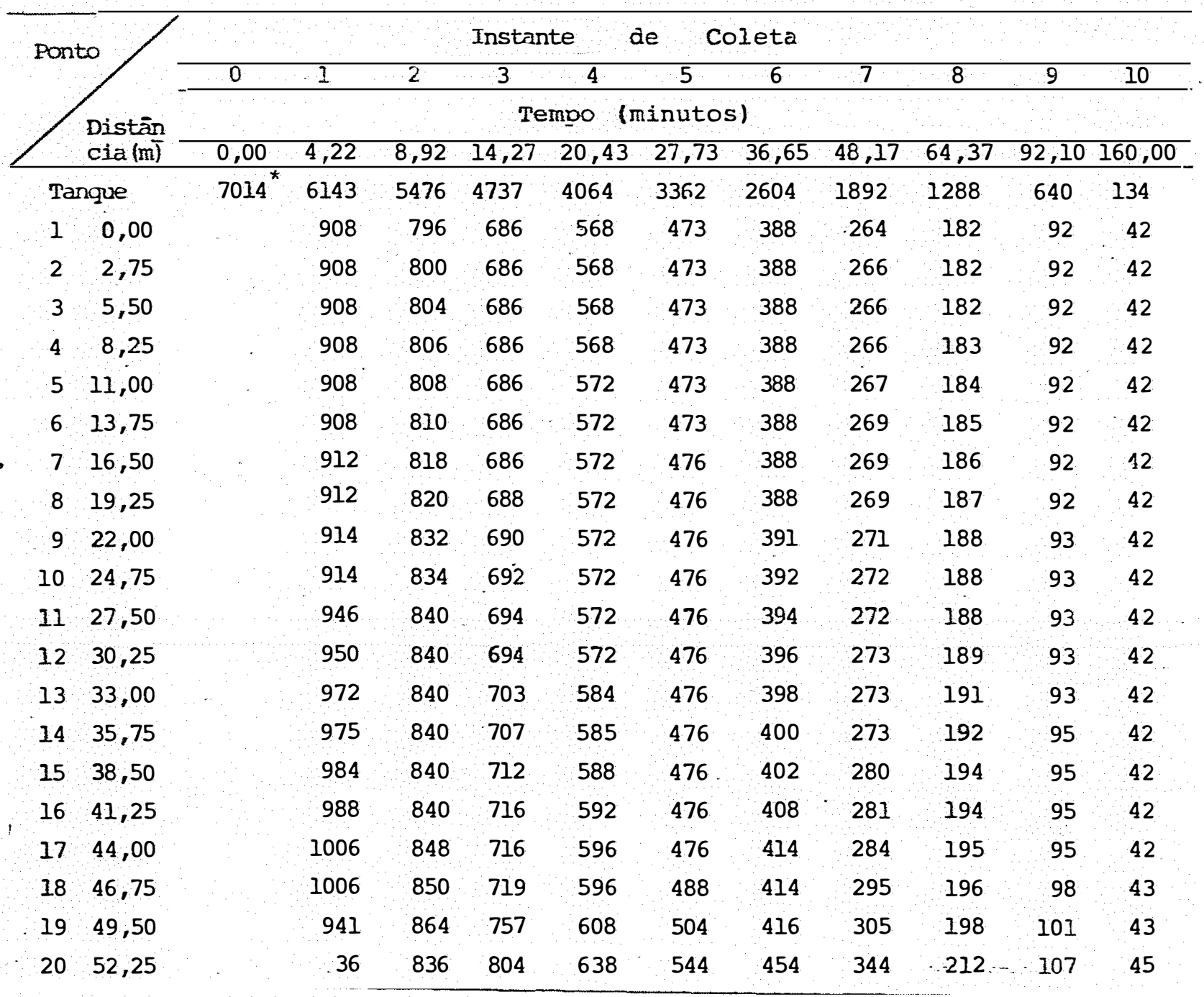

* teor inicial no tanque 


\subsubsection{TEOREs no TANQUe de Fertilizante}

Com os teores de cloreto obtidos de amostras coletadas na saida do tanque (Tabelas 2 a 4), foram calculadas as concentrações relativas nos diversos instantes de cole ta, para os tempos de fertirrigação de 40,80 e 160 minutos. Esses valores de concentração relativa e equações de regres são estão apresentados na Tabela 5 .

Com os dados apresentados na Tabela 5 , usando se as médias dos tempos de fertirrigação, construiu-se a Fi gura 14 .

Analisando-se os dados e equações de regressão obtidos, apresentados na Tabela 5 e Figura 14, verifica-se que os valores de concentração relativa reduziram com o au mento do volume derivado (V), porém, estas reduções foram ca da vez menores com o transcorrer do tempo, apresentando com portamento exponencial.

Pode-se descrever matematicamente este proces so por meio de uma equação diferencial.

Seja:

$$
\begin{aligned}
& y(t)= \text { concentração relativa no instan } \\
& \text { te } t \\
& \frac{d y}{d t}= \text { taxa de variação da concentra } \\
& \quad \text { ção relativa em relação ao tempo, } \\
& \text { sendo que } \frac{d y}{d t} \text { é proporcional a } y
\end{aligned}
$$


TABELA 5 - Concentrações relativas médias de cloreto para diversos valores de $V$ (volume que oassou pelo tan que) /v (volume do tanque).

\begin{tabular}{|c|c|c|c|c|}
\hline \multirow{3}{*}{$\left(\frac{V}{V}\right)$} & \multicolumn{4}{|c|}{$y=$ concentração relativa $(q)$} \\
\hline & \multicolumn{3}{|c|}{ tempo de fertirrigação } & \multirow{2}{*}{ média $\underline{d}$} \\
\hline & $40 \mathrm{~min}$ a 7 & $80 \min \underline{b}$ & $160 \mathrm{~min}$ & \\
\hline 0,000 & 100,0 & 100,0 & 100,0 & 100,0 \\
\hline 0,105 & 93,7 & 88,5 & 87,6 & 89,9 \\
\hline 0,223 & 76,3 & 77,6 & 78,1 & 77,3 \\
\hline 0,357 & 64,0 & 67,2 & 67,5 & 66,2 \\
\hline 0,511 & 55,3 & 56,6 & 57,9 & 56,6 \\
\hline 0,693 & 48,1 & 47,7 & 47,9 & 47,9 \\
\hline 0,916 & 37,4 & 38,4 & 37,1 & 37,6 \\
\hline 1,204 & 28,0 & 27,7 & 27,0 & 27,6 \\
\hline 1,609 & 17,7 & 18,7 & 18,4 & 18,3 \\
\hline 2,302 & 8,8 & 9,2 & 9,1 & 9,0 \\
\hline 4,000 & 2,6 & 1,8 & 1,9 & 2,1 \\
\hline \multicolumn{5}{|c|}{ 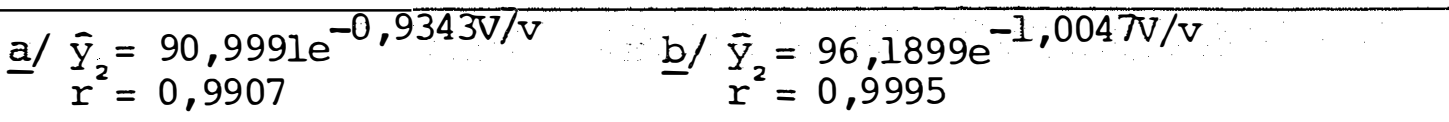 } \\
\hline \multicolumn{2}{|c|}{$\begin{array}{l}\text { c/ } \bar{y}=95,2271 e^{-0,9959 V / v} \\
r^{2}=0,9987\end{array}$} & d) $\begin{array}{l}\bar{y}_{2}=9 \\
r^{2}=0\end{array}$ & $15 e^{-0,9757 v / 2}$ & \\
\hline
\end{tabular}


64.

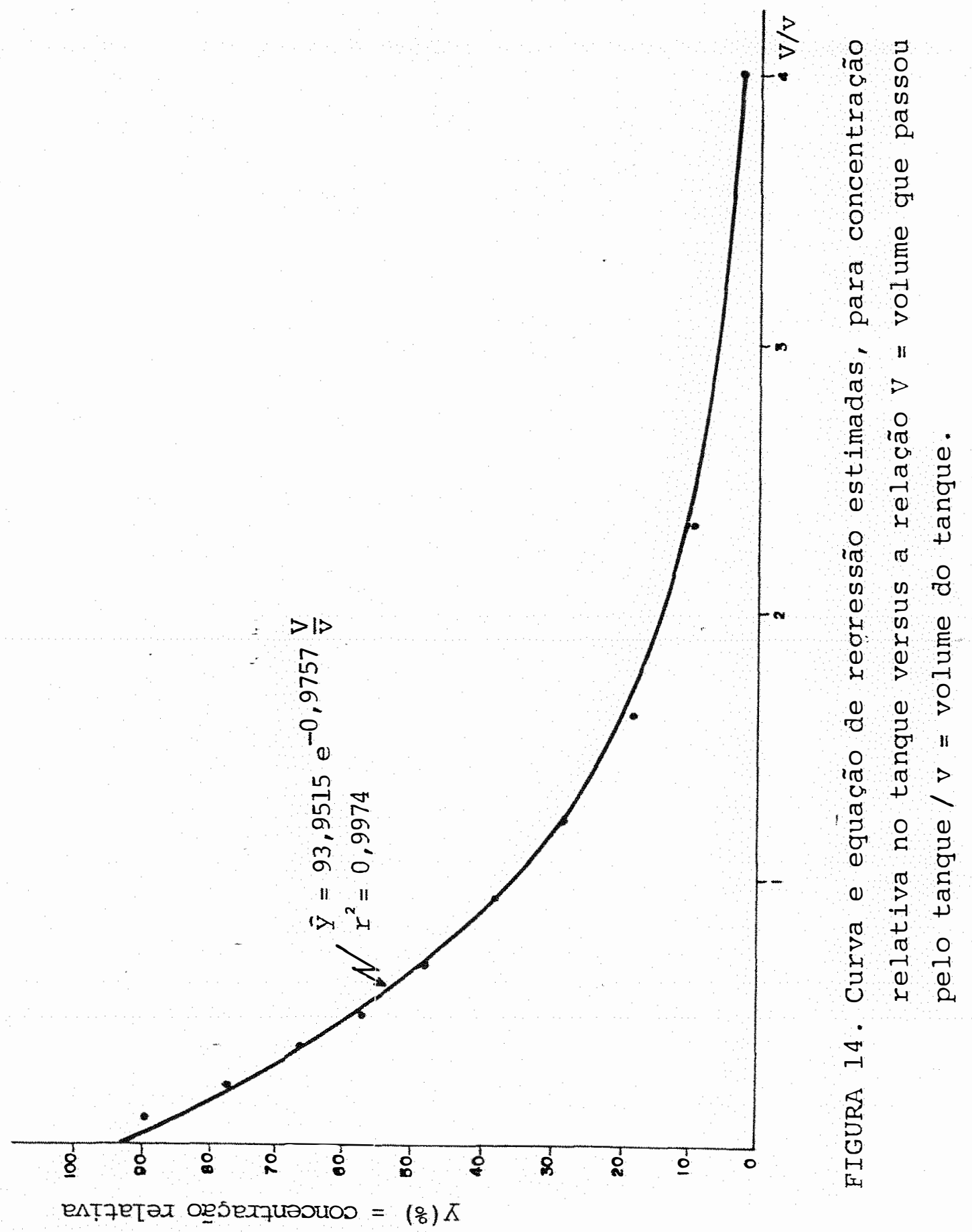


65.

Então:

$$
\frac{d y}{d t}=-k y
$$

onde:

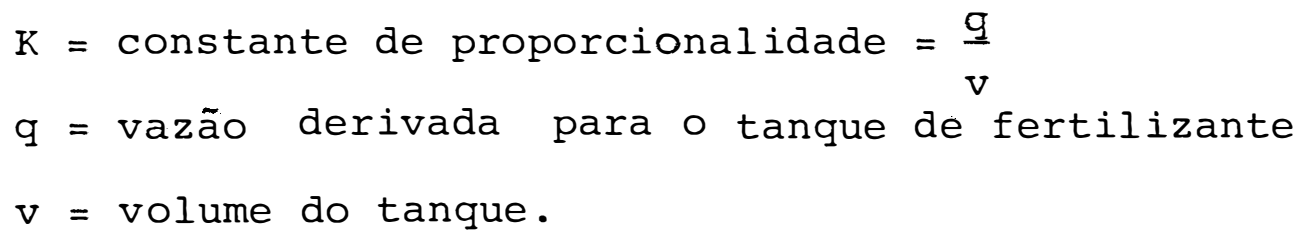

A eq. (4) trata-se de uma equação diferen cial ordināria de primeira ordem.

Se essa equação possui uma solução $y(t)$, sua derivada deve ser proporcional a y. Isso também é válido para as funções exponenciais.

De maneira geral, a função $e^{-K t}$ pode ser es crita como:

$$
y(t)=C \cdot e^{-K t}
$$

onde C é uma constante genérica.

Essa equação é uma solução geral da eq. (4) . Considerando-se a concentração inicial presen te no tanque igual a 100 , tern-se que definir $C$, de modo que pa ra $t=0, y=100$.

Assim, $y(0)=c \cdot e^{-K \cdot 0}=100$, ou $c=100$. 
Empregando-se esse valor de $\mathrm{C}$, a eq. (5) se transforma em $y(t)=100 \cdot e^{-K t}$.

$$
\begin{aligned}
\text { Sendo } k=\frac{q}{v}, \\
y(t)=100 \cdot e^{-q / v \cdot t} \\
\text { Como } q \cdot t=v(\text { volume derivado), tem-se: } \\
y(t)=100 \cdot \mathrm{e}^{-v / v}
\end{aligned}
$$

As médias de concentrações relatịvas dos três tempos de fertirrigação, apresentadas na Tabela 5 , foram sub metidas à análise de regressão na forma $\bar{y}=\bar{a} \cdot e^{\mathrm{bx}}$.

Essa equação foi linearizada aplicando-se lo garítimo, assumindo a forma $\ell n \bar{y}=\ell n a ̂+b x$, que pode ser rees crita como $y=a+b x$, onde $x=\frac{v}{v}$.

A análise de regressão dos valores observados apresentou os seguintes resultados:

$$
\begin{aligned}
& \text { coeficiente de determinação }\left(x^{2}\right)=0,998 \\
& \text { coeficiente angular (b) }=-0,976 \\
& \text { coeficiente linear (a) }=4,543 \\
& \text { variāncia total }=1,231 \\
& \text { variāncia explicada }=1,228 \\
& \text { variāncia inexplicada }=0,003 \\
& \text { equação de regressão }: \hat{y}=93,9515 \mathrm{e}^{-0,976 \frac{\mathrm{V}}{\mathrm{V}}}
\end{aligned}
$$


Essa equação de regressão foi comparada estatisticamente com a eq. 6 , com o teste $t$, confrontando-se os coeficientes angulares e lineares. Não se verificaram diferenças significativas entre os parāmetros testados, ao nível de $5 \%$ de probabilidade, indicando que a equação de regressão obtida não diferiu estatisticamente da equação teórica $\left(y=100 \cdot e^{-v / v}\right)$.

\subsubsection{TEORES NA LINHA DË GOTEJADORES \\ O avanço da solução fertilizante na tubulação} ocorre por difusão e transporte de massa; a difusão depende do gradiente de concentração e o transporte de massa se dá devido ao fluxo.

Analisando-se a Tabela 2, verifica-se que para taxa de injeção de $372 \mathrm{l} / \mathrm{h}$, até os primeiros instantes de coleta a solução injetada avançou ao longo da linha, porém, ainda não havia atingido o final da mesma. O alcance do final da linha ocorreu entre os momentos 3 e 4 , isto é, entre 3,57 e 5,10 minutos.

Por outro lado, pode-se verificar principalmente a partir de 9,13 minutos que, com o transcorrer da fer tirrigação, os maiores teores de cloreto foram obtidos nos úl timos pontos de amostragem. Isso indica um acúmulo do ferti lizante no final da linha devido à extremidade da mesma, após o último gotejador, ter sido mantida fechada.

Com taxa de injeção de 186 l/h (Tabela 3), a solução fertilizante atingiu o último gotejador logo após o 
68.

instante 2 (4,47 minutos); de 10,22 minutos até o final da fertirrigação, nota-se também o acúmulo do fertilizante na extremidade final da linha.

Para a taxa de injeção de 93 l/h (Tabela 4), pode-se notar que a solução fertilizante atingiu o final da Iinha próximo de 4,22 minutos. Evidenciaram-se também maiores teores de cloreto no final da linha, a partir de 14,27 minutos, revelando acúmulo.

Comparando-se as três taxas de injeção, anali sando-se conjuntamente as Tabelas 2, 3 e 4, verifica-se que para os três casos o tempo decorrido do início da aplicação do fertilizante até chegar na extremidade da linha foi prati camente o mesmo, ou seja, em torno de cinco minutos.

Esse comportamento indica que a velocidade de caminhamento da șolução injetada independeu da taxa de aplicação (vazão derivada ao tanque). Uma vez que para cada tạ xa de aplicação utilizou-se determinada concentração de clo reto, pode-se deduzir que as diferenças de concentração não evidenciaram variações no processo de difusão.

Ainda comparando-se as três vazões de derivação, para todas elas, após a solução fertilizante ter atingi do toda a extensão da linha, os últimos pontos mantiveram-se com maiores teores de cloreto, revelando acúmulo na extremidade final da linha de gotejadores. 


\subsubsection{Quantidade APLiCADA DE CLORETO}

Com os dados de concentração de cloreto, apre sentados nas Tabelas 2, 3 e 4, considerando-se os intervalos de tempo entre os consecutivos instantes de coleta, calcularam se as quantidades aplicadas de cloreto, da seguinte maneira:

$$
\text { Quantidade de cloreto }(g)=\frac{q \cdot t \cdot c}{1000}
$$

onde,

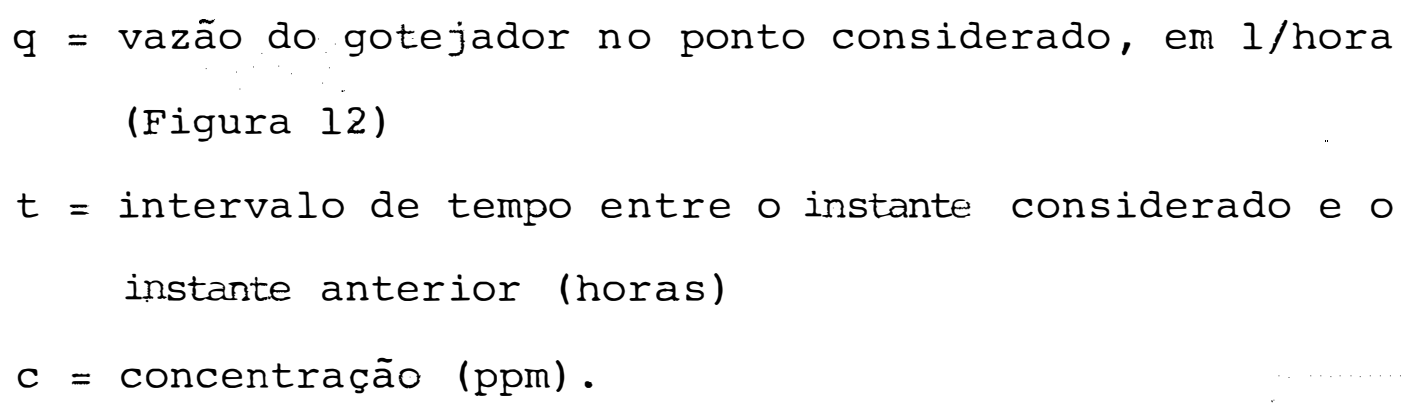

As quantidades aplicadas, resumidas como mé dias de trēs repetições, estão apresentadas a seguir nas Tabe las 6,7 e 8, para as vazões de derivação de 372,186 e 93 l/hora, respectivamente.

Como se pode verificar nestas c tabelas,
efetuou-se o somatório das quantidades cada in
tervalo de tempo, tendo-se os totais resultantes de todo pe
ríodo de fertirrigação para os diversos pontos de coleta.
Esses totais de cloreto foram analisados está
tisticamente através dos testes $F$ e Tukey, bem como submeti
dos a análises de regressão.


70.

TABELA 6 - Quantidade média aplicada de cloreto (g), entreos instantes de coleta, para vazão de derivação de $3721 / \mathrm{h}$ e tempo de fertirrigação de 40 minutos.

\begin{tabular}{|c|c|c|c|c|c|c|c|c|c|c|c|c|}
\hline \multirow{4}{*}{\multicolumn{2}{|c|}{$\begin{array}{l}\text { ponto } \\
\text { ciatan (m) }\end{array}$}} & \multicolumn{10}{|c|}{ Instante de coleta de amostras (minutos) } & \multirow{4}{*}{ Total } \\
\hline & & &, 05 &, 23 & 3,57 & $; 10$ &, 93 & .13 & $12,03 \quad 1$ & $16,10 \quad 2$ & $23,03 \quad 40,00$ & \\
\hline & & \multicolumn{10}{|c|}{ Intervalo entre os instantes (horas) } & \\
\hline & & 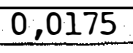 & 7 & 0,0223 & & 0,0305 & 0,0367 & 0,0483 & 3. 0,0678 & 80,1155 & 50,2628 & \\
\hline 1 & 0,00 & 0,062 & 0,072 & 0,074 & 0,073 & 0,074 & 0,069 & 0,072 & 0,062 & 0,053 & 0,040 & 0,651 \\
\hline 2 & 2,75 & 0,062 & 0,071 & 0,074 & 0,072 & 0,074 & 0,068 & 0,070 & 0,061 & 0,054 & 0,040 & 0,646 \\
\hline 3 & 5,50 & 0,060 & 0,071 & 0,074 & 0,071 & 0,075 & 0,068 & 0,072 & 0,063 & 0,054 & 0,040 & 0,648 \\
\hline 4 & 8,25 & 0,060 & 0,071 & 0,075 & 0,072 & 0,076 & 0,068 & 0,072 & 0,062 & 0,054 & 0,040 & 0,650 \\
\hline 5 & 11,00 & 0,059 & 0,072 & 0,075 & 0,071 & 0,076 & 0,068 & 0,071 & 0,061 & 0,054 & 0,040 & 0,647 \\
\hline 6 & 13,75 & 0,056 & 0,072 & 0,076 & 0,072 & 0,077 & 0,070 & 0,071 & 0,063 & 0,054 & 0,039 & 0,650 \\
\hline 7 & 16,50 & 0,052 & 0,072 & 0,077 & 0,072 & 0,076 & 0,069 & 0,071 & 0,064 & 0,054 & 0,039 & 0,646 \\
\hline 8 & 19,25 & 0,049 & 0,071 & 0,077 & 0,072 & 0,076 & 0,069 & 0,071 & 0,064 & 0,054 & 0,040 & $0, t, 43$ \\
\hline 9 & 22,00 & 0,043 & 0,071 & 0,077 & 0,073 & 0,078 & 0,069 & 0,072 & 0,065 & 0,054 & 0,039 & 0,641 \\
\hline 10 & 24,75 & 0,037 & 0,071 & 0,077 & 0,074 & 0,078 & 0,070 & 0,072 & 0,066 & 0,054 & 0,039 & 0,638 \\
\hline 31 & 27,50 & 0,029 & 0,071 & 0,078 & 0,074 & 0,078 & 0,070 & 0,073 & 0,066 & 0,055 & 0,039 & .633 \\
\hline 12 & 30,25 & 0,016 & 0,067 & 0,078 & 0,074 & 0,079 & 0,071 & 0,074 & 0,066 & 0,054 & 0,039 & 0,618 \\
\hline 13 & 33,00 & 0,006 & 0,067 & 0,079 & 0,076 & 0,080 & 0,071 & 0,075 & 0,067 & 0,054 & 0,039 & 0,614 \\
\hline 14 & 35,75 & 0,002 & 0,067 & 0,080 & 0,077 & 0,080 & 0,072 & 0,075 & 0,066 & 0,054 & 0,039 & 0,612 \\
\hline 15 & 38,50 & 0,001 & 0,066 & 0,081 & 0,077 & 0,082 & 0,072 & 0,076 & 0,068 & 0,055 & 0,039 &, 617 \\
\hline 16 & 41,25 & 0,001 & 0,058 & 0,082 & 0,078 & 0,083 & 0,074 & 0,076 & 0,068 & 0,056 & 0,039 & 0,615 \\
\hline 17 & 44,00 & 0,001 & 0,038 & 0,082 & 0,080 & 0,085 & 0,075 & 0,077 & 0,070 & 0,058 & 0,040 & 0,606 \\
\hline 18 & 46,75 & 0,001 & 0,010 & 0,080 & 0,084 & 0,088 & 0,079 & 0,079 & 0,071 & 0,059 & 0,041 & 0,592 \\
\hline 19 & 49,50 & 0,001 & 0,001 & 0,066 & 0,089 & 0,092 & 0,082 & 0,086 & 0,076 & 0,064 & 0,042 & 0,599 \\
\hline 20 & 52,25 & 0,001 & 0,001 & 0,001 & 0,013 & 0,084 & 0,101 & 0,116 & 0,110 & 0,098 & 0,055 & 0,580 \\
\hline
\end{tabular}


TABELA 7 - Quantidade média aplicada de cloreto (g), entre os instantes de coleta, para vazão de derivaçāo de $186 \mathrm{l} / \mathrm{h}$ e tempo de fertirrigação de 80 minutos.

\begin{tabular}{|c|c|c|c|c|c|c|c|c|c|c|c|c|}
\hline \multirow{4}{*}{\multicolumn{2}{|c|}{$\begin{array}{l}\text { Ponto } \\
\text { ciatan (m) }\end{array}$}} & \multicolumn{10}{|c|}{ Instante de coleta de amostras (minutos) } & \multirow{4}{*}{ Total } \\
\hline & & &, 10 &, 47 & 13 & $0,22 \quad 13$ & $3,87 \quad 18$ & $18,33 \quad 24$ & $4,08 \quad 32$ & $2,18 \quad 4 t$ & $6,05 \quad 80,00$ & \\
\hline & & \multicolumn{10}{|c|}{ Intervalo entre os instantes (horas) } & \\
\hline & &, 0350 & & 0,0443 & 0,0515 & 0,0608 & 0,0743 & 30,0958 & 0,1350 & 0,2312 & 0,5658 & \\
\hline 1 & 0,00 & 0,118 & 0,116 & 0,117 & 0,115 & 0,122 & 0,120 & 0,120 & 0,110 & 0,088 & 0,061 & 1,087 \\
\hline 2 & 2,75 & 0,116 & 0,116 & 0,116 & 0,115 & 0,122 & 0,120 & 0,119 & 0,109 & 0,089 & 0,060 & 1,082 \\
\hline 3 & 5,50 & 0,116 & 0,117 & 0,116 & 0,116 & 0,122 & 0,120 & 0,119 & 0,107 & 0,090 & 0,060 & 1,083 \\
\hline 4 & 8,25 & 0,116 & 0,118 & 0,116 & 0,117 & $0,122^{2}$ & 0,120 & 0,122 & 0,106 & 0,088 & 0,060 & 1,085 \\
\hline .5 & 11,00 & 0,115 & 0,117 & 0,116 & 0,119 & 0,122 & 0,120 & 0,123 & 0,108 & 0,088 & 0,060 & 1,088 \\
\hline 6 & 13,75 & 16 & 0,118 & 0,116 & 0,118 & 0,122 & 0,120 & 0,123 & 0,108 & 0,088 & 0,059 & 088 \\
\hline 7 & 16,50 & 0,117 & 0,118 & 0,116 & 0,119 & 0,121 & 0,121 & 0,120 & 0,108 & 0,087 & 0,060 & 1,087 \\
\hline 8 & 19,25 & 0,117 & 0,118 & 0,116 & 0,120 & 0,121 & 0,120 & 0,120 & 0,109 & 0,090 & 0,059 & 1,039 \\
\hline 9 & 22,00 & 0 , & 0,117 & 16 & 0 & 0 & 20 & 21 & 0,110 & 0,091 & 0,059 & 1,091 \\
\hline 10 & 24,75 & 0,117 & 0,118 & 0,114 & 0,123 & 0,120 & 0,120 & 0,120 & 0,109 & 0,090 & 0,059 & 1,090 \\
\hline 11 & 27,50 & 0,116 & 0,119 & 0,114 & 0,123 & 0,120 & 0,122 & 0,118 & 0,109 & 0,091 & 0,059 & 1,091 \\
\hline 12 & 30,25 & 0,114 & 0,118 & 0,113 & 0,123 & 0,120 & 0,122 & 0,118 & 0,109 & 0,090 & 0,058 & 1,085 \\
\hline 13 & 33,00 & 0,112 & 0,118 & 0,112 & 0,123 & 0,119 & 0,121 & 0,117 & 0,109 & 0,090 & 0,058 & 1,079 \\
\hline 14 & 35,75 & 0,106 & 0,117 & 0,114 & 0,124 & 0,120 & 0,122 & 0,118 & 0,108 & 0,092 & 0,059 & 1,080 \\
\hline 15 & 38,50 & 0,091 & 0,116 & 0,114 & 0,124 & 0,122 & 0,124 & 0,118 & 0,109 & 0,092 & 0,061 & 1,071 \\
\hline 16 & 41,25 & 0,058 & 0,118 & 0,115 & 0,125 & 0,121 & 0,122 & 0,118 & 0,113 & 0,092 & 0,060 & 1,042 \\
\hline 17 & 44,00 & 0,011 & 0,118 & 0,117 & 0,127 & 0,120 & 0,125 & 0,118 & 0,114 & 0,093 & 0,060 & 1,003 \\
\hline 18 & 46,75 & 0,002 & 0,118 & 0,121 & 0,128 & 0,119 & 0,127 & 0,121 & 0,115 & 0,095 & 0,060 & 1,006 \\
\hline 19 & 49,50 & 0,002 & 0,121 & 0,122 & 0,128 & 0,121 & 0,131 & 0,123 & 0,121 & 0,099 & 0,061 & 1,029 \\
\hline 20 & 52,25 & 0,002 & 0,002 & 0,099 & 0,140 & 0,137 & 0,150 & 0,143 & 0,147 & 0,121 & 0,071 & 1,012 \\
\hline
\end{tabular}


TABELA 8 - Quantidade média aplicada de cloreto $(g)$, entre os instantes de coleta, para vazão de derivação de $93 \mathrm{l} / \mathrm{h}$ e tempo de fertirrigação de 160 minutos.

\begin{tabular}{|c|c|c|c|c|c|c|c|c|c|c|c|c|}
\hline \multirow{4}{*}{\multicolumn{2}{|c|}{$\begin{array}{l}\text { Ponto } \\
\text { Distañ } \\
\text { cia (m) }\end{array}$}} & \multicolumn{11}{|c|}{ Instante de coleta de amostras (minutos) } \\
\hline & & \multirow{2}{*}{\multicolumn{2}{|c|}{4,22}} & \multirow[t]{2}{*}{3,92} & 14,27 & 20,432 & $27,73 \quad 36$ & \multicolumn{2}{|c|}{$36,65 \quad 48,17$} & \multicolumn{2}{|c|}{$64,37 \quad 92,10 \quad 160,00$} & \multirow{3}{*}{ Iotal } \\
\hline & & & & & \multicolumn{7}{|c|}{ Intervalo entre os instantes (horas) } & \\
\hline & & 0,0703 & 0,0783 & 0,0892 & 0,10 & 0,1217 & 70,1487 & 0,1920 & 00,2700 & 00,4622 & 1,1317 & \\
\hline 1 & 0,00 & 0,220 & 0,215 & 0,211 & 0,202 & 0,199 & 0,199 & $v, 175$ & 0,170 & 0,148 & 0,164 & 1,903 \\
\hline 2 & 2,75 & 0,220 & 0,215 & 0,210 & 0,200 & 0,198 & 0,198 & 0,176 & 0,169 & 0,147 & 0,163 & 1,896 \\
\hline 3 & 5,50 & 0,218 & 0,215 & 0,209 & 0,200 & 0,197 & 0,198 & 0,175 & 0,168 & 0,146 & 0,163 & 1,889 \\
\hline 4 & 8,25 & 0,218 & 0,215 & 0,208 & 0,199 & 0,196 & 0,197 & 0,174 & 0,168 & 0,146 & 0,162 & 1,883 \\
\hline 5 & 11,00 & 0,216 & 0,214 & 0,208 & 0,199 & 0,195 & 0,196 & 0,174 & 0,168 & 0,145 & 0,162 & 1,877 \\
\hline 6 & 13,75 & 0,216 & 0,214 & 0,206 & 0,198 & 3. 0,194 & 0,195 & 0,174 & 0,168 & 0,144 & 0,161 & 1,870 \\
\hline 7 & 16,50 & 0,216 & 0,216 & 0,206 & 0,197 & 0,196 & 0,196 & 0,174 & 0,169 & 0,144 & 0,160 & 1,874 \\
\hline 8 & 19,25 & 0,215 & 0,215 & 0,206 & 0,197 & 0,194 & 0,196 & 0,173 & 0,169 & 0,143 & 0,159 & 1,867 \\
\hline 9 & 22,00 & 0,214 & 0,217 & 0,205 & 0,196 & $5 \quad 0,194$ & 0,196 & 0,174 & 0,169 & 0,144 & 0,158 & 1,867 \\
\hline 10 & 24,75 & 0,214 & 0,217 & 0,204 & 0,195 & 0,192 & 0,196 & 0,173 & 0,169 & 0,142 & 0,158 & 1,860 \\
\hline 11 & 27,50 & 0,220 & 0,218 & 0,204 & 0,194 & 0,192 & 0,196 & 0,173 & 0,168 & 0,142 & 0,157 & 1,864 \\
\hline 12 & 30,25 & 0,220 & 0,216 & 0,204 & 0,193 & 30,191 & 0,195 & 0,172 & 0,168 & 0,142 & 0,156 & 1,857 \\
\hline 13 & 33,00 & 0,224 & 0,216 & 0,206 & 0,196 & 0,190 & 0,194 & 0,172 & 0,168 & 0,144 & 0,156 & 1,866 \\
\hline 14 & 35,75 & 0,224 & 0,214 & 0,206 & 0,196 & 0,189 & 0,195 & 0,171 & 0,169 & 0,143 & 0,155 & $1,8 \in 2$ \\
\hline 15 & 38,50 & 0,225 & 0,213 & 0,206 & 0,196 & 0,189 & 0,194 & 0,175 & 0,170 & 0,143 & 0,154 & 1,865 \\
\hline 16 & 41,25 & 0,225 & 0,212 & 0,206 & 0,196 & 0,188 & 0,195 & 0,175 & 0,170 & 0,142 & 0,154 & 1,863 \\
\hline 17 & 44,00 & 0,228 & 0,214 & 0,205 & 0,197 & 0,187 & 0,196 & 0,176 & 0,170 & 0,144 & 0,153 & 1,870 \\
\hline 18 & 46,75 & 0,226 & 0,213 & 0,206 & 0,196 & 0,191 & 0,196 & 0,182 & 0,170 & 0,146 & 0,156 & 1,882 \\
\hline 19 & 49,50 & 0,211 & 0,216 & 0,216 & 0,199 & 0,196 & 0,197 & 0,187 & 0,170 & 0,149 & 0,155 & 1,896 \\
\hline 20 & 52,25 & 0,008 & 0,208 & 0,228 & 0,208 & 0,210 & 0,215 & 0,210 & 0,183 & 0,157 & 0,162 & 1,789 \\
\hline
\end{tabular}


4.3.3.1. VAZÃO DE DERIVAÇÃO DE 372 1/h E TEM PO DE FERTIRRIGAÇÃO DE 40 MINUTOS

Os valores obtidos na análise de variāncia de quantidades totais de cloreto estão apresentados na Tabela 9. Observando-se esta análise, verifica-se que houve efeito significativo de tratamentos (distāncia do gote jador ao início da linha).

A análise de regressão indicou que as equações linear e quadrática foram significativas ao nível de 1\% de probabilidade, com coeficientes de determinação de $88,6 \%$ e $6,5 \%$, respectivamente.

Como o coeficiente de determinação para a equa ção linear foi elevado e muito maior que o coeficiente da equação quadrática, considerou-se que a variação da quantidạ de de cloreto aplicado em função das distāncias dos gotejadô res ao início da linha, comportou-se segundo a equação de regressão linear. 
TABELA 9 - Análise de variância de quantidade total de clore. to em diferentes pontos na linha de gotejadores, com vazão de derivação de $3721 / \mathrm{h}$ e tempo de fer tirrigação de 40 minutos.

\begin{tabular}{|c|c|c|c|c|c|}
\hline $\begin{array}{l}\text { FONTE DE } \\
\text { VARTAÇÃO }\end{array}$ & $\begin{array}{l}\text { SOMA DE } \\
\text { QUADRADOS }\end{array}$ & $\begin{array}{l}\text { GRAUS DE } \\
\text { ITBERDADE }\end{array}$ & $\begin{array}{l}\text { QUADRADO } \\
\text { MEDIO }\end{array}$ & $\begin{array}{l}\text { VAIOR } \\
\text { DE F }\end{array}$ & $r^{2}$ \\
\hline IJNEAR & $2,45053 \cdot 10^{-2}$ & 1 & $2,45053.10^{-2}$ & $155,48 * *$ & $88,6 \div$ \\
\hline QUADRATICA & $1,79018.10^{-3}$ & 1 & $1,79018 \cdot 10^{-3}$ & $11,36 * *$ & $6,5 \%$ \\
\hline COBBICA & $4,34023.10^{-5}$ & 1 & $4,34023 \cdot 10^{-5}$ & $0,28 \mathrm{~ns}$ & $0,2 \%$ \\
\hline $\begin{array}{l}\text { DESVIO DA } \\
\text { REGRESSĀO }\end{array}$ & $1,30808 \cdot 10^{-3}$ & 16 & $8,17550 \cdot 10^{-5}$ & $0,52 \mathrm{~ns}$ & $4,7 \%$ \\
\hline BIOCOS & $3,72715.10^{-2}$ & 2 & $1,86358 \cdot 10^{-2}$ & 118,24 ** & \\
\hline TRATAMENTOS & $2,76470 \cdot 10^{-2}$ & 19 & $1,45511 \cdot 10^{-3}$ & $9,23 * \star$ & \\
\hline RESIDUO & $5,98907 \cdot 10^{-3}$ & 38 & $1,57607.10^{-4}$ & & \\
\hline TOTAL & $7,09076 \cdot 10^{-2}$ & 59 & & & \\
\hline \multicolumn{2}{|c|}{$C V=2,00 \%$} & \multicolumn{3}{|c|}{ Média Geral $=0,627667 \mathrm{~g}$} & \\
\hline
\end{tabular}

Regressão linear: $\bar{y}=0,694257-2,54892 \cdot 10^{-3} \mathrm{x}$

Regressão quadrática: $\bar{y}=0,683749-1,27514 \cdot 10^{-3} \mathrm{X}-2,43786 \cdot 10^{-5} \mathrm{x}^{2}$

ns = não significativo estatisticamente.

** = significativo estatisticamente a $1 \%$ de probabilidade.

Na Figura 15 estão apresentados os valores mé dios observados e curva de regressão para a equação Iinear. Analisando-se a Figura 15, verifica-se que, embora a inclinação da curva seja pequena, ela indica que as quantidades de cloreto diminuiram continuamente do início pa ra o final da linha. 
75.

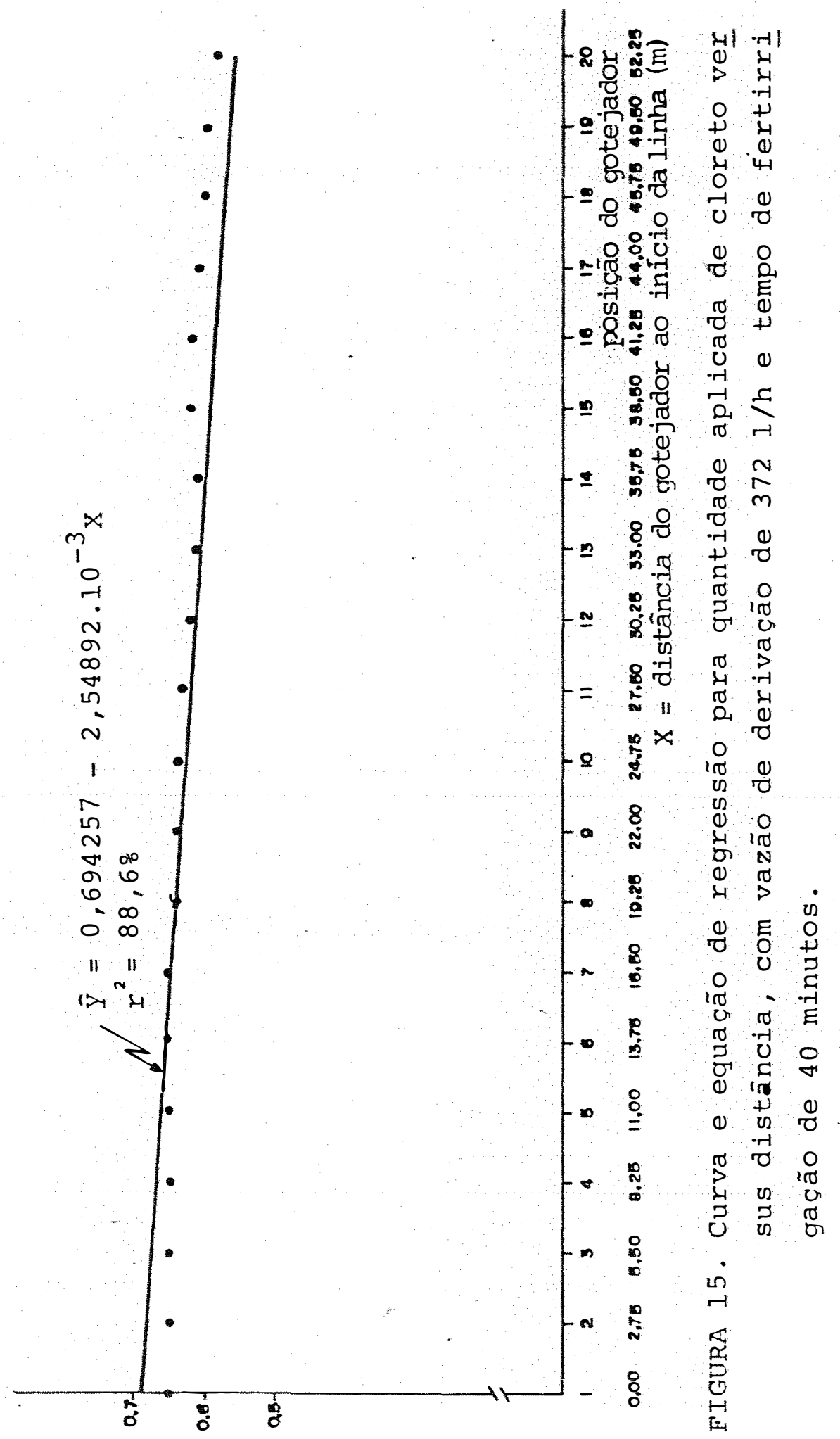

(5) о7әтото

әр әрерт7uеnb $=K$ 
Na Tabela 10 estão apresentadas as médias de totais de cloreto aplicado para os diversos pontos ao longo da linha de gotejadores, bem como o resultado do teste de Tukey e o Coeficiente de Uniformidade de Christiansen.

Observando-se a Tabela 10, verifica-se que 0 teste de Tukey revelou diferenças estatisticas entre as quantidades de cloreto aplicadas aos diversos pontos. Porém, as médias do ponto 1 ao 16 não diferiram entre si, e também, a uniformidade de aplicação, medida pelo Coeficiente de Chris tiansen, foi bastante alta $(98,8 \%)$.

4.3.3.2. VAZÃO DE DERIVAÇÃO DE 186 I/h E TEM PO DE FERTIRRIGAÇÃO DE 80 MINUTOS

Os valores obtidos na análise de variāncia pa ra esta aplicação estão apresentados na Tabela 11 .

observando-se esta análise, verifica-se que houve efeito significativo de tratamentos.

o desdobramento desse efeito indicou que as equações de regressão de primeiro e segundo grau foram signi ficativas ao nivel de $1 \%$ de probabilidade, com coeficientes de determinação de $58,6 \%$ e $26,5 \%$, respectivamente.

Uma vez que a equação linear apresentou maior coeficiente de determinação, considerou-se que a variação da quantidade de cloreto aplicado comportou-se conforme a equação de regressão linear apresentada. 
TABELA 10 - Quantidade média aplicada de cloreto (g), para diversos pontos na linha de gotejadores, com va zão de derivação de $3721 /$ h e tempo de fertirrigação de 40 minutos.

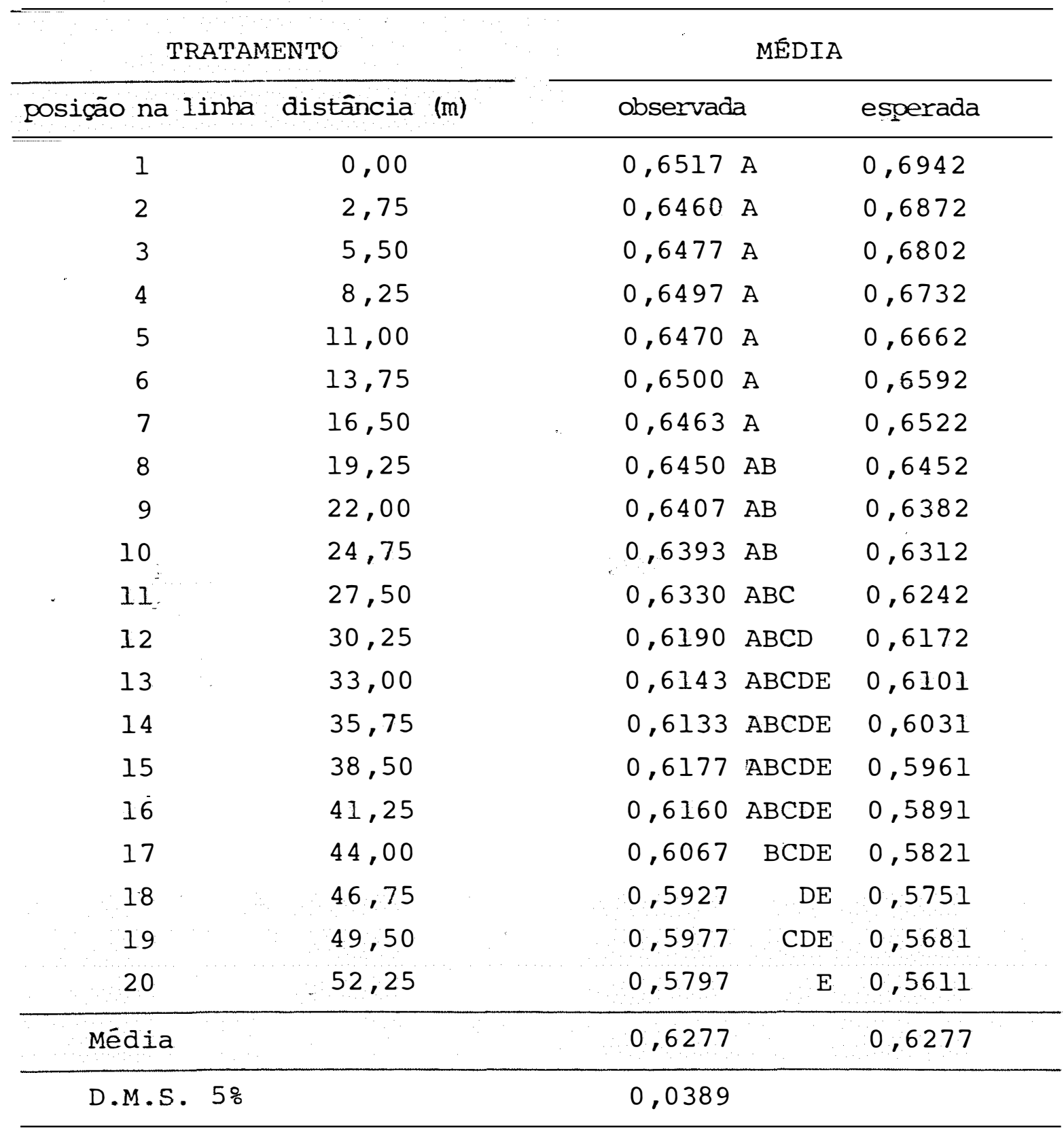

Coeficiente de Uniformidade de Christiansen $98,8 \%$

médias seguidas pela mesma letra não diferem estatisticamente entre si a 5 응 probabilidade. 
TABELA 11 - Análise de variāncia de quantidade total de clo reto em diferentes pontos na linhade gotejadores, com vazão de derivação de $1861 / \mathrm{h}$ e tempo de fer tirrigação de 80 minutos.

\begin{tabular}{|c|c|c|c|c|c|}
\hline $\begin{array}{l}\text { EONIE DE } \\
\text { VARIACÅO }\end{array}$ & $\begin{array}{l}\text { SOMA DE } \\
\text { QUADRADOS }\end{array}$ & $\begin{array}{l}\text { GRAUS DE } \\
\text { LIBERDADE }\end{array}$ & $\begin{array}{l}\text { QUADRADO } \\
\text { MEEDIO }\end{array}$ & $\begin{array}{l}\text { VALOR } \\
\text { DE F F }\end{array}$ & $r^{2}$ \\
\hline IIINEAR & $3,19401 \cdot 10^{-2}$ & 1 & $3,19401.10^{-2}$ & $525,03 * \star$ & 58,6 ? \\
\hline QUADRATTICA & $1,44373.10^{-2}$ & 1 & $1,44373 \cdot 10^{-2}$ & 237,32 ** & $26,5 \div$ \\
\hline CÚBICA & $5,82213.10^{-5}$ & 1 & $5,82213 \cdot 10^{-5}$ & $0,96 \mathrm{~ns}$ & $0,1 \%$ \\
\hline $\begin{array}{l}\text { DESVIO DE } \\
\text { REGRESSÃO }\end{array}$ & $8,10685 \cdot 10^{-3}$ & 16 & $5,06678 \cdot 10^{-4}$ & $8,33 * \star$ & $14,9:$ \\
\hline BLOCOS & $1,04012.10^{-1}$ & 2 & $5,20060 \cdot 10^{-2}$ & $854,87 \star \star \star$ & \\
\hline TRATAMENTOS & $5,45425 \cdot 10^{-2}$ & 19 & $2,87066 \cdot 10^{-3}$ & $47,19 * \star$ & \\
\hline RESIDUO & $2,31171.10^{-3}$ & 38 & $6,08345 \cdot 10^{-5}$ & & \\
\hline TOTAL & $1,60866 \cdot 10^{-1}$ & 59 & & & \\
\hline
\end{tabular}

$$
\mathrm{CV}=0,73 \% \quad \text { Média Geral }=1,06845 \mathrm{~g}
$$

Regressão linear: $\hat{y}=1,4447 \mathrm{X}-2,91001 \cdot 10^{-3} \mathrm{X}$

Regressão quadrática: $\hat{y}=1,11463+7,07348 \cdot 10^{-4} \mathrm{x}-6,92317 \cdot 10^{-5} \mathrm{x}^{2}$

ns = não significativo estatisticamente.

** = significativo estatisticamente a $1 \%$ de probabilidade

Na Figura 16 estão apresentados os valores mé dios observados e curva de regressão para a equação linear.

Analisando-se a Figura 16, verifica-se que se melhantemente ao obtido para o tempo de fertirrigação de 40 minutos, embora a inclinação da curva seja pequena, as quantidades de cloreto diminuíram continuamente do início até o final da linha. 


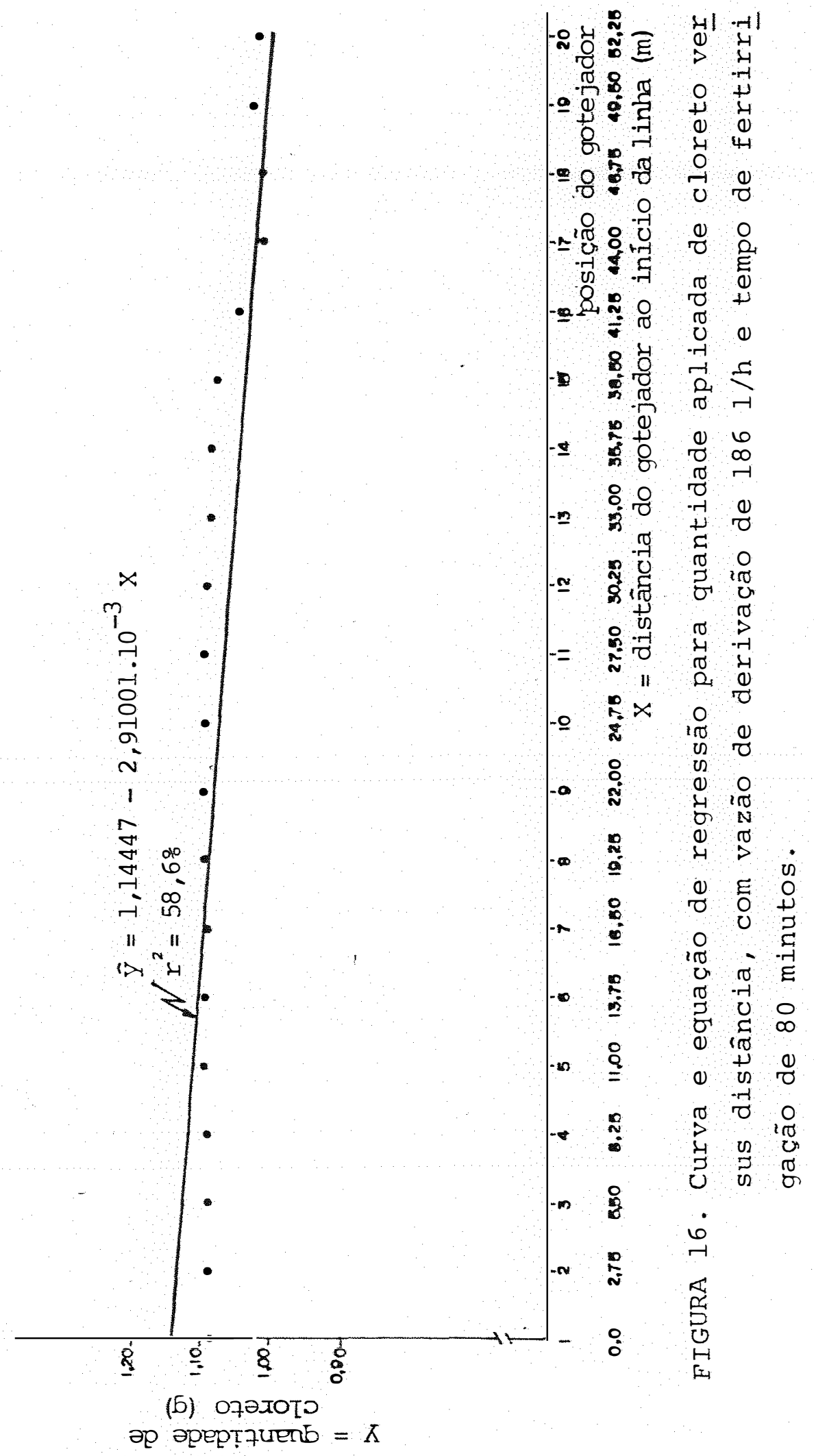


Na Tabela 12 estão apresentadas as médias de totais de cloreto aplicado, bem como o resultado do teste de Tukey e o Coeficiente de Uniformidade de Christiansen.

Analisando-se a Tabela 12, verifica-se que 0 teste de Tukey revelou que há diferencas significativas entre médias. Porém, semelhantemente ao tempo de aplicação de 40 minutos, as médias do ponto 1 ao ponto 15 não diferiram en tre si. O Coeficiente de Uniformidade de Christiansen foi também bastante elevado $(97,3 \%)$, revelando alta uniformidade de aplicação.

4.3.3.3. VAZÃO DE DERIVAÇÃO DE $931 / \mathrm{h}$ E TEMPO DE FERTIRRIGAÇÃO DE 160 MINUTOS

Os resultados obtidos na análise de variância para esta aplicação estão apresentados na Tabela 13.

Por ineio desta anālise de variância, observase que houve efeito significativo de tratamentos e as equações de regressão foram significativas para o primeiro, se gundo e terceiro grau.

Tal como obtido para os tempos de fertirrigação de 40 e 80 minutos, para o tempo de 160 minutos, a equa ção de regressão do primeiro grau apresentou maior coeficien te de determinação. 
TABELA 12 - Quantidade média aplicada de cloreto (g), para diversos pontos na linha de gotejadores, com va zão de derivação de $186 \mathrm{l} / \mathrm{h}$ e tempo de fertirrigação de 80 minutos.

\begin{tabular}{|c|c|c|c|c|}
\hline \multicolumn{2}{|c|}{ TRATAMENTO } & \multicolumn{3}{|c|}{ MEDIA } \\
\hline posição na linha & distância (m) & observadi & & esperada \\
\hline 1 & 0,00 & 1,0863 & & 1,1445 \\
\hline 2 & 2,75 & 1,0820 & & 1,1365 \\
\hline 3 & 5,50 & 1,0833 & A & 1,1285 \\
\hline 4 & 8,25 & 1,0860 & & 1,1205 \\
\hline 5 & 11,00 & 1,0880 & & 1,1125 \\
\hline 6 & 13,75 & 1,0873 & A & 1,1045 \\
\hline 7 & 16,50 & 1,0867 & & 1,0965 \\
\hline 8 & 19,25 & 1,0890 & & 1,0885 \\
\hline 9 & 22,00 & 1,0913 & A & 1,0724 \\
\hline 10 & 24,75 & 1,0910 & A & 1,0724 \\
\hline 11 & 27,50 & 1,0903 & A & 1,0644 \\
\hline 12 & 30,25 & 1,0850 & A & 1,0564 \\
\hline 13 & 33,00 & 1,0797 & A & 1,0484 \\
\hline 14 & 35,75 & 1,0797 & A & 1,0404 \\
\hline 15 & 38,50 & 1,0710 & A & 1,0324 \\
\hline 16 & 41,25 & 1,0427 & B & 1,0244 \\
\hline 17 & 44,00 & 1,0037 & D & 1,0164 \\
\hline 18 & 46,75 & 1,0057 & $C D$ & $I, 0084$ \\
\hline 19 & 49,50 & 1,0287 & $\mathrm{BC}$ & 1,0004 \\
\hline 20 & $-52,25$ & 1,0117 & $\mathrm{CD}$ & 0,9924 \\
\hline Média & & 1,0684 & & 1,0684 \\
\hline D.M.S. $5 \frac{\circ}{6}$ & & 0,0242 & & \\
\hline
\end{tabular}

Coeficiente de Uniformidade de Christiansen 97,3\%

médias seguidas pela mesma letra não diferem estatisticamente entre si a $5 \circ$ de probabilidade. 
TABELA 13 - Análise de variância de quantidade total de clo reto aplicado em diferentes pontos na linha de gotejadores, com vazão de derivação de $931 / \mathrm{h} e$ tempo de fertirrigação de 160 minutos.

\begin{tabular}{|c|c|c|c|c|c|c|}
\hline $\begin{array}{l}\text { FONIE DE } \\
\text { VARTACAOA }\end{array}$ & $\begin{array}{l}\text { SOMA DE } \\
\text { QUADRADOS }\end{array}$ & $\begin{array}{l}\text { GRAUS DE } \\
\text { IIBEERDADE }\end{array}$ & $\begin{array}{l}\text { QUADRADO } \\
\text { MEDIO }\end{array}$ & \multicolumn{2}{|c|}{ VALOR } & $r^{2}$ \\
\hline IINEAR & $7,86072.10^{-3}$ & 1 & $7,86072 \cdot 10^{-3}$ & 143,94 & $\star \star$ & $25,4 \div$ \\
\hline QUADRATICA & $7,07415 \cdot 10^{-4}$ & 1 & $7,07415.10^{-4}$ & 12,95 & $\star \star$ & $2,3 \div$ \\
\hline CÚBICA & $4,70949 \cdot 10^{-3}$ & 1 & $4,70949.10^{-3}$ & 86,24 & $\star \star$ & $15,2 \div$ \\
\hline $\begin{array}{l}\text { DESVIO DE } \\
\text { REGRESSÃO }\end{array}$ & $1,76825 \cdot 10^{-2}$ & 16 & $1,10516 \cdot 10^{-3}$ & 20,24 & $\star \star$ & $57,1 \div$ \\
\hline BLOCOS & $3,81470 \cdot 10^{-2}$ & 2 & $1,90735 \cdot 10^{-2}$ & 349,26 & $\star \star$ & \\
\hline TRATAMENIOS & $3,09601 \cdot 10^{-2}$ & 19 & $1,62948 \cdot 10^{-3}$ & 29,84 & $\star *$ & \\
\hline RESIDUO & $2,07520 \cdot 10^{-3}$ & 38 & $5,46105 \cdot 10^{-5}$ & & & \\
\hline TOTAL & $7,11823.10^{-2}$ & 59 & & & & \\
\hline \multicolumn{2}{|c|}{$C V=0,40 \%$} & \multicolumn{2}{|c|}{ Média Geral $=1,8698$} & 9 & & \\
\hline \multicolumn{7}{|c|}{$\begin{array}{l}\text { Regressão linear: } \bar{y}=1,90752-1,44363 \cdot 10^{-3} \mathrm{X} \\
\text { Regressão cúbica: } \bar{y}=1,97192-0,017506 \mathrm{x}+7,64573 \cdot 10^{-4} \mathrm{x}^{2}-9,55978 \cdot 10^{-6} \mathrm{x}\end{array}$} \\
\hline
\end{tabular}

** significativo estatisticamente a $1 \%$ de probabilidade.

Assim, considerou-se que a variação da quanti dade de cloreto, em relação à distāncia do gotejador ao iní cio da linha, obedeceu um modelo linear, segundo a equação de regressão apresentada. Também, embora o coeficiente angu lar desta equação seja pequeno, ele indica que as quantidades de cloreto diminuiram continuamente do início até o final da linha.

Na Figura 17 estão apresentados os valores mê dios observados e curva de regressão para a equação linear. 
83.

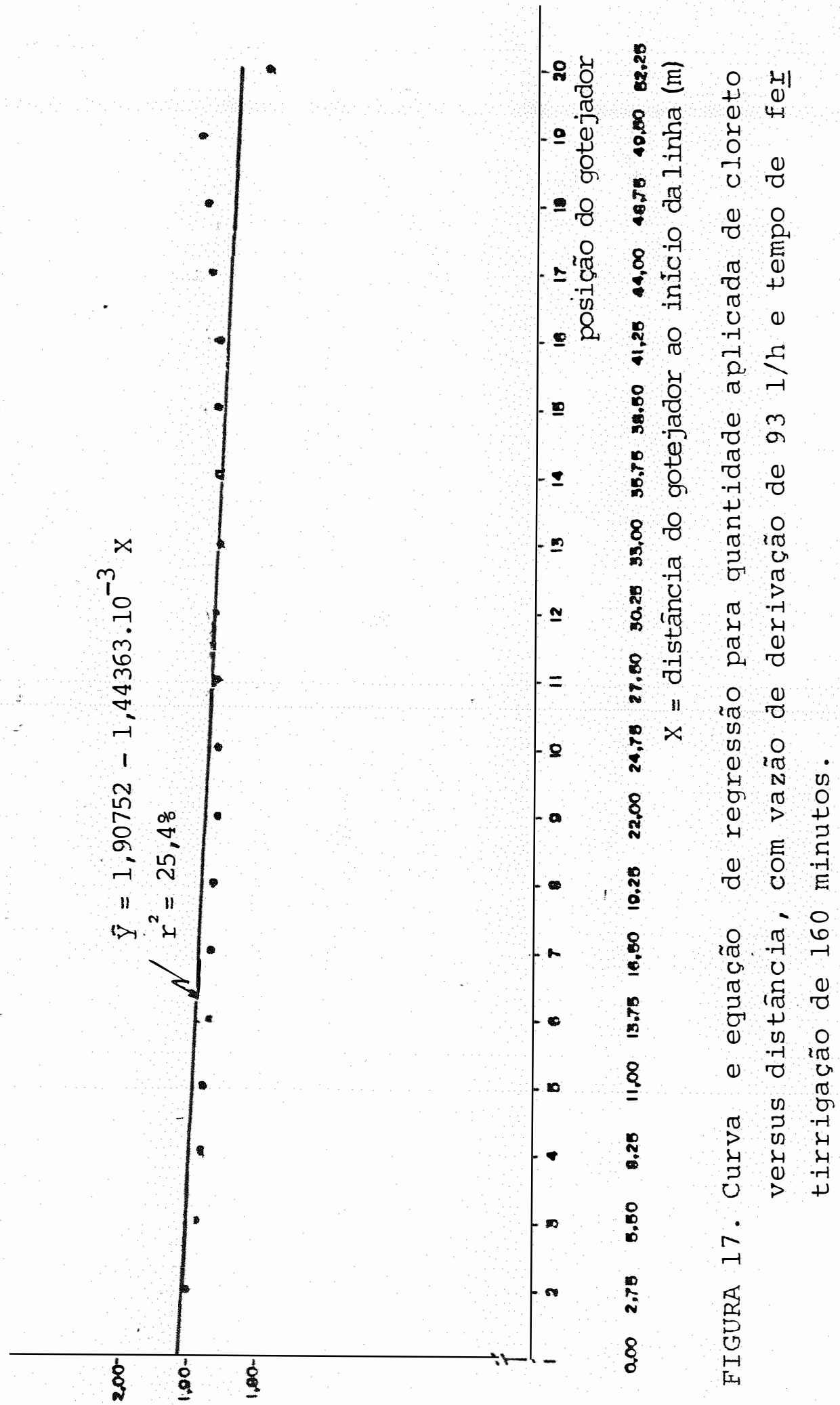

(5) 07จxото

әр әрерттиепб $=\pi$ 
Na Tabela 14 estão apresentadas as médias de totais de cloreto aplicado, o resultado do teste de Tukey e - Coeficiente de Uniformidade de Christiansen.

Analisando-se a Tabela 14 pode ser observado que o teste de Tukey revelou diferenças significativas en tre médias.

Porém, tal como nas aplicações de 40 e $80 \mathrm{mi-}$ nutos, a maioria das médias não diferiram entre si, o que po de ser constatado entre os tratamentos 5 a 17 . O Coeficien te de Uniformidade de Christiansen foi também bastante eleva do $(97,3 \%)$, indicando alta uniformidade de aplicação.

4.4. INJEÇÃO COM BOMBA

4.4.1. TAXA DE INJEÇ̃̃O DA BOMBA

Segundo instruções do fabricante (ASBRASII, 1985), a frequēncia do pistão da bomba pode ser de um a doze golpes por minuto, injetando aproximadamente 0,5 1/golpe, cor respondendo 30 a 360 1/hora, respectivamente.

No presente trabalho, as medições feitas para determinação dos volumes de ejeção e injeção resultaram em 1,39 e 0,5566 1/golpe, respectivamente, com uma relação de $2,5 / 1$.

Conhecido o volume de injeção e tendo-se estabe lecido que com a bomba injetora seriam realizadas fertirrigações com uma única vazão de injeção (372 1/h, durante 40 minutos), re gulou-se para 11,15 golpes/min a frequēncia do pistão da bomba. 
TABEIA 14 - Quantidade média aplicada de cloreto (g), para diversos pontos na linha de gotejadores, com va zão de derivação de $931 / \mathrm{h}$ e tempo de fertirriga çāo de 160 minutos.

\begin{tabular}{|c|c|c|c|c|c|}
\hline \multicolumn{2}{|c|}{ TRATAMENTO } & \multicolumn{4}{|c|}{ MEDIA } \\
\hline Posição na linha & distância (m) & \multicolumn{2}{|c|}{ observada } & \multicolumn{2}{|r|}{ esperada } \\
\hline 1 & 0,00 & 1,9030 & & & 1,9075 \\
\hline 2 & 2,75 & 1,8960 & & & 1,9035 \\
\hline 3 & 5,50 & 1,89032 & $B C$ & & 1,8996 \\
\hline 4 & 8,25 & 1,8830 & $\mathrm{ABCD}$ & & 1,8956 \\
\hline 5 & 11,00 & 1,8770 & $\mathrm{BCDE}$ & & 1,8916 \\
\hline 6 & 13,75 & 1,8717 & CDE & & 1,8877 \\
\hline 7 & 16,50 & 1,8700 & $\mathrm{CDE}$ & & 1,8837 \\
\hline 8 & 19,25 & 1,8640 & $\mathrm{DE}$ & & 1,8797 \\
\hline 9 & 22,00 & 1,8640 & $\mathrm{DE}$ & & 1,8758 \\
\hline 10 & 24,75 & 1,8590 & $E$ & - & 1,8718 \\
\hline 11 & 27,50 & 1,8623 & $\mathrm{DF}$ & & 1,8678 \\
\hline 12 & 30,25 & 1,8563 & $E$ & 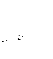 & 1,8638 \\
\hline 13 & 33,00 & 1,8650 & $\mathrm{DE}$ & & 1,8599 \\
\hline 14 & 35,75 & 1,8620 & $\mathrm{DE}$ & & 1,8559 \\
\hline 15 & 38,50 & 1,8657 & $\mathrm{DE}$ & & 1,8519 \\
\hline 16 & 41,25 & 1,8643 & $\mathrm{DE}$ & & 1,8480 \\
\hline 17 & 44,00 & 1,8720 & $\mathrm{CDE}$ & & 1,8440 \\
\hline 18 & 46,75 & 1,88232 & $\mathrm{ABCD}$ & & 1,8400 \\
\hline 19 & 49,50 & 1,8980 & & & 1,8361 \\
\hline 20 & 52,25 & 1,7900 & $\mathrm{~F}$ & & 1,8321 \\
\hline Média & & 1,8698 & & & \\
\hline D.M.S. 5\% & & 0,0229 & & & \\
\hline
\end{tabular}

Coeficiente de Uniformidade de Christiansen 97,38

médias seguidas pela mesma letra não diferem estatisticamente entre si a 5 응 de probabilidade. 
86.

\subsubsection{TEORES DE CLORETO}

Os teores médios de cloreto obtidos nas amos tras coletadas nos 20 pontos ao longo da linha de gotejadores, para os dez instantes de coleta, estão apresentados na Tabela 15 .

Analisando-se esta tabela, verifica-se que até os três primeiros instantes de coleta pode-se identificar o avanço da solução fertilizante para a extremidade final da Iinha de gotejadores.

Semelhantemente à injeção de solução com derí vação de fluxo, o tempo para alcance da extremidade da linha pela solução deu-se após 4 minutos, indicando que a velocida de de caminhamento da mesma independeu do tipo de injeção.

$$
\text { Após esse tempo (4 minutos), verifica-se }
$$

que até o final da injeção de fertilizante pela bomba $140 \mathrm{mi}$ nutos), a concentração de cloreto manteve-se praticamente constante no decorrer do tempo e ao longo da linha de goteja dores, sendo semelhante à concentração prevista na mesma no final da aplicação, ou seja, 317,8 ppm.

Desse modo, diferentemente do obtido com inje ção por derivação de fluxo, não se constataram maiores teores de cloreto para os pontos finais da linha de gotejadores, indicando que não ocorreu acúmulo nessa região. Essa diferença de comportamento provavelmente se deu devido à solução injetada na rede pela bomba não sofrer variação de concentra ção durante a aplicação e devido injeção de solução em menor concentração. 
87.

TABEIA 15 - Teor $\stackrel{2}{2}$ médio de cloreto (ppm), obtido com taxa de injeção de $3721 / \mathrm{h}$, durante 40 minutos, com bomba injetora.

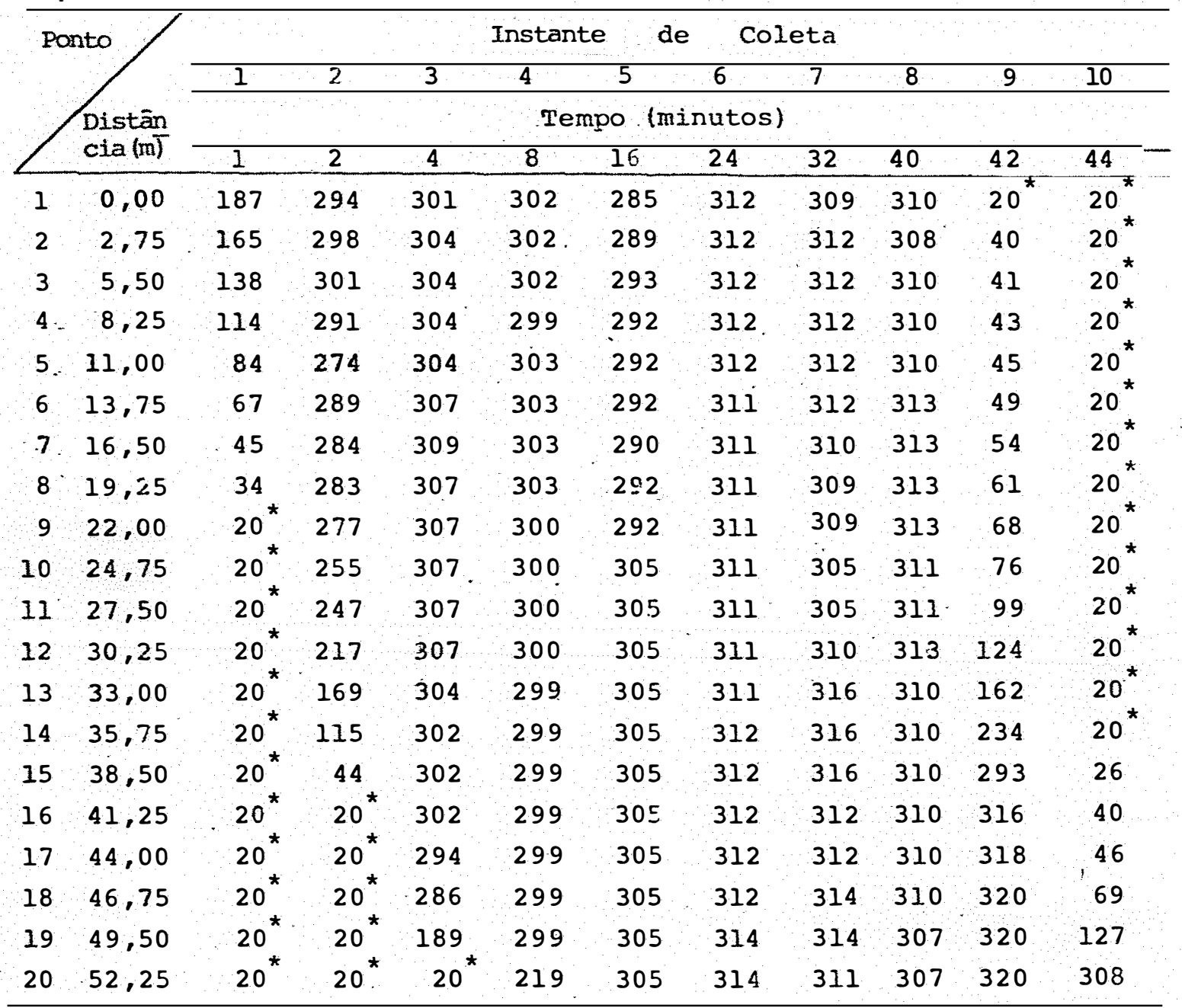

$1 /$ teor da solução no tanque $=601$ ppon

teor natural da àgua 


\subsubsection{QUANTIDADE APLICADA DE CLORETO}

Da mesma maneira realizada para derivação de fluxo (item 4.3.3.), calcularam-se as quantidades aplicadas de cloreto entre instantes consecutivos para cada ponto de co leta.

Estas quantidades, resumidas como médias de três repetições, estão apresentadas a seguir na Tabela 16 .

As quantidades totais de cloreto, para cada ponto amostrado na linha de gotejadores, foram analisadas através dos testes F e Tukey e regressões, conforme apresen tado na Tabela 17 .

Através dessa tabela, verifica-se que houve efeito significativo de tratamentos.

o desdobramento desta significāncia revelou efeito linear e cúbico, com coeficientes de determinação de $80,4 \%$ e $8,9 \%$, respectivamente.

Como o coeficiente da 'equação linear foi mui to maior que o coeficiente da equação cūbica, considerou-se que a quantidade aplicada de cloreto em relação à posição na Iinha de gotejadores, comportou-se segundo a equação de regressão de primeỉro grau. 
TABELA 16 - Quantidade média aplicada de cloreto (g), entre instantes de coleta, com bomba injetora de fertilizantes, à taxa de injeção de $372 \mathrm{l} / \mathrm{h}$ e tempo de fertirrigação de 40 minutos.

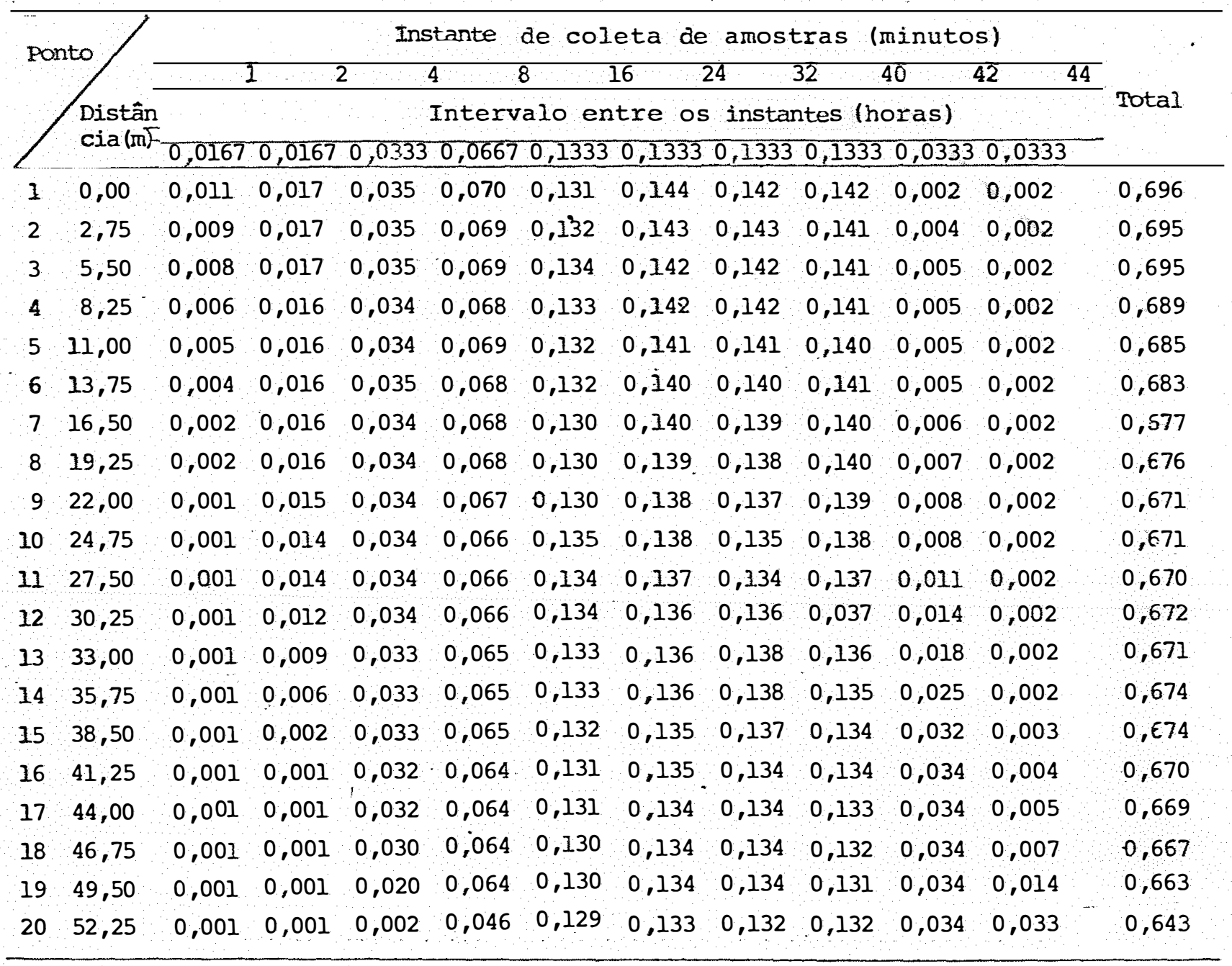


TABELA 17 - Análise de variância de quantidade total de clo reto aplicado em diferentes pontos na linha de go tejadores, com bomba injetora de fertilizantes.

\begin{tabular}{|c|c|c|c|c|c|}
\hline $\begin{array}{l}\text { FONIE DE } \\
\text { VARIACAAO }\end{array}$ & $\begin{array}{l}\text { SOMA DE } \\
\text { QUADRADOS }\end{array}$ & $\begin{array}{l}\text { GRAUS DE } \\
\text { ITBERDADE }\end{array}$ & $\begin{array}{l}\text { QUADRADO } \\
\text { MÉDIO }\end{array}$ & $\begin{array}{l}\text { VALOR } \\
\text { DE F }\end{array}$ & $r^{2}$ \\
\hline LINEAR & $7,44140 \cdot 10^{-3}$ & 1 & $7,44140 \cdot 10^{-3}$ & $203,93 \star \star$ & $80,4 \%$ \\
\hline QUADRÁTICA & $3,51154 \cdot 10^{-5}$ & 1 & $3,51154.10^{-5}$ & 0,96 ns & $0,4 \%$ \\
\hline CÚBICA & $8,24265 \cdot 10^{-4}$ & 1 & $8,24625.10^{-4}$ & $22,60 * *$ & $8,9 \div$ \\
\hline $\begin{array}{l}\text { DESVIO DA } \\
\text { REGRESSÃO }\end{array}$ & $9,59037.10^{-4}$ & 16 & $5,99398 \cdot 10^{-5}$ & $1,64 \mathrm{~ns}$ & $10,4 \%$ \\
\hline BIOCOS & $6,29616 \cdot 10^{-3}$ & 2 & $3,14808.10^{-3}$ & $86,27 \star \star$ & \\
\hline 'IRATAPANTOS & $9,26018 \cdot 10^{-3}$ & 19 & $4,87378 \cdot 10^{-4}$ & $13,36 * \star$ & \\
\hline RESIDUO & $1,38664 \cdot 10^{-3}$ & 38 & $3,64905 \cdot 10^{-5}$ & & \\
\hline TOTAI & $1,69430 \cdot 10^{-2}$ & 59 & & & \\
\hline
\end{tabular}

$\mathrm{CV}=0,89 \% \quad$ Média Geral $=0,676233 \mathrm{~g}$

Regressão linear: $\bar{y}=0,712929-0,0014046 \mathrm{x}$

Regressão cúbica: $\bar{y}=0,737113-7,79081 \cdot 10^{-3} x+3,13521 \cdot 10^{-4} x^{2}-4,00027 \cdot 10^{-6} x^{3}$

ns = não significativo estatisticamente.

$\star \star$ = significativo estatisticamente ${ }^{\prime} 1 \%$ de probabilidade.

$\mathrm{Na}$ Figura 18 estão apresentadas a curva de re gressão e a equação linear caliculada.

Analisando-se a Figura 18, verifica-se que se melhantemente ao obtido para as aplicações com derivação de fluxo, a quantidade de cloreto resultante da aplicação com bomba injetora pōde ser representada por uma equação do pri meiro grau. Embora a inclinação da curva seja pequena, também se nota que a quantidade aplicada diminuiu continuamente do início para o final da linha. 
91.

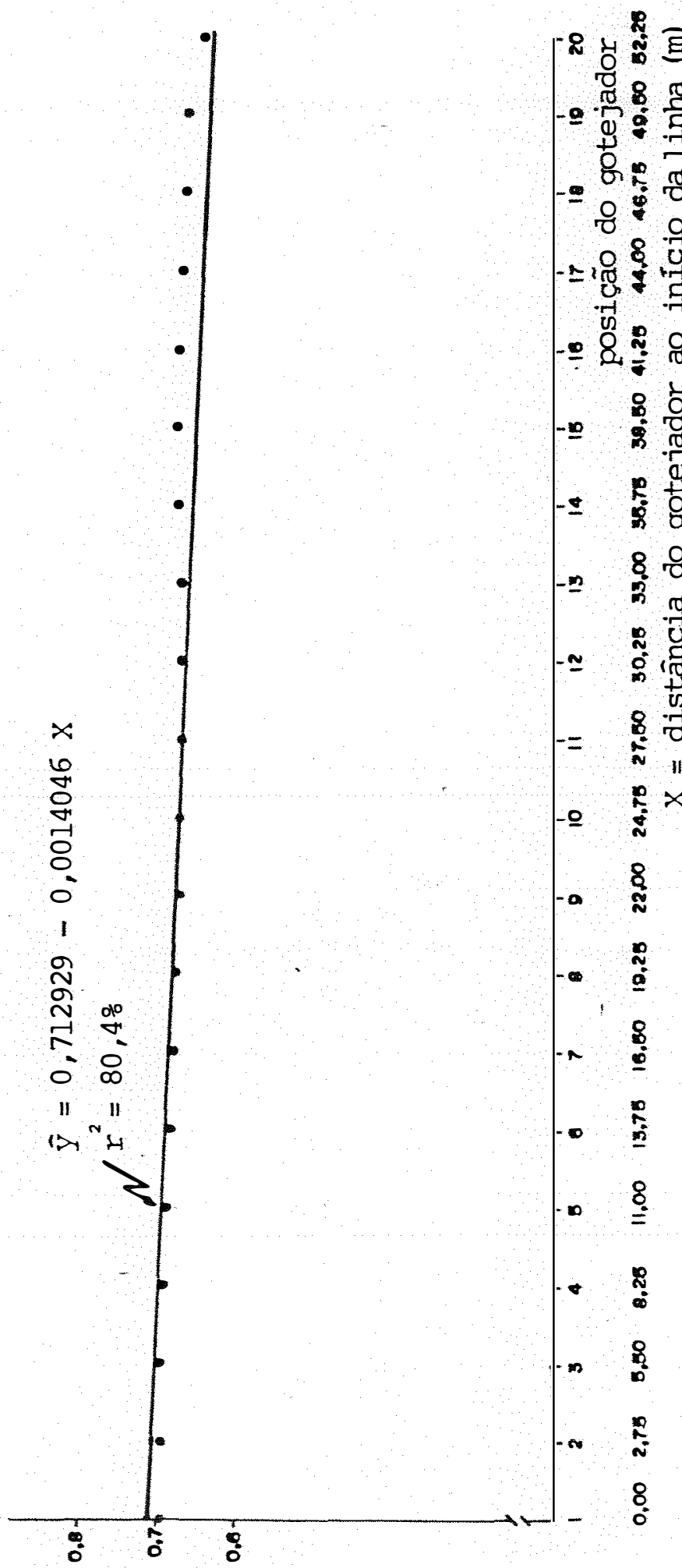

$\begin{array}{ll}0 & \pi \\ + & x \\ 0 & \pi \\ 0 & +\end{array}$

7

0 .

0.

o 2

0

$\rightarrow$ ह $\vec{E}$

$\begin{array}{llll}0 & 0 & N & 0 \\ -0 & 0 & -7 & \sigma\end{array}$

- $8 \quad 0 \quad \begin{gathered}0 \\ 0\end{gathered}$

8 o $0 \begin{array}{lll}0 & 0 & 0\end{array}$

$\begin{array}{lllll}8 & 0 & + & 0 & 0 \\ 0 & 0 & 0\end{array}$

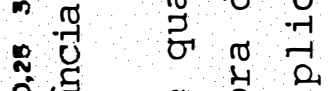

- I 4 \&

i 0

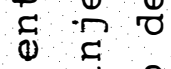

N $1 \quad 0 \quad$ F 0

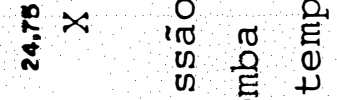

$\& \quad$ o 00

(1)

잉

- $\quad$ N

$0 \quad \pi$ N

in 0

हु थ 0

- 0 o

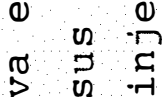

प

(b) 07әxоโว

әр әрертұтеnб $=K$ 
Na Tabela 18 estão apresentadas as médias de totais de cloreto aplicado, o resultado do teste de Tukey e o Coeficiente de Uniformidade de Christiansen.

$$
\text { Analisando-se a Tabela 18, verifica-se qúe, }
$$
tal como ocorrido para as aplicações com derivação de fluxo, o teste de Tukey indicou diferenças significativas entre as médias de quantidades de cloreto aplicado aos diversos pontos. Porém, a uniformidade de aplicação medida pelo coeficiente de Christiansen foi muito alta $(99,4 \%)$, indicando que a aplicação foi uniforme.

\subsection{Comparação entre Aplicaç̃o com derivaç̃o de Fluxo E COM BOMBA INJETORA}

Os dados e análises de quantidades aplicadas de cloreto, quando observados conjuntamente, para as três aplicações com derivação de fluxo e com bomba injetora, con forme pode-se verificar pelas Tabelas $10,12,14$ e 18 e Figu ras 15 a 18, mostram que foram semelhantes, ou seja: a uni formidade de aplicação, avaliada pelo Coeficiente de Uniformidade de Christiansen, foi sempre alta, sendo maior ou igual a 97,3\%; para todas as aplicações, as equações de regressão indicaram que a quantidade de cloreto diminuiu do início pa ra o final da linha. 
TABELA 18 - Quantidade média de cloreto $(\mathrm{g})$ aplicado com bom ba injetora de fertilizantes, em diversos pontos da linha de gotejadores.

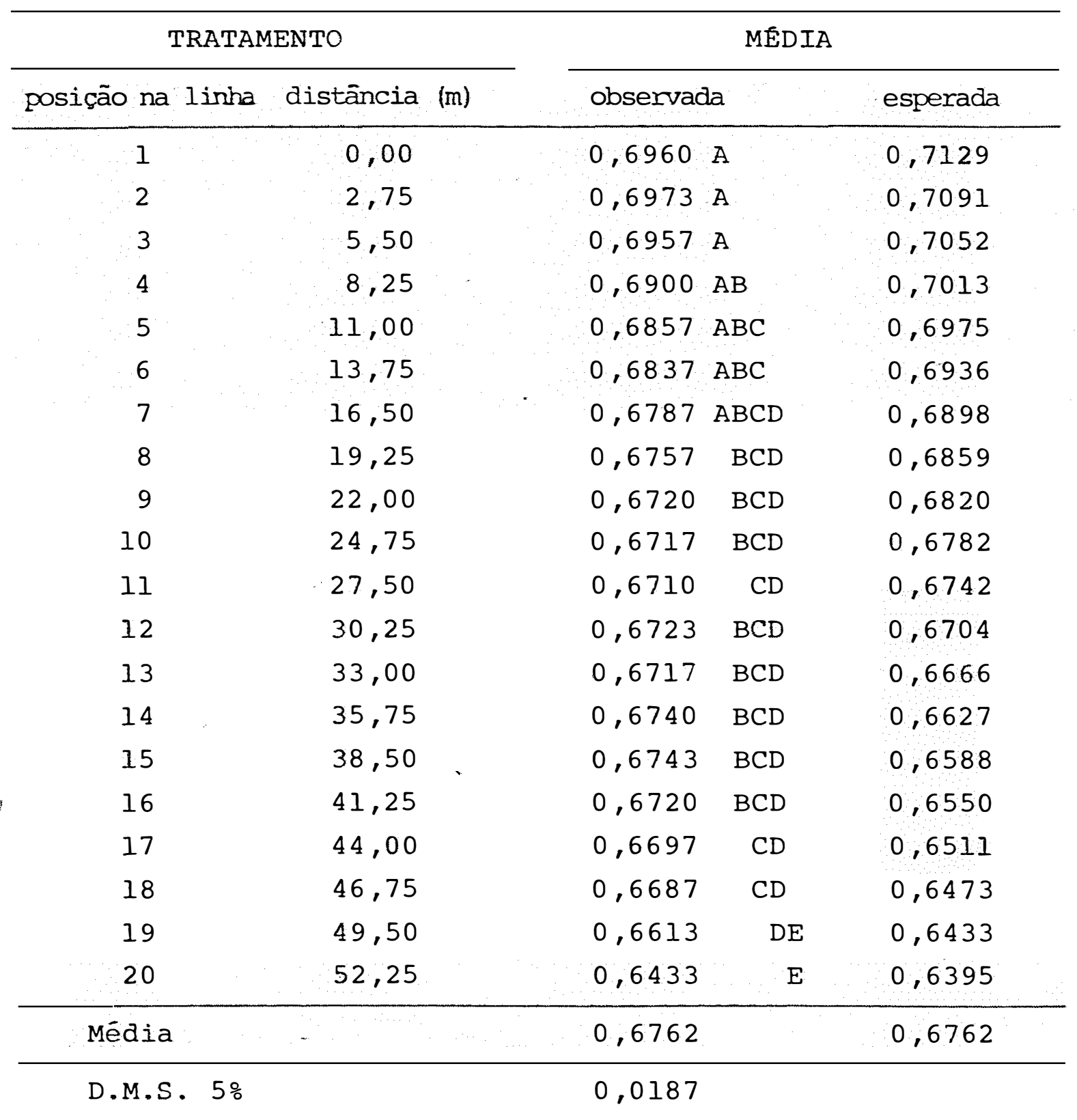

Coeficiente de Uniformidade de Christiansen $99,4 \%$

médias seguidas pela mesma letra não diferem estatisticamente entre si a 5\% de probabilidade. 
94.

As máximas reduções porcentuais foram estima das relacionando-se a diferença de quantidade aplicada no início e no final da linha, dividida pela média de aplicação. Estes valores, para injeção com derivação de fluxo (vazões de 372, 186 e $931 / \mathrm{h}$ ) e com bomba injetora (vazão de 372 l/h), foram $21,2 \% ; 14,2 \% ; 4,0 \%$ e $10,8 \%$, respectivamente.

Uma das causas dessas reduções de cloreto apli cado é a diminuição de vazão dos gotejadores ao longo da li nha, em consequéncia de perda de carga, conforme pode ser ve rificado nas Figuras 11 e 12. Estimando-se do mesmo modo rea lizado para quantidade de cloreto, a máxima redução de vazão é de $8,2 \%$

O decréscimo da quantidade apliçada de clore to com o aumento do comprimento da linha de gotejadores, po de também ser explicado devido ao tempo de avanço da solução fertilizante do início até o final da mesma.

Verificando-se as Tabelas $2,3,4$ e 15, obser va-se que este tempo foi aproximadamente cinco minutos. Des se modo, durante as fertirrigações, os pontos finais recebe ram solução fertilizante por menor tempo em comparação aos pontos iniciais.

Essas máximas reduções diminuíram com o aumento do tempo de fertirrigação para injeção com derivação de fluxo, uma vez que o tempo de avanço representa menor fração do tempo de fertirrigação quando aumenta-se este último. 
Com 372 l/h a redução foi 21,2 요 com derivação de fluxo, diminuindo para 10,88 quando usou-se a bomba, pois para essa, além da concentração ser mantida constante, termi nada a aplicação continuou-se a fertirrigação durante 4 minu tos, havendo um recesso de cloreto na linha nesse periodo.

Na Figura 19 estão apresentadas as curvas e equações de regressão de quantidades aplicadas de cloreto, pa ra os sistemas utilizados de injeção de fertilizante.

Para se verificar possiveis diferenças entre os dois sistemas de injeção, as equaçōes de regressão foram comparadas pelo teste $t$, confrontando-se os coeficientes an gulares e as quantidades de cloreto aplicadas ao longo da linha, não sendo constatadas diferenças significativas entre os parāmetros testados, ao nível de 5\% de probabilidade. I so indicou que as quantidades aplicadas de cloreto, bem como o decréscimo das mesmas çom o aumento do comprimento da $1 \underline{i}$ nha de gotejadores, foram semelhantes para os dois sistemas utilizados. 


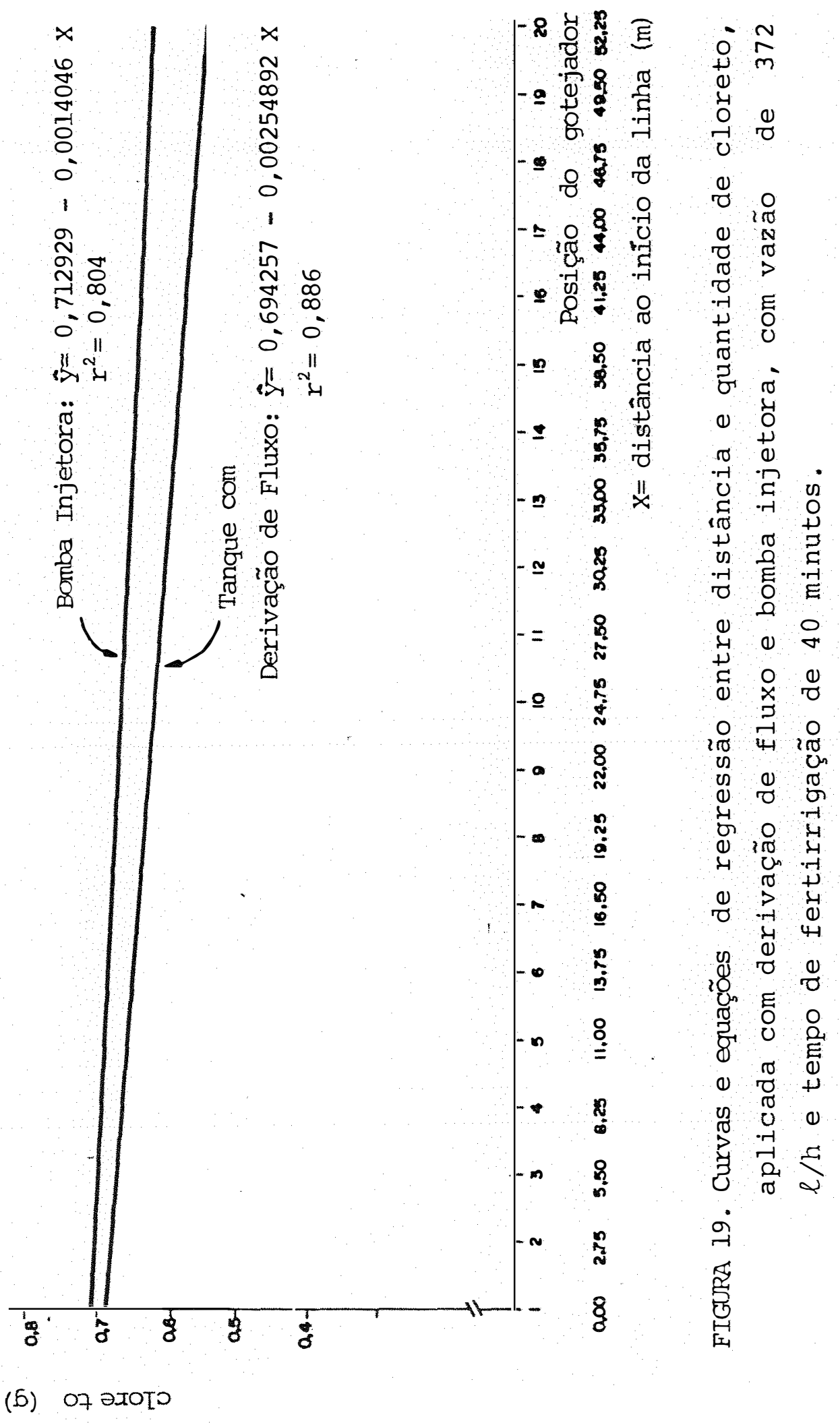

әр әрертұлuen $=\pi$ 


\section{CORCLUSÕES}

Utilizando-se tanque de derivação de fluxo e bomba injetora de fertilizantes para injeção de solução de $\mathrm{KCl}$ e empregando-se o ion cloneto como traçador, no estudo da distribuição espacial e temporal do mesmo pelo sistema de irrigação, foram obtidas as seguintes conclusões:

a) A equação determinada para estimar a vazão derivada através do tanque de fertilizantes segue o modelo: $q=\mathrm{K} \cdot \mathrm{H}^{0,5}$, sendo:

$q=$ vazão derivada $(\ell / h)$

$\mathrm{H}=$ diferença de pressão (kPa).

Essa equação expressa o Teorema de Torricelli, indicando que a vazão é ṕroporcional à raiz quadrada da diferença de pressão, sendo que $\mathrm{K}$ assumirá diferentes valores em função da instalação do tanque à rede de irrigação.

b) A redução da concentração do ín cloreto no tanque de fer tilizantes, em relação à sua concentração inicial no mesmo, apresentou modelo exponencial, segundo a equação

$$
Y=100 \cdot e^{-V / V}, \text { sendo: }
$$


$Y=$ concentração relativa de cloreto $\left(\frac{8}{8}\right)$;

e = base do logaritmo neperiano;

$\mathrm{V}=$ volume derivado através do tanque;

$\mathrm{v}=$ volume do tanque.

c) A pressão de serviço na linha de gotejadores ocorreu em po sição correspondente a $39 \%$ do seu comprimento. Do início da linha até essa posição a perda de carga represen tou $75 \%$ da perda de carga total;

d) O ín cloreto aplicado com sistema de derivação de fluxo, usando-se vazões de 93, 186 e 372 l/h e aplicação com bomba injetora com vazão de 372 l/ha, teve a mesma velocidade de avanço na linha de gotejadores;

e) A distribuição de cloreto ao Iongo da Iinha de gotejadores, aplicado com derivação de fluxo e com bomba injetora, pōde ser representada por uma equação do primeiro grau, indicando que as quantidades de cloreto diminuem continuamen te do início para o final da linha;

f) Não houve diferença de comportamento entre aplicação com tanque de derivação de fluxo e bomba injetora, uma vez que as quantidades de cloreto distribuidas e as reduções dessas quantidades ao longo da linha de gotejadores não diferiram entre os dois sistemas, testados com injeção de 372 $\ell / h$ e tempo de aplicação de 40 minutos; 
g) Para injeção com derivação de fluxo, as diferenças entre quantidade de cloreto distribuido no inicio e no final da linha de gotejadores reduziram com aumento do tempo de aplicação, sendo de $21,2 \%, 14,2 \%$ e 4,0\% para os tempos de 40,80 e 160 minutos, respectivamente. Isso indicou que tem pos de aplicação mais longos levam a menores diferenças en tre quantidades de fertilizante distribuido aos diversos pontos da linha;

h) A uniformidade de distribuição de cloreto aplicado pela li nha de gotejadores, injetado com tanque de derivação e com bomba injetora, avaliada pelo Coeficiente de Uniformidade de Christiansen foi elevada, sendo maior ou igual a $97,3 \%$, revelando que o fertilizante aplicado à rede de irrigação propagou-se adequadamente-pela mesma. 
.100 .

\section{REFERENNCIAS BIBLIOGRÁFICAS}

ASBRASIL (Aspersão no Brasil S/A). Bomba injetora de ferti lizantes ASBRASII. Mimeografado. São Bernardo do Campo, $1985,1 \mathrm{p}$.

BOAZ, M. \& HALEVY, I. Trickle irrigation. Newsletter Israel Agriculture. State of Israel, Ministry of Agriculture. Jerusalem, p. 39-57, 1974.

BRESSIER, E. Trickle-drip irrigation: principles and aplica tion to soil-water management. Advance in Agronomy, New York, 29: 344-393, 197?.

CHRISTIANSEN, J.E. Irrigation by sprinkling. Agricultural Experimental Station, Berkeley, Bulletin no 670, 1942. $124 \mathrm{p}$.

DIXON, J.W. \& MASSEY JR., F.J. Introduction to statistical analysis. Tokyo, McGraw-Hill Kogakusha Ltda, 3.ed., 1969. p. 207-210.

F.A.O. (Food Agricultural Orcanization). Localized irrigation. Irrigation and drainage paper, Rome, no 36, 1980. 201 p. 
FINKEL, H.J. CRC Handbook of Irrigation Thecnology. Boca Raton, Florida, vol. I, 1982. 369p.

FREY, D. Quimigacion. Fertilización y control de malezas y plagas com el agua de riego. Agricultura de las Americas, Kansas, 30 (12): 14, 16, 18, 1981.

FRIZZONE, J.A.; ZANINI, J.R.; DIAS PAES, L.A.; NASCIMENTO, V. M. Fertirrigação mineral. Ilha Solteira, UNESP, Boletim Técnico 2, 1985. 31p.

GOLDBERG, D.; GORNAT, B.; RIMON, D. Drip irrigation: princi ples, design and agricultural practices. Israel, Drip Irrigation Scientific Publications, 1976. 296p.

GOLDBERG, D. \& SHMUELI, M. Drip irrigation - A method used under arid and desert conditions of high water and soil salinity. Transactions of the ASAE, Michigan, 13: 38-41, 1970 .

GROBBELAAR, H.L. \& IOURENS, F. Fertilizer applications with drip irrigation. In: INTERNATIONAL DRIP IRRIGATION CONGRESS. Proceedings, San Diego, p. 405-410, 1974.

HAGIN, J. \& TUCKER, B. Fertilization of dryland and irrigated soils. New York, 1982. 188p.

HOLMAN, H. Fertilizer and chemical injection for irrigation systems. Citrus \& Vegetable Magazine, Tampa, 41 (7): 26$28,46-48,1978$. 
KELLER, J. \& KARMELI, D. Trickle irrigation design. California, Rain Bird Sprinkler Manufacturing Corporation, 1975. $133 p$.

KENNEDY, J.W. Your irrigation system has a larger role than applying water. Irrigation Farmer, Melbourne, Il (3), p.2, 1984 .

POMPA, P.G. La técnica y la tecnologia del riego por aspersion. Madrid, Ministerio de Agricultura, p. 214-221, 1974. RAPOSO, J.R. A rega por aspersão. Lisboa, Livraria Clássica Editora, 1979. 339p.

ROLSTON, D.E.; RAUSCHKOLB, R.S.; PHENE, C.J.; MILLER, R.J.; URIU, K.; CARLSON, R.M.; HENDERSON, D.W. Apolying nutrients and other chemicals to trickle-irrigated crops. University of California, Division of Agricultural Science, Bulletin $1893,14 \mathrm{p}, 1981$.

SHANI, M. La fertilizacion combinada con el riego. Israel, Ministerio de Agricultura, 1981. 36p.

SOIL CGNSERVATION SERVICE - USDA. National Engineering Harnhook. Section 15, Chapter 11 - Sprinkler Irrigation, Washington, 1968. $83 \mathrm{p}$. 
WIERSMA, J.L. Sprinkler irrigation system + fertilizer = fertigation. Farm \& Home, South Dakota Research, 20 (1): $5-8,1969$.

WOODWARD, G.D. Sprinkler irrigation. New York, Sprinkler Irrigation Association, 1959. 377p.

ZAGATTO, E.A.G.; JACINTO, A.O.; REIS, B.F.; KRUG, F.J.; BER GAMIN FILHO, H.; PESSENDA, L.C.R.; MORTATTI, J.; GINE, M. F. Manual de análises de plantas e águas empregando sis temas de injeção em fluxo. Piracicaba, CENA-USP, 1981, $45 \mathrm{p}$. 